\title{
Addressing Gupt Rog: Narrative prevention counselling for STI/ HIV prevention-A guide to AYUSH and allopathic practitioners
}

Bonnie K. Nastasi

Niranjan Saggurti

Population Council

Stephen L. Schensul

Ravi K. Verma

Meena Gandhi

Follow this and additional works at: https://knowledgecommons.popcouncil.org/departments_sbsr-hiv

Part of the Demography, Population, and Ecology Commons, Family, Life Course, and Society Commons, International Public Health Commons, and the Medicine and Health Commons How does access to this work benefit you? Let us know!

\section{Recommended Citation}

Nastasi, Bonnie K., Niranjan Saggurti, Stephen L. Schensul, Ravi K. Verma, and Meena Gandhi. 2007. "Addressing Gupt Rog: Narrative prevention counselling for STI/HIV prevention-A guide to AYUSH and allopathic practitioners." New Delhi: IIPS, UCHC, ICR, Walden University, and Population Council. 


\section{ADDRESSING GUPT ROG Narrative Prevention Counselling for STI/HIV Prevention}

A Guide to AYUSH and Allopathic Practitioners

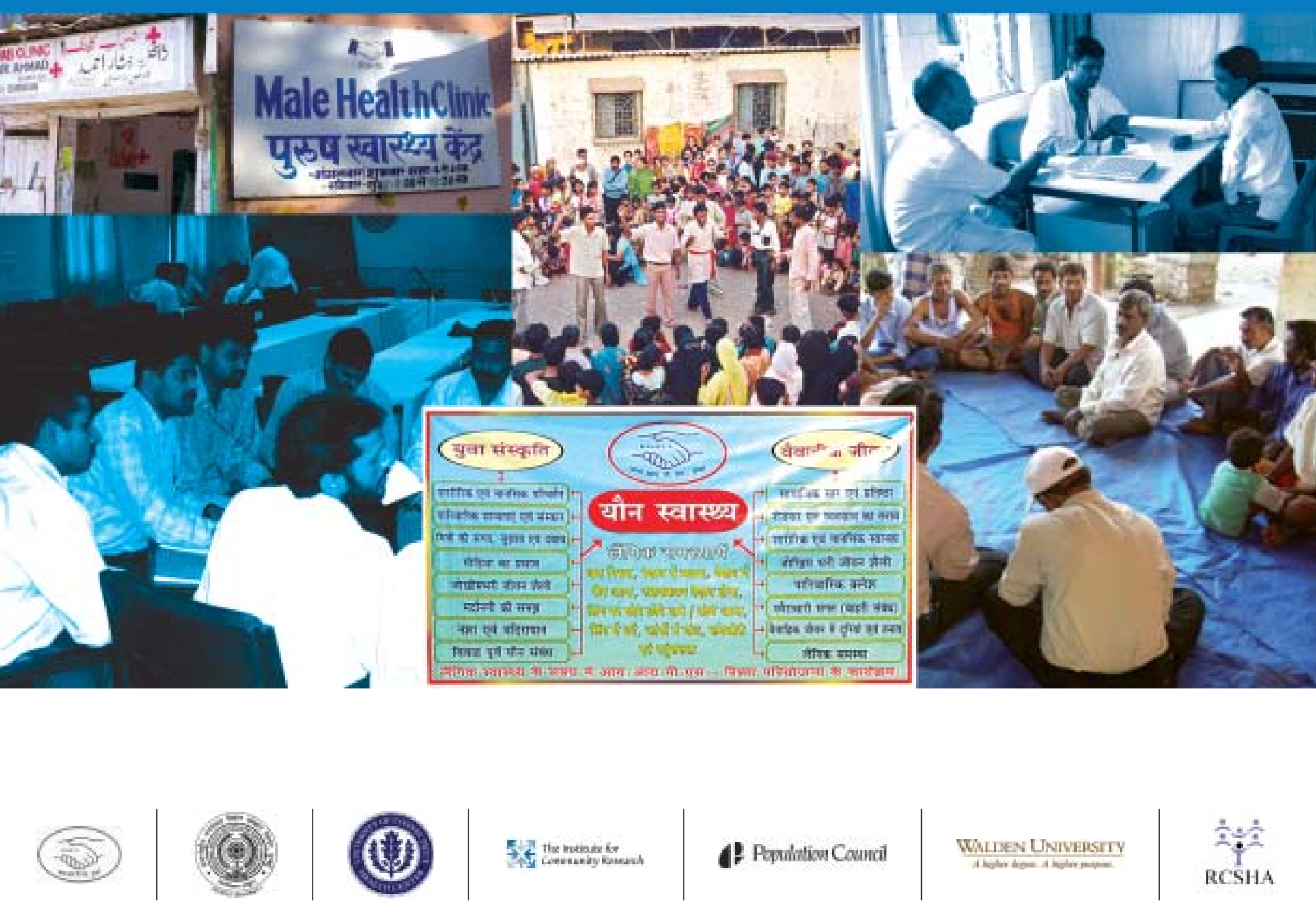




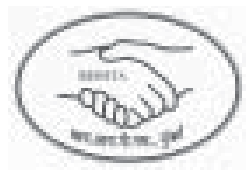

RISHTA (meaning 'relationship' in Hindi/Urdu and has an acronym 'Research and Intervention on Sexual Health: Theory to Action) project was funded by the National Institute of Mental Health (ROI \#MH64875) during 20022007 and was implemented by the International Institute for Population Sciences (IIPS), Mumbai in partnership with

- Center for International Community Health Studies at the University of Connecticut School of Medicine, USA

- Institute for Community Research, USA

- Population Council, New Delhi, India

- Walden University, USA

This manual was authored by: Bonnie K. Nastasi PhD, Walden University, USA. bonnastasi@yahoo.com; Niranjan Saggurti PhD, Population Council, New Delhi, India. nsaggurti@popcouncil.org; Stephen L.Schensul PhD, Center for International Community Health Studies, University of Connecticut School of Medicine, USA. schensul@nso2. uchc.edu; Ravi K.Verma PhD, Population Council, New Delhi, India.rverma@popcouncil.org; Meena Gandhi MD, RCSHA, New Delhi, India mng1969@yahoo.co.uk

For more information, please contact:

Niranjan Saggurti

Population Council

142, Golf Links

New Delhi I 10003

Tel: +9| I| 417434|0-1।

Fax: $+91 \mid 141743412$

Email:Vthomas@popcouncil.org

Website: www.popcouncil.org

Designed \& Produced by:

Creative Inc.

Ph: 9| || 41634469 


\section{ADDRESSING GUPT ROG Narrative Prevention Counselling for STI/HIV Prevention}

A Guide to AYUSH and Allopathic Practitioners

Population Council, New Delhi, India International Institute for Population Sciences (IIPS), Mumbai, India University of Connecticut School of Medicine (UCHC), USA Institute for Community Research, USA

Walden University, USA 


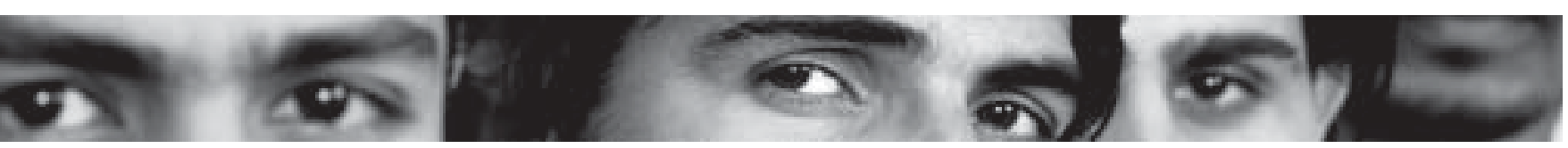

\section{TABLE OF CONTENTS}

Foreword

Acknowledgements

Introduction: About the manual

AYUSH practitioners - an enormous resource for STIs/HIV prevention

$\mathrm{VI}$

Reasons for collaboration

VII

Reasons for collaboration

RISHTA Project and AYUSH initiative

What is the purpose of this manual?

VII

VII

VIII

IX

Section I. Background of AYUSH \& Allopathic practitioners in I STI and HIV/AIDS

Ayurveda and Siddha $\quad 2$

Unani 3

Homeopathy $\quad 4$

Allopathy 5

Practices regarding STI/RTI case management in AYUSH $\quad 6$

Section II. Gupt Rog: Epidemiological, psychosocial elements, 9 and management

Why focus on Gupt Rog? 10

Gupt Rog and associated life factors: Findings from RISHTA Project I I

Gupt Rog and associated factors $\quad 12$

Life factors and Gupt Rog $\quad 14$

Perceived etiology (causal factors) $\quad 14$

Risky lifestyle: Alcohol use, blue films, risky sexual practices and peer influence 15

$\begin{array}{ll}\text { Masculinity } & 17\end{array}$

$\begin{array}{ll}\text { Marital relationships } & 18\end{array}$

$\begin{array}{ll}\text { Perceived consequences of Gupt Rog } & 20\end{array}$

Section III. Behaviour Change: Narrative Prevention Counselling (NPC) 23

What is NPC? 24

Why use NPC? 25

How is NPC different from other approaches to HIV/STI prevention? 25

How does NPC fit with existing approaches in Indian systems of medicine? 25

How effective is NPC? 25

Applying NPC to Gupt Rog 28

Counselling 28

Communication skills and techniques $\quad 29$

Record keeping 33 


\section{Figures}

Figure I. Narrative Prevention Counselling 24

Figure 2. Assessment 33

Figure 3. Interpretation $\quad 4$ I

$\begin{array}{llr}\text { Figure } 4 . & \text { Prevention } & 48\end{array}$

\section{Tables}

Table I. Gupt Rog symptoms reported by men in Mumbai slums

\section{Exercises}

Exercise I. How would you treat Gupt Rog symptoms?

Exercise 2. How important are men's perceptions of causes of Gupt Rog? 14

Exercise 3. How important are life style factors in treating Gupt Rog? 16

Exercise 4. How important are men's views of masculinity in treating Gupt Rog? 17

Exercise 5. How important is the marital relationship in treating Gupt Rog? 19

Exercise 6. How important are perceived consequences in treating Gupt Rog? 20

Exercise 7. How do you communicate with patients? $\quad 32$

Exercise 8. Patient A 36

$\begin{array}{lll}\text { Exercise 9. Patient B } & 37\end{array}$

Exercise 10. Patient A's profile \& case sheet $\quad 43$

Exercise II. Patient B's profile \& case sheet $\quad 46$

Exercise 12. Patient A's story of health 5 I

Exercise 13. Patient B's story of health 52

\section{Annexures}

A. Flow charts on syndromic management of STls 56

B. Glossary of local slangs used for STI 64

C. Case Sheet and Graphic Profile 66

D. Sample Case Analysis $\quad 68$

$\begin{array}{ll}\text { E. Tips for Trainers } & 77\end{array}$ 

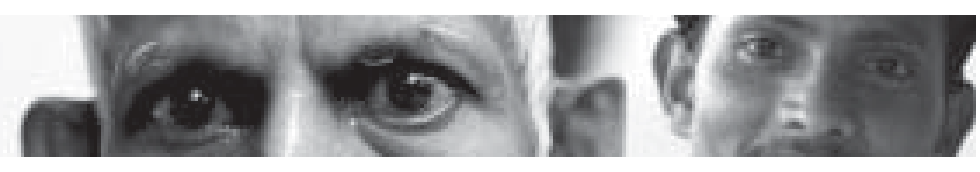

\section{FOREWORD}

India has over 600,000 registered practitioners of AYUSH who practice homeopathic, ayurvedic and unani systems of medicine. Currently there are 3,000 AYUSH hospitals and 23,000 AYUSH dispensaries in the country. Although AYUSH practitioners have always been a major resource, they have not been integrated into the health system in India. In recent years, however, their contribution has been acknowledged and efforts have been made to integrate ayurvedic, homeopathic, siddha and unani systems of medicine within India's national health programme.

While the practitioners of these systems of medicine treat all illnesses, they have a special niché in providing services to address men's sexual health concerns or Gupt Rog (hidden illness). A project on Research and Intervention in Sexual Health: Theory to Action (RISHTA) was undertaken by the International Institute for Population Sciences, Mumbai in partnership with the School of Medicine, University of Connecticut, the Institute for Community Research, Connecticut, Walden University, Boston, Resource Centre on Sexual Health and HIV/AIDS, New Delhi and the Population Council, New Delhi, in three slum communities in Mumbai, from 200 I to 2007. The objective of the project was to control the spread of Sexually Transmitted Infections (STIs) including HIV through the involvement of doctors practicing all forms of medicine. A holistic approach, that included psychological socio-cultural and relationship factors, was employed to integrate key concepts from the AYUSH and allopathic systems of medicine. Treatment-seeking for Gupt Rog was used as an entry-point for health promotion and risk-reduction through a community-based approach wherein all practicing doctors became primary partners in project implementation.

This manual, an outcome of the project, provides information on the application of Narrative Prevention Counselling to Gupt Rog cases. It includes practical exercises and supplementdry material to facilitate the understanding, learning and application of concepts into practice; the materials were developed during the project when doctors were trained to counsel cases suffering from Gupt Rog. There is great potential for the use of this manual in the prevention and management of STIs and HIV as the Government of India is currently scaling up its efforts to develop and promote the AYUSH system of medicine in the country.

I congratulate my colleagues for their enormous contribution in developing this manual which provides an important resource for both AYUSH and allopathic practitioners of medicine as they implement programmes to prevent the spread of Sexually Transmitted Infections.

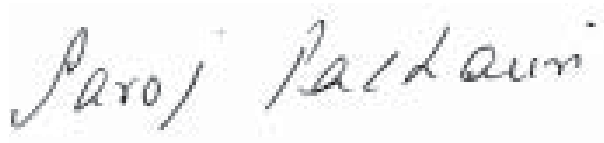

Saroj Pachauri, MD, PhD

Regional Director

South and East Asia

Population Council 


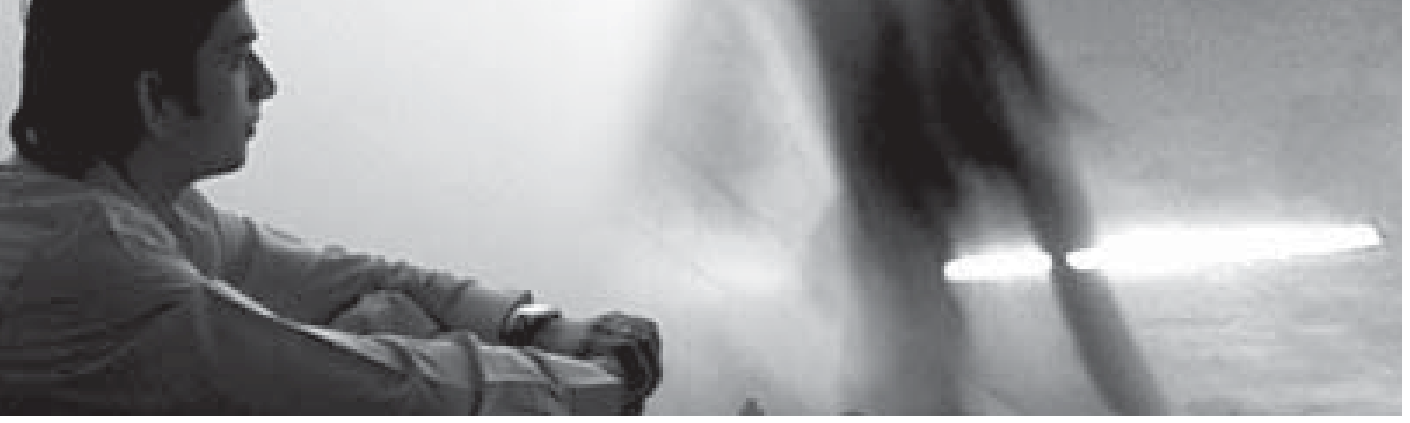

\section{ACKNOWLEDGEMENTS}

This manual is the product of our six-year (2002-2007) research and intervention programme known as RISHTA (meaning 'relationship' in Hindi/Urdu and is an acronym for 'Research and Intervention on Sexual Health: Theory to Action), which has received support from various institutions including academia, local, national and international organisations, state and central governmental institutions.

We acknowledge the support and inputs of RISHTA project team, all the implementing partners and the Resource Centre on Sexual Health and HIVIAIDS (RCSHA). We are grateful to the RISHTA team including Abdelwahed Mekki-Berrada and Joseph A. Burleson of University of Connecticut School of Medicine, Dr. Pertti J. Pelto, Consultant, Dr. Sarah Hawkes of the London School of Hygiene and Tropical Medicine, and Dr. G. Rama Rao, Dr. Sharad S. Narvekar, Rajendra Singh, Dr. Sumitra Sharma, Dr. Papiya Guha Majumdar PhD, and Dr. TV Sekher of the International Institute for Population Sciences.

We are particularly thankful to Department of AYUSH, Government of India and to name a few: Dr. V P Singh, CCRH; Dr. Mehr e Alam, CCRUM; Dr. M Shamoon, Advisor - Unani Medicine; and Dr. Usha Baweja, Consultant to RCSHA for having reviewed the manual and giving constructive inputs.

We acknowledge the dedication and support of Dr. Radha Y Aras and her colleagues at T N Medical College and Nair Hospital and all the AYUSH doctors in study communities for effective implementation of the Narrative Prevention Counselling in their practice and guiding us to development of this manual. We would also gratefully acknowledge the assistance and participation of all those individuals and doctors who at different stages gave important contributions for publishing this manual.

We also thank Jean Schensul PhD, Institute for Community Research, USA for her timely guidance.

We would like to acknowledge the contributions made by $\vee \mathrm{L}$ Thomas, Aslam Naved for their administrative and logistical support.

Last but not the least, the team acknowledges the contributions made by the community leaders, various stakeholders, men, women in the communities who were instrumental in sharing information and giving insights to the project at various levels and has made this manual relevant for all the healthcare practitioners. 


\section{INTRODUCTION ABOUT THE MANUAL}

\section{AYUSH practitioners - an enormous resource for STIs/ HIV prevention}

The non-allopathic Indian medical systems of treatment are consolidated under the umbrella of AYUSH - Ayurveda, Yoga and Naturopathy, Unani, Siddha and Homeopathy. The Department of AYUSH is responsible for regulating, developing and propagating these officially recognised systems, facilitating research in traditional pharmacopeias and regulating ISM\&H education and practice in all officially recognised indigenous streams of medicine.

Today, AYUSH has directorates in 18 states and four research councils (CCRAS, CCRUM, CCRH, CCRYN) to initiate and guide, develop and coordinate scientific research in different aspects of respective systems, both fundamental and allied. Presently, India has over 600,000 registered practitioners of AYUSH, including Ayurveda doctors (60\%), homeopaths (30\%), and Unani providers (6\%). There are nationwide about 70 registered AYUSH providers and 50 allopathic practitioners per 100,000 populations (Ministry of Health and Family Welfare, 2004; World Health Organisation, 2004). In addition, there are 3,000 AYUSH hospitals (with a total of 60,000 beds); and 23,000 AYUSH dispensaries in India.

Thus, the Department of AYUSH is an immense infrastructure and manpower that could be utilised to support STI/RTI and HIV prevention and control.

\section{Reasons for collaboration}

Research demonstrates that sexual health and STI problems are best addressed within a holistic approach that is more characteristic of the Indian traditional healing systems than allopathic medicine. This holistic approach is a vital part of addressing HIV/ STI risk reduction at a time of the growing epidemic in India.

AYUSH practitioners form a part of a well established system throughout the country, are easily approachable to people even in areas where the formal (public) medical facilities are not available, and are comparatively inexpensive, making them more acceptable and affordable for people.

Studies have shown that for STI symptoms, an AYUSH practitioner is often the first port of call, especially for men.

There may be many reasons for this including:

- The practitioners are usually ethno-centric and are able to use the local language, thus helping the patient in identifying with them and feeling a level of comfort.

- They are in sync with the local belief system, with reference to STIs, as the local logic is usually a continuum of the indigenous/ local medical system.

- The practitioners belong to a school of thought that propagates holistic patient-centric care, with an emphasis on detailed history taking and counseling of patients. These aspects of a consulltation and the holistic approach are essential to effective STI/HIV management.

The impetus for this manual was a five-year research and intervention project conducted with AYUSH and allopathic providers serving men in three slum communities of Mumbai, the Research 


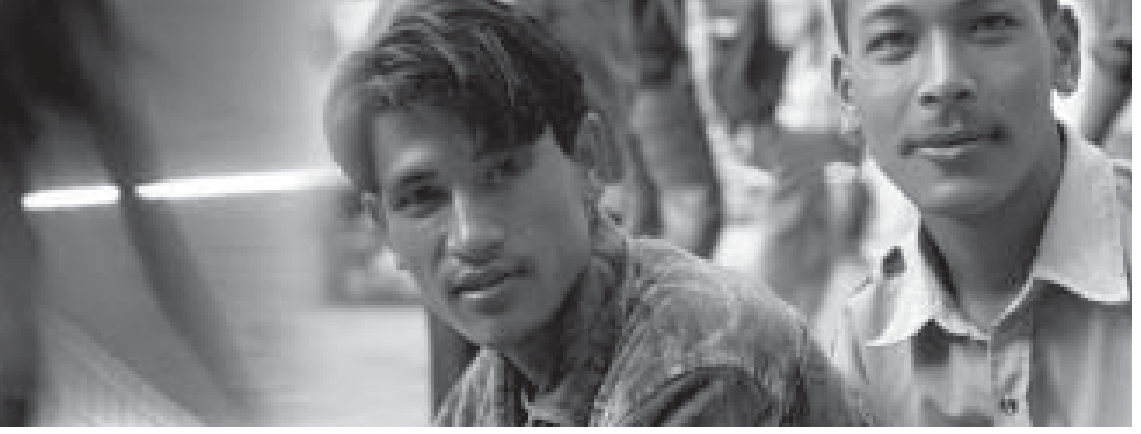

and Intervention in Sexual Health: Theory to Action (RISHTA) project. Providers played a key role in developing and implementing an approach addressing men's sexual health concerns (Gupt Rog) that targeted psychological, social-cultural, and relationship factors that were shown in formative research to be related to reported symptoms of Gupt Rog. Thus, treatment seeking for Gupt Rog (dhat, kamjori or garmi) became the entry point for health promotion and risk reduction for STIs including HIV. As a result, doctors became primary partners in community efforts to reduce sexual risks and began to approach sexual health concerns from a holistic perspective that integrated key concepts from AYUSH systems of medicine. In addition, doctors' implementation of a narrative approach to Gupt Rog resulted in decreased risk for men.

In this manual, we provide detailed information related to the application of Narrative Prevention Counselling (NPC) to Gupt Rog cases, with examples, practice exercises, and supplementary materials to facilitate understanding, learning, and application in practice. We also provide findings from the RISHTA project showing how men's beliefs and lifestyle factors relate to sexual risks. Supplementary educational materials related to STIs and syndromic management (based on the World Health Organisation model), and the Indian systems of medicine are provided as appended materials.

The training/educational materials included herein are based on content and exercises that were effective in preparing the doctors in the project to implement NPC in their practice. These materials and the model of training and practice were adapted throughout the project based on feedback from the doctors as they attempted to apply NPC with men who presented Gupt Rog symptoms. Initial training was conducted for 16 hours over four days, followed by nine ( $1-2$ hour) sessions across a two- year period. The follow-up sessions were based on doctor's requests for extended or refresher training on topics such as sexual dysfunctions and application of NPC to cases. Training activities included lectures, practice exercises, and role playing of cases. The content of the training across two years is reflected in this manual.

\section{RISHTA project and AYUSH initiative}

The Population Council in collaboration with International Institute of Population Science (IIPS), Mumbai, and several US institutions, University of Connecticut School of Medicine, Institute for Community Research, and Walden University, has been implementing a research-based intervention project, RISHTA and has been working successfully with a large system of healthcare providers-both allopathic and non-allopathic (AYUSH) to reduce STI/HIV risk among men. The project demonstrates that the combination of strong culturally-based sexual health concerns and the presence of private nonallopaths who manage these problems present a window of opportunity for intervention programmes to address the challenge of HIV/STI prevention and early case identification in India.

The major findings of the project are:

- The first port of contact for treatment of Gupt Rog is the AYUSH healthcare practitioners. RISHTA suggests that one in every two men in the age group of 21-40 years have had at least one Gupt Rog problem during the last three months. The great majority of these men who seek treatment for Gupt Rog problems use practitioners of ayurveda, unani, siddha, homeopathy, naturopathy, yoga and other Indian medical traditions.

- 'Family doctors': A large number of patients go 


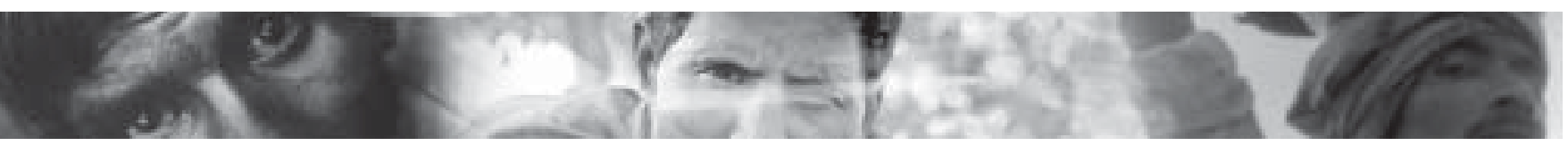

to these providers who are easily available in the community called doctor (Indianised English term refers to vaidyas, hakims and homeopaths in the community). They are seen by their patients as the 'family doctor' and treat multiple members of the same family

Unlike allopaths, these practitioners' cultural and medical knowledge concerning Gupt Rog is consistent with men's explanatory models and understandings of health and disease.

The obvious advantages of collaborating with AYUSH parishioners is evident from the RISHTA project, which trained $32 \mathrm{AYUSH}$ providers, in its study area, towards effective management of sexual health problems, with the help of Narrative Prevention Counselling (NPC).

The RISHTA study reports that:

- The training was very positively received by AYUSH providers, as evidenced by pre and post evaluation and by calls for monthly refresher training.

- An interim assessment of the impact of the training on the AYUSH providers indicated that there was a significant increase in the number of men being seen for sexual health problems, the willingness of men to discuss their sexual health problems, and referrals by AYUSH providers to other services within the healthcare system.

- $\quad$ AYUSH providers also reported that the frequent trainings provided them with an opportunity to network among their fellow providers and to seek out assistance from them after the training.

- Prior to the intervention, AYUSH providers served in the role of 'family doctor,' dealing with common complaints that included cold, fever, and diarrhea. After the training, the AYUSH providers reported that they felt more comfortable dealing with their patients with sexual health problems and that their patients felt more comfortable in raising these problems.

- Further, AYUSH providers reported that men presented sexual health problems at shorter intervals after onset of problem (a mean of five months) rather than delaying treatment (a mean of 20 months) as was the case prior to intervention.

\section{What is the purpose of this manual?}

This manual is designed to enhance the knowledge of AYUSH, allopathic and other healthcare practitioners on Gupt Rog and associated factors and provide guidance on addressing Gupt Rog for the prevention of STIs and HIV.

This manual hopes to encourage the involvement of the practitioners of various streams of $\mathrm{AYUSH}$ and Allopathy in the fight against HIV/AIDS, especially in the prevention and detection of STIs and HIV.

The manual will take you through various sections on STI, Gupt Rog and HIV/AIDS and has been adapted from/based on the research and intervention conducted under RISHTA (Research and Intervention in Sexual Health: Theory to Action).

\section{Who is it for?}

We hope that the manual can be an important tool for AYUSH and allopathic practitioners, trainers of AYUSH and allopathic providers, and for other professionals who want to work/are working in this field.

The manual has been divided into four subsections:

- Basic introduction of STI and HIV/AIDS

- Gupt Rog: Introduction, epidemiological and psychosocial elements, and management

- Behaviour Change: Narrative Prevention Counselling

- FAQs on Gupt Rog, STIs, and HIV/AIDS. 


\section{SECTION J}

\section{2 \\ Background of AYUSH and allopathic practitioners in STI and HIV/AIDS}

- Ayurveda and Siddha

- Unani

- Homeopathy

- Allopathy

- Practices regarding STI/RTI case management in AYUSH 


\section{AYUSH AND ALLOPATHIC PRACTITIONERS IN STI AND HIV/AIDS}

The theoretical frameworks of the non-allopathic medical systems are based on holistic perspectives and approaches. The canonical texts of ayurveda (Charaka Samhita; Susruta Samhita), siddha (Siddha literature in Tamil), homeopathy (Hahnemann's work) and unani medicine (Galen; Al Razi; Ibn Sina) all focus on a harmony between physical and mental activity, environment, and diet, which contribute to the preservation of health. Indian systems of medicine hold that health is a dynamic process, not just an absence of disease. Their emphasis is on the maintenance of health and a balanced state of the body, mind, and emotions as well as social, moral and spiritual welfare. These systems are more patient - centred where the personality and social situation of the patient is as significant as their physical problem.

\section{Ayurveda and Siddha}

The universal truth

According to ayurveda and siddha, the human body is a microcosmic replica of the universe, both constituted of and classified into five elements (earth/solidity; water/fluidity; fire/heat; air/ movement; ether/space). These five elements translate into the body and organs as three humours (air, bile, and phlegm). The third main component of the human body is seven dhatus: one of which, called sukra, enters into the formation and cycle of sperm and ovum. When sukra is disturbed, it results in reproductive and sexual health problems. In the same way, any disturbance in the equilibrium of the elements, humours and thatus results in disease.

In ayurveda, diagnosis is always done of the patient as a whole. The physician takes a careful note of the patient's internal physiological characteristics and mental disposition. She also studies other factors such as the affected bodily tissues, humours, the site at which the disease is located, patient's resistance and vitality, his daily routine, dietary habits, the gravity of clinical conditions, condition of digestion and details of personal, social, economic and environmental situation of the patient.

The main principle of treatment is thus to maintain or restore equilibrium. This system of medicine promotes a preventive and positive health approach and treatment includes:

- Avoiding risky behaviour

- Avoiding unbalanced regimens

- Administering appropriate drugs after making a diagnosis

- Ensuring a balanced state of body, mind, emotions, social, moral and spiritual welfare.

The STI case management involves:

- Detailed history is taken to assess the patient's internal physiological characteristics and mental disposition; part of body affected, site of lesion; patients' daily routine; dietary habits

Indian systems of medicine hold that health is a dynamic process, not just an absence of disease. Their emphasis is on the maintenance of health and a balanced state of the body, mind, and emotions as well as social, moral and spiritual welfare. 


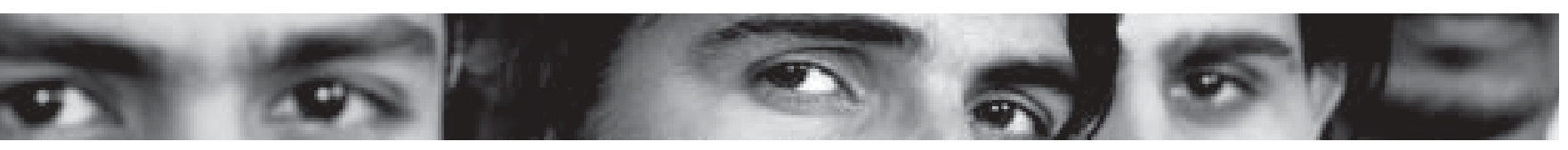

and patient's personal, social, economic and environmental situation

- Examination of the patient involves pulse examination; examination of tongue and eyes; general physical examination; examination of skin ear and general tactile and auditory functions

- Investigations include faeces examination and examination of urine

- Administering treatment which involves: avoiding causative factors responsible for disequilibrium of the body matrix, giving medicines, suitable diet, activity and regimen for restoring the balance and strengthening the body to prevent/minimise diseases in the future.

Ayurveda has developed a very vivid analytical description of the stages and events that take place since the causative factors commence to operate until the final manifestation of disease. So, the system has an additional advantage of knowing the possible onset of disease, much before the latent symptoms become apparent. This enhances the preventive role of this system of medicine by making it possible to take proper and effective steps in advance, to arrest further progress in pathogenesis or to take suitable therapeutic measures to curb the disease in its earliest stage of onset.

In the siddha system of medicine, emphasis is given to the fact that medical treatment is oriented not merely to disease but has to take into account the patient, environment, the meteorological consideration, age, sex, race, habits, mental frame, habitat, diet, appetite, physical condition, physiological constitution, etc. The history is taken to assess and understand the above given parameters.

The diagnosis of diseases involves:

- Identifying the causative factors through the history, the examination of pulse, urine, eyes,

\section{Ayurveda has developed a very vivid analytical description of the stages and events that take place since the causative factors commence to operate until the final manifestation of disease}

study of voice, colour of body, tongue and the status of the digestive system

- The system has worked out detailed procedure of urine examination which includes study of its colour, smell, density, quantity and oil drop spreading pattern

- The diagnosis involves the study of person as a whole as well as his disease

- The treatment given is individualistic, which ensures that mistakes in diagnosis and treatment are minimal

\section{Unani}

\section{The right combination of vital elements}

In arabic, the term 'unani' means 'Greek' and 'unani' medicine is also called Islamic, Arab, Greco-Islamic, or humoral medicine. It stems mainly from the Greco-Hellenic and Islamic civilizations. According to unani medicine, all beings are made up of basic elements (earth, air, water, fire), temperaments and qualities (cold, hot, wet, dry), humours (blood, phlegm, yellow and black bile) and forces (natural, vital, and psychic). In this system, health is a state of the body in which there is equilibrium of these components, and when this equilibrium is disturbed, disease occurs.

Appropriate unani medicine is given to achieve an optimal balance (eukrasia) for each person. Unani treatment is based on the contraria contraris 


\section{Unani treatment is based on the contraria} contraris principle, "to treat a disease by its opposite" (e.g. a 'hot' disease is cured with a 'cold' medicine).

principle, 'to treat a disease by its opposite' (e.g. a 'hot' disease is cured with a 'cold' medicine).

Diseases are mainly diagnosed with the help of pulse (nabz), physical examination of the urine and stool. also, patients are examined systematically to make the diagnosis easy as spot diagnosis with the help of simple, modern gadgets.

Unani medicine is also considered holistic in its consideration of physical and mental activity, environment, and diet, which contribute to the preservation of health (Brain, 19866; Dols, 19847; Leslie, 1976; Ministry of Health and Family Welfare, 20049; Temkin, $1973^{10}$ ).

\section{Homeopathy}

\section{Get to the root cause}

The term homeopathy derives from the Greek homois (similar) and pathos (disease/suffering). Homeopathy was developed in Germany and appeared discreetly in the midst of the political and medical effervescence of modern India in the 19 th century.

According to homeopathy, 'miasm' (from the Greek to pollute) is the main cause of all diseases. The human body contains an innate vital force that, is weakened during illness.

Treatment is based on similia similibus principle (Latin, "like are cured by like"); a remedy, which by its 'nature' is most similar to the symptom, is prescribed in the minimum dose and administered to the patient. This remedy stimulates the 'vital force' or existing defense mechanism of the body, which is failing when disease occurs.

Homeopathy, like ayurveda and unani, is also considered holistic in its concern with environmental,

Brain, P. 1986. Galen on bloodletting. A study of the origins, developing and validity of his opinions, with a translation of the three works. Cambridge: Cambridge University Press.

2 Dols, M.W. 1984. Medieval Islamic medicine: Ibn Ridwan's treatise on the prevention of bodily ills in Egypt. Berkeley.

3 Leslie C. 1976 The ambiguities of medical revivalism in Modern India. In Leslie C. (ed.) Asian medical systems: A comparative study. University of California Press:356-367.

4 Ministry of Health and Family Welfare. 2004. "Department of Ayurveda, Yoga \& Naturopathy, Unani, and Siddha. Web site: http:// indianmedicine.nic.in/."

Temkin, O. 1973. Galenism. Rise and decline of a medical philosophy. Itahca: CornellUniversity Press.

6 Brain, P. 1986. Galen on bloodletting. A study of the origins, developing and validity of his opinions, with a translation of the three works. Cambridge: Cambridge University Press.

Dols, M.W. 1984. Medieval Islamic medicine: Ibn Ridwan's treatise on the prevention ofbodily ills in Egypt. Berkeley.

8 Leslie C. 1976 The ambiguities of medical revivalism in Modern India. In Leslie C. (ed.) Asian medical systems: A comparative study. University of California Press:356-367.

9 Ministry of Health and Family Welfare. 2004. "Department of Ayurveda, Yoga \& Naturopathy, Unani, and Siddha. Web site: http:// indianmedicine.nic.in/."

10 Temkin, O. 1973. Galenism. Rise and decline of a medical philosophy. Itahca: Cornell University Press. 

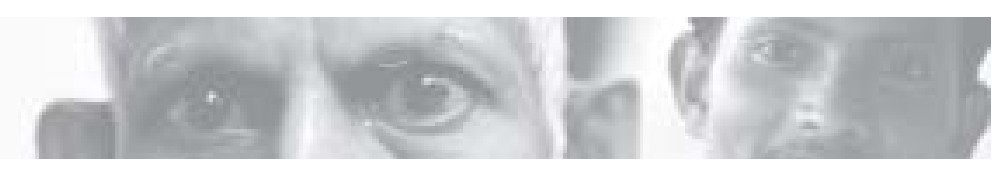

social and emotional determinants upon which action is taken for better treatment (Gala, 2000"; Leslie, 1976'2; Ministry of Health and Family Welfare, 2004'3). Homeopathy does not treat disease per se. The physicians' interest is not only to alleviate the patients' present symptoms but also his long-term well being.

There is a strong and prevalent system of indigenous medical care in India and a multitude of different providers in the formal and informal sectors. Sexual health problems are best dealt within a holistic framework. This is so because sexual health problems are multidimensional in that they are culturally defined, socially constructed, and emotionally experienced, and cannot be reduced to their bodily dimension. They are perceived as 'secret illnesses', and are linked to several dimensions such as lifestyle, marital relationships, extramarital and marital sexual behaviour, and masculinity, to mention only these domains (Schensul et al. 2004 ${ }^{14}$ ). Also, humoural epistemology and its transcultural variants that make ayurveda and unani medicine possible, is more than the foundation of medical theory and practice. Humoural and homeopathic epistemology simultaneously allows specific cultural constructions of disease (Pugh, 2003 ${ }^{15}$ ) and serves as the basis for social knowledge and social relationships (Good and Good, 1992'16): it is a way of life (Leslie, 1992 ${ }^{17}$ ).

Homeopathy, like ayurveda and unani, is also considered holistic in its concern with environmental, social and emotional determinants upon which action is taken for better treatment.

\section{Allopathy}

\section{The science of healing}

As far as STIs are concerned, allopathic system focuses on the following for case management:

- History taking, which includes general information about the patient, also helps to build rapport between the provider and the patient; past and present sexual history and past and present treatment history

- Details of present symptoms

- Detailed general physical examination and local examination

- Arriving at a provisional diagnosis

- Collection of appropriate specimen (blood, pus/ swab/ scrapings/ tissue) for confirmatory

Gala, D. 2000. Homoeopathy for common diseases. Mumbai: Navneet Publishers (India) Limited.

12 Leslie C. 1976 The ambiguities of medical revivalism in Modern India. In Leslie C. (ed.) Asian medical systems: A comparative study. University of California Press:356-367.

13 Ministry of Health and Family Welfare. 2004. "Department of Ayurveda, Yoga \& Naturopathy, Unani, and Siddha. Web site: http:// indianmedicine.nic.in/."

14 Schensul, S. L., Mekki-Berrada A., Nastasi B., Verma R. K. 2004 (in progress) The emotional, social and cultural dimensions of male sexual health problems in India.

5 Pugh J.F. 2003, Concepts of arthritis in India's medical traditions: Ayurvedic and Unani perspectives. Social Sciences and Medicine, 56:4I 5-424.

16 Good B., Good M.J..D., 1992, The Comparative Study of Greco-Islamic Medicine: The Integration of Medical Knowledge into Local Symbolic Contexts. In Leslie C. and Young A. (eds.) Paths to Asian Medical Knowledge. University of California Press:257- 27I.

17 Leslie C. 1992 Interpretation of illnesses: Syncretism in Modern Ayurveda. In Leslie, C. \& Young, A. (eds.) Paths to Asian Medical Knowledge. University of California Press: 177-208. 


\section{Allopathy takes various symptoms and laboratory examinations into consideration before suggesting appropriate treatment.}

diagnosis (optional, not required in syndromic diagnosis and management of STIs)

- Laboratory examination of collected pus/swab if laboratory facilities are available to identify the causative agent(s)

- Administering the appropriate antibiotics as per NACO guidelines

- Counselling for safe sex practices

- Partner notification and treatment

- Follow up to confirm cure

\section{Practices regarding STI/RTI case management in AYUSH}

The practitioners of the Indian medical system can be divided into the 'purists' and the 'integrationists'. The 'purist' is the traditional vaidya who has been educated for several years by a guru to whom he is professionally, socially, supernaturally and eternally linked by the Lord Siva (Basham, 1976 18). The student is taught the tenants of ayurvedic medicine from the Sanskrit canonical texts and becomes a purist but not officially registered by the government, because he did not attend any of the non-allopathic medical colleges licensed by the Ministry of Health and Family Welfare. The purist uses only traditional medicines (zadi buti) and classical diagnostic methods described above. In fact, the traditional vaidya 'keeps alive' the Sanskrit classical texts of ayurvedic medicine, and adopts a holistic perspective, an ecological approach that takes into account the multidimensionality of health and illness, and where, 'disease makes sense only in its totality' (Bibeau, 1982 ${ }^{19}$ ).

The treatment of reproductive and sexual problems focuses mainly on:

- Behaviour changes

- Use of rejuvenative and invigorating foods and natural (herbal) remedies (Al-Dahbi20, 1992; Ranade, |9992').

- Seek to understand patients' physical and physiological complaints by eliciting patients' well being, social problems, diet, rest and activity patterns, including any risky behaviour that may have an impact on patients' health (Nordstrom, $1988^{22}$ ) through dialogue with the patient.

- The underlying medical epistemology of this holistic and ecological approach is that 'disease makes sense only in its totality' (Bibeau, 198223).

In practice, many practitioners employ a more 'integrationist' approach involving classical holism

Basham A.L., 1976, The practice of medicine in ancient and medieval India. In Leslie C. (ed.) Asian medical systems: A comparative study. University of California Press: | 8-43.

19 Bibeau G. 1982, A systems approach to Ngbandi medicine. In Yoder P.S. (eds.) African health and healing systems. Los Angeles, California, Crossroads Press:43-84.

20 Al-Dahbi, A.A. (I 992-13th/I 4th century). Al-tibb al-nabawi. Beyrout: Dar haya al-ulum.

21 Ranade, S. ( 1999). Natural healing through ayurveda. Delhi: Motilal Banarsidass.

22 Nordstrom, C. R. ( 1988). Exploring pluralism. The many faces of ayurveda. Social Science \& Medicine, 27(5), $479-489$. 
and a more expeditious symptomatic approach. The RISHTA project elicited that:

- Although the integrationists respect and have some knowledge of the classical texts of ayurevda, siddha, unani and/or homeopathy, the holism inherent to these texts is hardly present at the 'practiced' and local level.
- Integrationists' use stethoscope more than the classical diagnostic method of pulse taking.

- The provider spends about I 5 minutes with each patient, due to the huge pressures of time, which leaves no time to conduct a detailed elicitation of patient's general well being, family problems, habits and risky behaviours. 



\section{SECTION II}

\section{Gupt Roge Epidemiological, psychosocial elements, and management}

- Why focus on Gupt Rog?

- Gupt Rog and associated life factors: Findings from RISHTA project

- Gupt Rog and associated factors

- Life factors and Gupt Rog

- Perceived etiology (casual factors)

- Risky lifestyle: Alcohol use, blue films, risky sexual practices and peer influence

- Masculinity

- Marital relationships

- Perceived consequences of Gupt Rog 


\section{Epidemiological, Psychosocial Elements, and Management}

\section{Why focus on Gupt Rog?}

- Gupt Rog and its component symptoms are well known to men in India.

- Gupt Rog is a major priority for men in treatment seeking.

- Gupt Rog includes symptoms that relate to performance problems, concerns about semen loss, and STIs.

- A significant number of men seek treatment for these problems, primarily with AYUSH providers, providing an opportunity of point-of-service contact for both treatment and prevention.

- Gupt Rog symptoms are related to engaging in risky sexual behaviour; thus Gupt Rog can be seen as a marker for HIV/STI risk.

- Gupt Rog problems affect and are affected by every aspect of men's lives.

The approach to Gupt Rog problems reflected in this manual is framed within the holistic approach consistent with traditional Indian systems of medicine. This approach focuses on changing men's thinking and lifestyle factors that contribute to risky behaviour. In particular, the approach focuses on changing men's thinking about sexuality, masculinity, relationships, and risky behaviour as a way of facilitating healthy decision making about engaging in sex. The focus in on the individual patient's thinking as it reflects both cultural beliefs and unique individual beliefs and experiences. The primary objective is to help men to see the link between risk for HIV/STI and their thinking and behaviour, and facilitate better choices about sex. The model, developed by the RISHTA team, is Narrative Prevention Counselling (NPC), which is described later.
The NPC integrates traditional concepts of holistic medicine with approaches from western-derived psychology that focus on the links of thinking and behaviour. NPC has been used effectively for health promotion and sexual risk reduction within treatment of men seeking help for Gupt Rog problems. NPC has been applied successfully to the practice of AYUSH medicine in the private sphere and allopathic medicine (in which heretofore there was little respect for Gupt Rog problems) in the public health sphere.

\section{RISHTA project implementation}

In response to concerns about the HIV/AIDS pandemic in India, the RISHTA (Research and Intervention in Sexual Health: Theory to Action) project was developed in 2001 to address the sexual health concerns and risk for HIV/STIs among married men in slum communities in Mumbai. While other projects used western-derived approaches of condom use, reduction in risky sex, and monogamy, the RISHTA project focused its attention on Gupt Rog. Research by the RISHTA team showed that instead of being driven by the fear of HIV/AIDS and other sexually transmitted diseases, men in these communities were more concerned with issues of sexual performance linked to semen inadequacy, related to semen loss through masturbation and nocturnal emission. RISHTA saw these concerns about sexual performance as an entry point for HIV/

NPC has been used effectively for health promotion and sexual risk reduction within treatment of men seeking help for Gupt Rog problems. 


\section{Gupt Rog and associated factors}

The findings presented in this section are based on interviews with 52 men and survey of 2,408 men living in three Mumbai slum communities.

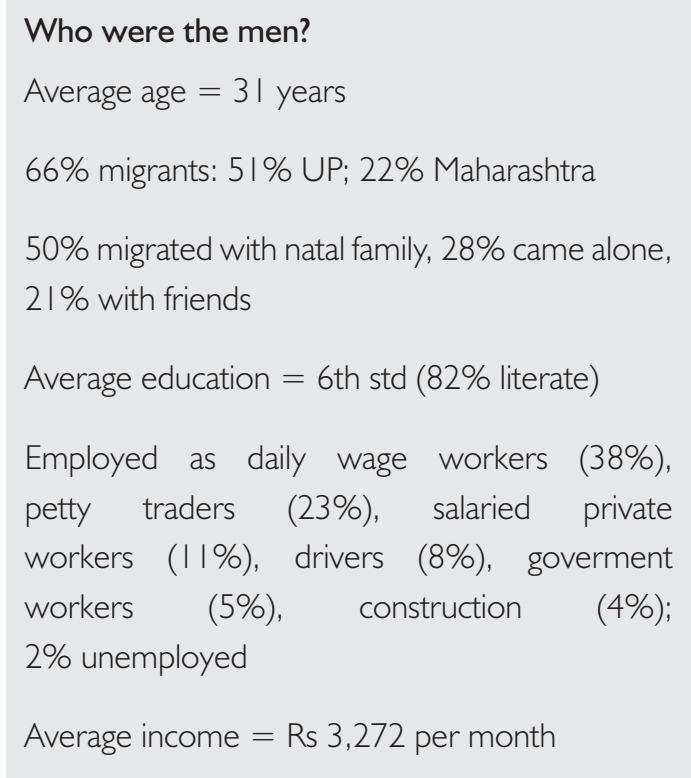

\section{Gupt Rog: Symptoms and Prevalence}

Men reported a variety of symptoms as Gupt Rog (see Table 1); 53\% of the men reported experiencing some type of Gupt Rog over the past three months. These symptoms can be characterised as three types:

- Sexual performance problems/concerns

- Semen-related problems/concerns

- Sexually Transmitted Infections (STIs)

\section{Treatment Seeking}

There were several important findings that suggested that peformance and semen-related concerns provided opportunities for providers to do preventive education and health promotion.

First, for all types of Gupt Rog, men were more likely to use 'English medicine' than traditional medicine, based on doctor's advice or as form of self-treatment

Table I: Gupt Rog symptoms reported by men of Mumbai slums

\section{Variety of Gupt Rog symptoms reported by men}

- Early ejaculation

- Nocturnal emission

- Problems with semen quality/low sperm count

- Masturbation or excessive masturbation

- Infertility

- Unable to conceive son

- Body heat

- Small or bent penis

- Loss of sexual desire

- Increased sexual desire (self or wife)

- Erectile dysfunction

- Impotency

- Semen loss due to masturbation or nocturnal emission
- Pain in penis

- Boils/blisters

- Itching

- Pus discharge

- Pimples on genitals

- Burning urination

- Change in skin colour of genitals

- Swelling around genitals

- Red urine

- Weakness

- Concentration/sleeping difficulties

- Difficulty urinating

- Tiredness/fatigue

- Burning in genitals

- Redness of penis

- Stomach pain 


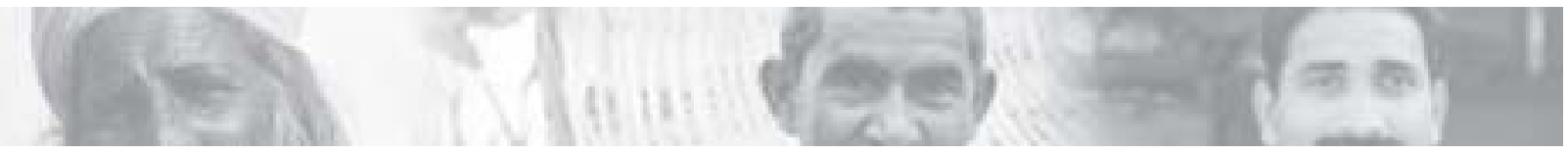

(get the medicine without seeing doctor). 79\% reported using English medicine prescribed by doctor and 68\% reported using English medicine to self-treat. Compare these to I5\% using zadibuti on doctor's advice and 29\% using zadi-buti to self-treat.

"If the semen (pani) comes before time, then I would take the treatment from the doctor. The doctor who gives English medicines, I would take treatment from him. I will take the medicines for two-four times. If I am benefiting then only I would continue my treatment else I would stop my treatment."

Second, men were most likely to seek treatment for STI-related symptoms, with 58\% seeking treatment.

Third, men were more likely to self-treat STI-related symptoms. Self-treatment was described as seeking English medicine from pharmacist or friend.
Fourth, men were more likely to seek additional treatment session with doctors for performance or semen-related concerns.

Fifth, men described going to several doctors seeking preferred treatments. In some cases, men talked about avoiding blood tests because of fear.

"First I showed to Dr. A. Then I went to Dr. B. He is famous for this treatment. He gave 10 penicillin injections and capsules for one month. With those medicines, I recovered fully, but when the medicines were over, once again I faced all these problems. Then Dr. referred me to blood test. I became scared and did not go there. Now I am taking treatment from Dr. C."

Interviews with doctors in the three communities confirmed that the primary treatment for Gupt Rog was 'English medicine' and counselling to avoid extramarital sex with commercial sex workers.

\section{Exercise 1}

How would you treat Gupt Rog symptoms?

Consider the problems listed in Table I. Based on your knowledge and experience, answer the following questions

How would you address sexual performance concerns in your practice?

How would you address semen-related concerns in your practice?

How would you address symptoms of STIs in your practice? 


\section{Life factors and Gupt Rog}

RISHTA research revealed several life factors associated with Gupt Rog:

- Perceived etiology: What causes the Gupt Rog?

- Risky lifestyle: Did the men engage in risky sex, watch blue films, or use alcohol? Did their male friends influence risky lifestyle? Did men engage in extramarital sex? If so, did they use condoms?

- Perceptions of masculinity and gender roles: How did men define 'real man'? What were their expectations for husband and wife?

- Marital relationships: Were men satisfied with their marital relationship? Were they satisfied with the sexual relationship in marriage? Did the husband and wife engage in conflict? Was there domestic violence in the marriage? Did the husband force the wife to have sex?

- Perceived consequences of Gupt Rog: What were the men's concerns about consequences of Gupt Rog for their health, their emotional well being (e.g., tension), their wives, their marital relationship, their standing in community?

\section{Perceived Etiology (Causal factors)}

The three causes of Gupt Rog most often cited by men were masturbation, extramarital sexual with commercial sex worker or extramarital sex with an older woman.

I. Men believed that masturbation could lead to nocturnal emission, infertility, bent penis, burning urination, impotence, semen loss, decreased sexual desire, early ejaculation, weakness, weak semen.

"I used to masturbate since I was I 5 - I 6 years old, by which I have wasted semen to a great extent. For which, I suffered from the problem of bent penis, lack of desire for sex, erection problem, early ejaculation."

2. Men believed that extramarital sex with a commercial sex worker could lead to pimples

\section{Exercise 2}

How important are men's perceptions of causes of Gupt Rog?

Consider the findings on men's views of the causes of Gupt Rog. Based on your knowledge and experience, answer the following questions.

How would you address men's concerns about masturbation and semen loss in your diagnosis and treatment of Gupt Rog? 
on genitals, itching, burning urination, pus discharge, AIDS.

"Garmi is very severe and it comes only after intercourse with CSWs."

3. Men believed that extramarital sex with older woman could lead to infertility, impotence, spoiled semen, weakness, not having a male child.

"Man should not do sex with an older woman, because they are very passionate (garam), for which man's semen becomes spoil."

The importance of semen as vital to men's wellbeing was evident in quotes such as the following;

"Semen is a vital part in man's life. If the quality, quantity and strength reduce, then man will be no more."

"Semen is very valuable (besh kimti). It is more important than blood in our body."

Risky lifestyle: alcohol use, blue films, risky sexual practices, and peer influence

The data collected from men revealed several aspects of a risky lifestyle - alcohol and tobacco use, blue films and other erotic/pornograpic media, and risky sexual practices. The use of alcohol, blue films and risky sex (e.g., with commercial sex workers) co-occurred and frequently involved peers. Thus, men often engaged in these activities when going out with male friends, suggesting peer influence. The majority of men (87\%) reported 'hanging' or 'roaming' with friends.

\section{Alcohol and tobacco use}

Men reported using the following substances during the past month.

$38 \%$ used pan with tobacco

$38 \%$ used bidi or cigarettes

\section{Key findings on alcohol and tobacco use prove that there is a widespread use of tobacco and alcohol amidst men which is affecting their sexual behaviour.}

$40 \%$ used gutka, mawa or chewing tobacco

|4\% reported drinking beer, |4\% English daru, and $8 \%$ desi daru.

Men reported drinking to feel better, concentrate better, and to increase sexual pleasure.

"When income is more, I take two-three pegs and feel like doing sex."

Men reported that drinking was associated with extramarital sex, forced sex with wife or erection difficulties.

"If that time [when I am drinking] she refuses, I force her for sex."

"After having drinks my penis does not get proper erection, so I prefer masturbation. If I am not having drinks, I like sexual intercourse."

Men reported using alcohol and tobacco with friends, as indicated in the following findings.

63\% used bhajan/kirtan with friends

$43 \%$ smoked cigarettes with friends

$51 \%$ used tobacco (eat/chew) with friends

$29 \%$ reported drinking alcohol with friends

$12 \%$ visited beer bars with friends

Blue films and other erotic/pornographic media

Men reported visiting video parlours, watching blue films with friends, and viewing other pornography such as posters and magazines. 
During the past six months, men reported using various forms of media.

$94 \%$ viewed posters

$27 \%$ viewed photographs

$13 \%$ viewed magazines

$12 \%$ viewed adult films

10\% viewed blue films

$12 \%$ reported viewing blue/adult films with friends

Men reported engaging in masturbation or mutual masturbation while watching blue films.

"When we [friends] were very excited we use to watch blue films at theatre as well as video parlours. There, while watching the movie, we use to masturbate."
Men reported blue films as a source of sexual information.

"Watching the blue films we come to know about various methods of doing sex. I watched many blue films before my marriage and learnt about sex."

\section{Risky sexual behaviour}

$23 \%$ of the men reported having engaged in extramarital sex at some time, while 13\% reported extramarital sex in the last 12 months.

Men reported having extramarital sexwith commercial sex workers, 'beer bar girls' and other women. Those who engaged in extramarital sex over the last 12 months reported the following sex partners:

$30 \%$ had sex with a commercial sex worker

\section{Exercise 3}

How important are lifestyle factors in treating Gupt Rog?

Consider the lifestyle factors that put men at risk for Gupt Rog: alcohol and tobacco use, blue films and other erotic/pornograpic media, risky sexual practices, and hanging with 'bad' peers.

Based on your knowledge and experience, answer the following questions;

How would you address a patient's lifestyle in the diagnosis and treatment of sexual performance problems?

How would you address a patient's lifestyle in the diagnosis and treatment of semen related concerns?

How would you address a patient's lifestyle in the diagnosis and treatment of STI symptoms? 


\section{Exercise 4}

How important are men's views of masculinity in treating Gupt Roag?

Consider mens' definitions of masculinity. Based on your knowledge and experience, answer the following questions.

How would you address masculinity in the diagnosis and treatment of sexual performance concerns?

How would you address a masculinity in the diagnosis and treatment of semen-related concerns?

How would you address a masculinity in the diagnosis and treatment of STIs?

$74 \%$ with another female

$5 \%$ with another male.

Men reported being introduced to risky sex by friends. They also reported visiting commercial sex workers and beer bars with their friends. $5 \%$ indicated that they had visited a commercial sex worker with friends. As noted earlier, 12\% visited beer bars with friends.

"Earlier I also used to go to the place where prostitutes live (randi bazaar) with my friends. We were discussing amongst us that today we are in the mood. So let us go and pass our time."

When asked about condom use, those who engaged in extramarital sex in the last 12 months reported the following:

$58 \%$ used condoms with commercial sex workers
$26 \%$ used condoms with other female partners

$6 \%$ used condoms with male partners.

Men also reported masturbation as an alternative to penetrative sex:

"Many times I visited in the beer bar, where lady's free service is available [charge more for beer but get free masturbation services from women working in the bars] even before and after marriage. But I never had intercourse with them. Only I use to get masturbation by them."

\section{Masculinity}

Men were asked to describe characteristics of masculinity or manliness - to describe a 'real man'. Men's responses focused on sexual performance, penis size, physical characteristics, bravery and power, as illustrated below. 


\author{
"The real man... \\ Should not suffer from early ejaculation and \\ semen loss \\ Should not masturbate \\ During sex, should give and receive satisfaction \\ Should have long, thick penis \\ Should initiate sex \\ Should be handsome \\ Has power and wealth \\ Is smart \\ Is brave during fights and not fearful."
}

However, men also identified characteristics that focused on responsibility to family, friends and society.

"But real man also...

Should not beat his wife

Should have good reputation in society, with friends and family

Shows the way and tells right $\mathrm{v} / \mathrm{s}$. wrong

Is capable of fulfilling economic responsibilities

Is ready to help when necessary."

\section{Marital relationships}

Quality of the marital relationship was reflected in men's depictions of the couples' sexual relationship, spousal conflict and partner/domestic violence.

\section{Sexual relationship}

Men's depictions provided insights into the sexual relationship. The following patterns were revealed.

First, frequency of marital sex varies widely. On the average, men reported having marital sex 10 times during the past month, but frequency ranged from less than 4 to more than 15 times per month.

Second, lack of privacy in small households interferes with the couple's sexual relationship.
Third, couples are uncomfortable discussing sex.

Fourth, sex is avoided during menstruation.

Fifth, Gupt Roag can create difficulties in sexual relationship. For example, men reported that early ejaculation or bent penis can interfere with sexual satisfaction of husband and wife.

Sixth, gender roles are evident within the sexual relationship.

Women are expected to be submissive and see sex as a duty. Expectations for women included the following.

Should be reluctant about sex and resist on first night.

Cannot refuse sex; it is her duty to keep husband sexually satisfied.

Should not express dissatisfaction with sexual life.

Enjoys painful sex.

Example: "The wife is expected to always cooperate when the husband wants sex and should never refuse him."

In contrast, men are expected to be dominant and forceful. Expectations for men included:

Should dominate his wife.

Is expected to perform painful sex, especially on first night.

Example: "In that day man should do intercourse till the wife say to stop, other wise wife will dominate the husband. I have seen in blue films, men use to do intercourse till the woman get pain. I also wanted to do like that. My wife was not ready to do sex."

Men linked sexual dissatisfaction with extramarital sex. 

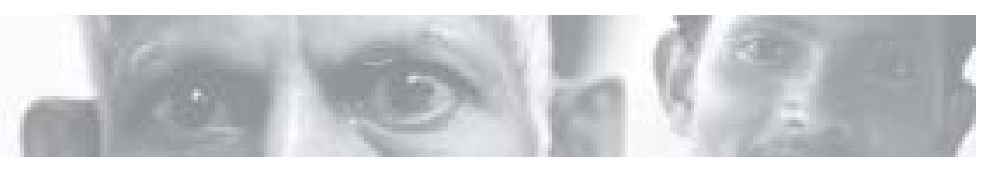

\section{Exercise 5}

How important is the marital relationship in treating Gupt Roag?

Consider the findings on marital relationships. Based on your knowledge and experience, answer the following questions.

How would you address the sexual relationship between husband and wife in the diagnosis and treatment of Gupt Roag?

How would you address marital conflict and domestic violence in the diagnosis and treatment of Gupt Roag?

"My wife is not capable to fulfill my sexual desire, so I am having extra relations because I could not force or beat for sex. Because, I got my marriage just four months back."

\section{Marital conflict and domestic violence}

Several patterns were evident in men's depictions of marital conflict.

First, many couples do not argue or fight and have satisfactory relationships.

Second, couples argue about a range of family and household issues, including children, money, household reponsibilities, and interference from other family members (e.g., in-laws).

Third, challenges to gender role expectations contribute to marital conflict. For example, couples argue because the wife questions the husband's authority, the wife wants to work outside of the home, or the husband perceives that the wife is not fulfilling her household or childrearing responsibilities.
Fourth, sexual difficulties in the marriage can lead to conflict, for example, if the wife if disinterested in or 'not ready' for sex; alternatively, if the wife expresses increased sexual desire.

$57 \%$ of men indicated that their wives cannot refuse sex.

$4 \%$ men reported that the last sexual encounter with their wives involved coercive or forced sex.

The following quote is indicative of the frustration related to sexual difficulties within marriage: "Wife's sexual desire is increased. Some time I want to rape her, I mean forcefully and longer penetration, so her desire would be became less."

Fifth, lifestyle factors contribute to marital conflict, for example, husband's alcohol use leads to conflict.

"But, as I had to work a lot and very hard, I got addicted to alcohol... Because of which I had quarrels with my wife. One day after drinking a lot I beat her." 


\section{Exercise 6 \\ How important are perceived consequences in treating Gupt Roag?}

Consider men's concerns about the consequences of Gupt Roag. Based on your knowledge and experience, answer the following questions.

How would you address emotional distress (tension, guilt, worry, anger) in the diagnosis and treatment of Gupt Roag?

How would you address consequences of the marital relationship (conflict, dissatisfaction) in the diagnosis and treatment of Gupt Roag?

How would you address the potential for the wife to be infected when diagnosing and treating Gupt Roag?

Marital conflict can involve domestic violence. When asked about marital violence over the past six months, $75 \%$ of the men reported having had violent arguments with their wives, and $28 \%$ reported physical violence involving kicking, punching or slapping.

\section{Perceived consequences of Gupt Roag} Men expressed concerns about potential or experienced consequences of Gupt Roag, ranging from emotional distress to domestic violence and thoughts of suicide, as illustrated by the following themes. These concerns are not always freely expressed but may require encouragement and probing by the provider. The communication skills section below provides some guidelines for eliciting such information.
Gupt Rog can lead to emotional distress - guilt, worry, tension, anger - and related difficulties in sleeping or concentrating.

\section{Gupt Rog can lead to:}

\section{Emotional distress}

Problem's in a couple's sexual relationship

Infection transfer to wife

Marital discord, Infidelity, domestic violence

\section{Suicide}




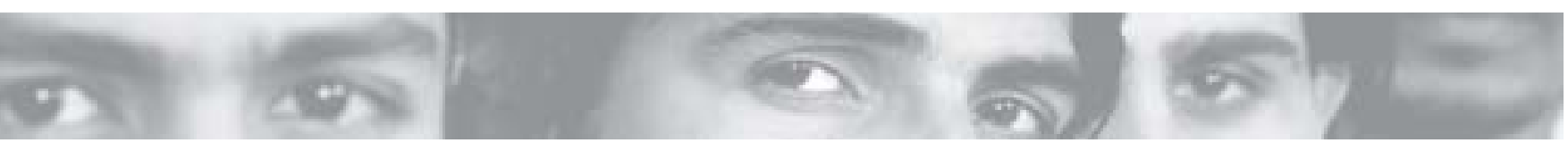

"For these problems, I can't sleep properly or concentrate in my work."

Gupt Rog can lead to problems in the couple's sexual relationship.

"When I got early ejaculations she seems not to be satisfied." "I don't feel for myself, but I am worried about my wife's satisfaction."

Gupt Rog can be transmitted to the wife.

"Wife also has pimples around her genital organs. She also has the problems I suffer from. She also complains about pain in her abdomen, burning urination problem, white discharge, even she looks like a TB patient."

Gupt Rog can lead to marital discord, infidelity, violence, and even suicide.

Wife can become angry, annoyed, or tease her husband. "If the wife is not satisfied with her husband, she must be starting sexual relations with some other person. When man comes to know about his wife's relationships with other, he might kill her or he himself make suicide." 



\section{SECTION III}

\section{Behaviour Change: Narrative Prevention Counselling (NPC)}

- What is NPC?

- Why use NPC?

- How is NPC different from other approaches to HIV/STI prevention?

- How does NPC fit with existing approaches in Indian systems of medicine?

- How effective is NPC?

- Applying NPC to Gupt Rog

- Counselling

- Communication skills and techniques

- Record keeping

- The steps of NPC

- Step 1. Assessment

- Step 2. Interpretation

o Step 3. Prevention 


\section{Narrative Prevention Counselling (NPC)}

\section{What is NPC?}

The model for addressing Gupt Rog problems discussed in this manual originated from a narrative counselling approach to prevention of STI/HIV (the NPC), developed by the RISHTA team (see Figure 1). The NPC provides a guide for expanding doctor's approach to history taking, diagnosis and treatment of Gupt Rog to include focus on prevention of HIV/STIs. The purpose of NPC is to identify factors such as patient's beliefs, lifestyle, marital relationship and behaviour which increase risk for engaging in risky sexual behaviour and consequent STIs; and to use that information in order to provide health education and risk reduction in addition to medical treatment for symptoms.

Figure I. Narrative Prevention Counselling

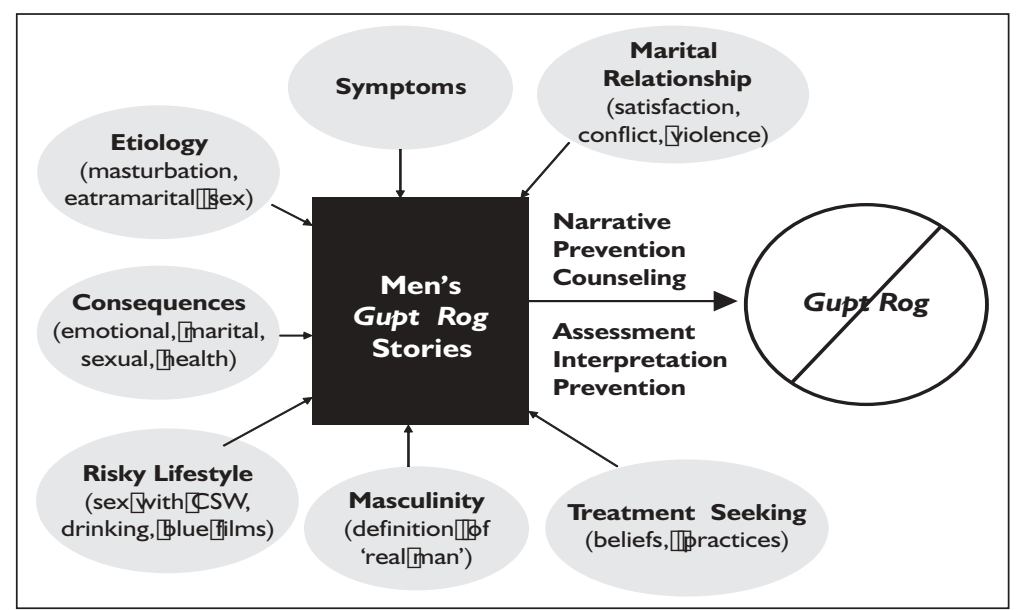

The structure of NPC follows the doctor's typical approach to treatment: gathering information through history taking, diagnosing the problem, and recommending treatment. NPC involves 3 steps: (I) Assessment (an extension of history taking); (2) Interpretation (an extension of diagnosis); (3) Prevention (an extension of treatment). At each step the doctor focuses on symptoms plus several life factors, as illustrated in Figure I:

- Symptoms

- Perceived causes

- Perceived consequences

- Treatment seeking

- Lifestyle (smoking, watching bluefilms, visting commercial sex workers, extramarital sex, hanging out with 'bad' peers)

- Marital relationship (communication with wife, conflicts, domestic violence, sexual relationship with wife)

- Perceptions of masculinity

In Assessment, the doctor gathers information about the life factors in addition to history taking regarding symptoms. In Interpretation, the doctor identifies which of the life factors contributes to the current problem or future risk. In Prevention, the doctor provides health education, 'counsels' men about the life factors which contribute to risk, how to avoid or reduce risk, and discusses the need to inform wife

The purpose of NPC is to identify factors such as patient's beliefs, lifestyle, marital relationship and behaviour which increase risk for engaging in risky sexual behaviour and consequent STls; and to use that information in order to provide health education and risk reduction in addition to medical treatment for symptoms. 

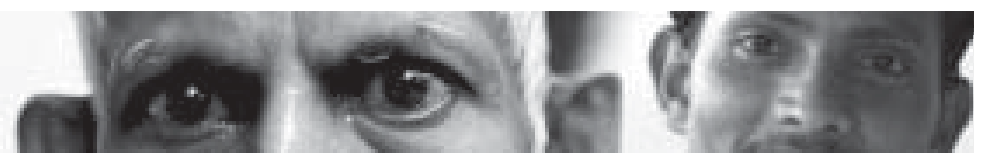

or other sexual partners, in addition to treatment, referral and follow-up for the symptoms. The NPC approach thus extends the focus of treatment of Gupt Rog to include counselling focused on health promotion and risk reduction of STIS/HIV.

\section{Why use NPC?}

- NPC provides a mechanism for conducting health promotion and sexual risk reduction in the treatment of men with Gupt Rog.

- NPC addresses symptoms plus cultural, relational and psychological factors that increase risk for Gupt Rog

- NPC focuses on patient's emotions, cognitions, behaviours and life situation related to Gupt Rog

- NPC individualises education and risk reduction to patient's needs and lifestyle, by focusing on the patient's story of Gupt Rog

\section{How is NPC different from other approaches to HIV/STI prevention?}

NPC builds on existing behaviour change models that have been shown to be effective for HIV/STI prevention. Consistent with these cognitivebehavioural models, NPC emphasises that the role of cognition/thinking in guiding behaviour, based on the assumption that changes in thinking (ideas, beliefs, values) are critical to behaviour change. Cognitions that influence behaviour are developed or transmitted through social interactions within a cultural context, resulting in narratives or scripts to guide behaviour. These culturally-transmitted cognitions not only guide behaviour, but also influence how one interprets both emotions, bodily processes, and experiences in social contexts. Thus, one's interpretation of internal reactions and life experiences as well as behaviour is highly influenced by cultural beliefs, transmitted through interpersonal interactions.

NPC addresses one of the primary limitations of existing cognitive-behavioural models - the failure to focus adequately on the social and cultural factors that influence thinking and behaviour. Just as risky thinking and behaviour can be influenced by the creation of certain narratives/stories, health promoting thinking and behaviour can be influenced in the same manner. In the application of NPC, providers make use of focused patient-provider interactions to identify the men's stories of their Gupt Rog and related life factors, critically examine the story to identify those life factors that influence or maintain sexual risk, and work with patients through a targeted 'Counselling' approach to create a revised story that includes health promoting thinking and behaviours.

\section{How does NPC fit with existing approaches in Indian systems of medicine?}

NPC is especially suited to traditional holistic approaches to medicine, in which illness and health are considered within a lifestyle framework. Thus, rather than focusing solely on symptoms, the provider examines the patients' thinking and lifestyle including diet, work habits, family situation, sources of tension, risky practices, etc. In a similar way, NPC extends treatment of Gupt Rog from focus on treating symptoms to an examination of men's thinking and lifestyle factors that contribute to the risk of Gupt Rog.

For allopathic providers, NPC involves an expansion of biomedical approach to incorporate a more holistic approach that characterises traditional AYUSH practice.

\section{How effective is NPC?}

\section{Impact on Provider Practice}

NPC was well received by both AYUSH and allopathic providers, who enthusiastically adopted NPC and integrated the prevention approach into their treatment for Gupt Rog. Following an initial four day training programme, doctors requested an additional eight training sessions over the course of 


\section{NPC is especially suited to traditional holistic} approaches to medicine, in which illness and health are considered within a lifestyle framework. Thus, rather than focusing solely on symptoms, the provider examines the patients' thinking and lifestyle including diet, work habits, family situation, sources of tension, risky practices.

\section{Impact on Patient Outcomes ${ }^{24}$}

The results for patient outcomes are as follows:

\begin{abstract}
Alcohol use with friends: There is a trend which shows that patients who visit the trained AYUSH providers have reduced alcohol use with friends to a greater extent than those who visit the untrainedAYUSH providers.Allotherrelationshipswere not significant.
\end{abstract}

Alcohol use in the last six months: There is a trend which shows that there was a small decrease in alcohol use among patients who visited trained AYUSH providers than those who visited untrained AYUSH providers. All other relationships were not significant.

Extramarital Sex: There was a significant effect for training. Those patients (both AYUSH and allopathic) who went to trained providers showed more of a decrease in EMS than those patients who went to untrained providers.

Forced sex: There were insufficient cases of men reporting forced sex to allow for statistical analysis (men are either under-reporting forced sex or do not see their actions as forced sex).

Satisfaction with marital sex: Those patients who visited the trained allopathic providers were significantly more likely to show an increase in satisfaction with marital sex than those who visited untrained (private) allopaths. No other relationships were significant.

Violent behaviour with spouse: Those patients who visited trained (both AYUSH and allopathic) providers

24 The analyses for patient outcomes compared 12 outcome variables for Time (pre-post- 6-month follow-up) $\times$ Training (trained v. untrained providers) and Time $\times$ Provider Type (Allopathic v. AYUSH) $\times$ Training. A series of co-variates were included in the analysis to assess the role of the type of patient, differential services on the outcomes. Co-variates included: Age difference between the man and his wife; Prior relationship with the provider; Number of visits to the provider; Number of services provided to the patient; Problem severity; Income. 
showed a significant reduction in violent behaviour with spouse while those patients visiting untrained providers showed an increase in violent behaviour with spouse. No other relationships were significant.

Impact of Gupt Rog problems: Those patients who visited the trained allopathic and AYUSH providers showed a more significant reduction in the impact of Gupt Rog problems on their lives than the patients who visited the untrained allopaths and AYUSH.

Real man (Masculinity) Scale: From Post-Treatment to Follow-Up, training was associated with a decrease (greater hyper-masculinity) in the scale for those patients with fewer doctors' visits, but was associated with an increase (more equity) in the scale for those with more doctors' visits.

Global assessment: From Baseline to Post-Test: For those with low doctor relationship, the more negative self assessment was less for those trained, but more for those high. For those with low number of doctor visits, the decrement was more for those trained, but equal for those high. For those low in Number of visits, the decrement was equal for those trained versus untrained, but for those high in Visits, those trained got worse than those untrained. For those low in Number of Symptoms, the decrement was equal for those trained versus untrained, but for those high in symptoms, those trained got worse than those untrained. For those low in Problem Severity, those untrained got worse than those trained, but for those high in Problem Severity, those trained got worse than those untrained. From Post-Test to Follow-Up: For those low in Number of Visits improvement occurred for those untrained but was more so for those trained. For those low in Number of Symptoms, the improvement was equal for those trained versus untrained, but for those high in Symptoms, those trained improved more than those untrained. For those low in Problem Severity, those untrained improved more than those trained, but for those high in Problem Severity, those trained improved more than those untrained.

All Causes: Patients of trained providers showed a significantly greater improvement in their attribution of causes of their Gupt Rog problem(s) as compared with untrained AYUSH. However, the patients of untrained allopaths showed greater improvement in attribution of causes than the trained allopaths in the $\mathrm{MHC}$.

From Baseline to Post-Test: From Baseline to Post-Test, for those low in Number of Services, both untrained and trained did not change, whereas for those high in Services, untrained got worse, but trained did not change. From Post-Test to Follow-Up: For those low in Number of Visits, trained improved more than untrained, whereas for those high in Visits, untrained improved more than trained.

STD Knowledge: Those patients who went to trained providers showed a significant increase in STD knowledge compared to those patients who went to untrained providers in pre and post treatment comparisons. For those patients who went to trained providers there was a trend showing a larger improvement between post-treatment and six month follow-up. This effect of training on STD knowledge was stronger for trained AYUSH v. untrained AYUSH between pre and post treatment than between trained allopathic $(\mathrm{MHC})$ and untrained (private) allopaths. From Baseline to Post-Test: for low doctor relationship, untrained did not change, but trained improved, whereas for high relationship, untrained and trained improved in parallel. 
Applying NPC to Gupt Rog

Formative research suggested that men sought treatment for symptoms related to dhat, kamjori and garmi, requesting some form of 'English' medicine. Doctors' approach to treatment of men with Gupt Rog symptoms (across dhat, kamjori, and garmi) typically involved taking case history, conducting physical exam when deemed warranted, referral for testing (for STIs) when deemed warranted, and 'counselling' focused on warning men about the risk for contracting STIs from commercial sex workers. History taking included gathering information about presented symptoms (severity, duration, prior attempts to treat) and questioning about exposure to STIs through sex with commercial sex workers.

NPC sought to expand the existing approaches to including a narrative approach that focused not only on symptoms,but also on perceived etiology, treatment seeking, perceptions of masculinity, lifestyle (alcohol, blue films, risky sex, peer influences), marital relationships, perceived or actual consequences, and tension related to the symptoms and concerns about consequences - we considered this to be the patient's 'narrative' or 'life story' of symptoms and associated life factors. In addition, the doctors conducted the history taking and physical exams consistent with their respective system of medicine discipline. This information was then used to develop a 'picture' of the patient's symptoms and life factors leading to identification of life factors that contributed to current or future STI/HIV risk. The 'picture' then provided the basis for narrative prevention counselling which included informational and emotional support to alleviate related tensions, and delivery of health promotion and risk reduction messages that addressed the patients' risky life factors.

Counselling

Counselling is a skill, a process of therapeutic communication which has to be practiced and honed over a period of time. It is helping a person in need with the aim of empowering them to cope with the ongoing crisis. It is focused and purposeful, and implicit in the process is the acceptance of the potential for change. A counsellor also needs to have the right attitudes, and the aptitude for the profession, in order to be effective.

In the process of counselling, the counsellor assists the client to:

- Explore and resolve difficulties they are experiencing

- Clarify conflicting issues

- Help the person discover alternative ways of managing themselves and situations, so that they can decide what course of action or behaviour is helpful for them

\section{ESSENTIALY COUNSELLING IS HELPING PEOPLE HELP THEMSELVES}

According to WHO, HIV/AIDS Counselling is a confidential dialogue between a client and a care provider aimed at enabling the client to cope with stress and take personal decisions related to HIV/AIDS. The Counselling process includes an evaluation of personal risk of HIV transmission and facilitation of prevention.

This includes information, education and psychosocial support and allows individuals to make decisions that facilitate coping and preventive behaviours 


\section{Rules of Counselling}

- Use appropriate language

- Remember details

- Do not under-estimate the power of non-verbal communication

- Be gentle

- Be genuine

- Be humble

- Have a sense of humour

Do not

- Give advice

- Judge

- Make premature interpretations

- Interrupt

- Take sides

- Use medical or psychiatric jargon

- Encourage dependence

- Convey disinterest

- Sneer or make fun of the client, or of their values, attitudes, or behaviours

\section{Steps in Counselling}

Goals are helpful for both the counsellor and client as they provide a sense of direction.

While setting goals it is important to differentiate between

Wishes - things that would be nice to have Aims - things that are hoped for Goals - things for which there is real commitment

The goals that are agreed upon must be:

- Realistic

- Measurable

- Positive

- Controllable

- Achievable
- Relevant

- Possible

- Time bound

The stages in the process are:

I Preparation

2 Initial session

3 Subsequent sessions

4 Building on success

5 Concluding the therapy

6 Doing the paperwork

(Source: Communication and Counselling manual of West Bengal Sexual Health Project unit)

\section{Communication Skills and Techniques}

To facilitate communication with patients, the first section reviews key communication skills for establishing rapport, gathering information, interpreting information to patients, and educating and influencing patients' thinking and behaviour. These skills and techniques are consistent with those used in variety of Counselling approaches, but are drawn specifically from the work of Allen Ivey (Ivey \& Ivey, 2003). The second section provides guidelines for record keeping and completion of recommended case sheets. Section three through five present the objectives, key questions, messages, examples, and practice exercises related to the respective steps of NPC: Assessment, Interpretation, Prevention.

\section{Why are communication skills important?}

Effective communication can facilitate building rapport with patient, gathering information, conveying the diagnosis and treatment plan, conveying education and risk reduction messages.

Particularly with regard to NPC, effective communcation can help the doctor to: 
- Understand the patient's viewpoint and presentation of Gupt Rog symptoms

- Understand how the patients life factors relate to Gupt Rog and risk of HIV/STIs

- Help the patient to see links between Gupt Rog and life factors

- Help the patient to change thinking, lifestyle, and behaviours to reduce sexual risk

This section provides an overview of key communication skills.

\section{How to make the patient comfortable?}

Since the questions to be asked are of personal nature it is important that there is a separate room with chairs, a table and a couch where the providers can interview and examine the patient on one to one basis. This will ensure that the patient is comfortable, is assured of secrecy and is encouraged to confide in the provider. The facility should also have a free supply of the equipment you feel you need to examine the patient.

Tips to establish rapport with patients

- Greet the patient

- Make eye contact

- Ask questions in local language

- Encourage patient to talk

- Listen to the patient

- Ask the patient's permission to ask sensitive questions

- Do not judge or moralise and do not force answers

Once the patient is assured of confidentiality and a rapport is established between the two, the patient will answer all the questions asked by the provider.

\section{Attending Skills}

Effective attending conveys to the patient that you are 'listening' and encourages disclosure. Attending can be conveyed non-verbally through body

\section{Effective communication can facilitate building rapport with patient, gathering information, conveying the diagnosis and treatment plan, conveying education and risk reduction messages.}

language such as posture, looking at the patient, and head gestures [nod]. It can also be conveyed verbally with one word encourages such as yes, I see, go on, uh-huh - what fits the culture??

\section{Listening Skills}

Effective listening facilitates the data gathering and diagnostic process. The basic listening skills include the following:

\section{Use of Questions}

Questions elicit information from the patient. The basic questions for gathering information include those used by journalists: Who? What? When? Where? How? Why?

Some questions (what, how, why, could) encourage the patient to talk and provide elaborated answers these are referred to as open questions.

Examples: What are your concerns? How did the problem start? What are the symptoms? Could you tell me about your relationship with your wife?

Other questions (who, when, where, is/are, do) are used to gather specific information or details, and often result in yes/no or short responses. These are closed questions.

Examples: When did you notice the symptoms? Where else have you sought advice? Is this the first time you have had this problem? Who are your sexual 

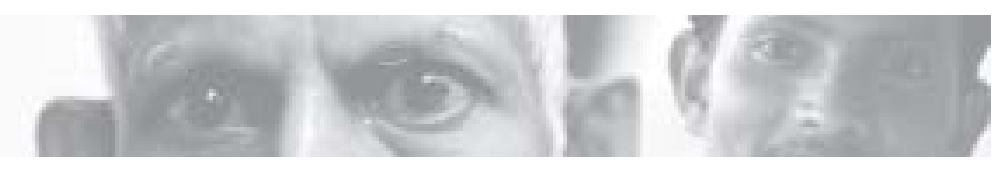

partners? Do you use a condom when you have sex with beer bar girls?

\section{Observation}

Much can be learned by watching the patient and how he responds to your questions and comments. The patient's facial expression and body language can be indicative of emotions such as discomfort, anxiety, or tension. Discrepancies between body language and what the patient says can be helpful for identifying issues that are of concern and potential areas for further questioning. For example, when discussing the potential consequences of STIs, the patient says he has no concerns yet his body is tensed.

\section{Encouraging, paraphrasing, summarising}

Encouraging, which can be conveyed verbally or non-verbally, can elicit more information from the patient. Encouragers are similar to listening skills described above.

Example: Doctor indicates with a nod for the patient to continue talking; or doctor says, "Tell me more about what happens when you are drinking with your friends."

Paraprasing and summarising what patient says can help to ensure that you understand correctly.

Example: " Let me see if I understand correctly. You say that this problem only occurs when your wife is at her home village and you are here in Mumbai alone."

\section{Reflecting feelings}

Reflecting feelings refers to acknowledging or confirming how the patient is feeling.

Example: "You seem to be tense when you talk about your relationship with your wife."
Focusing Skills

Focusing helps the patient to identify life factors that contribute to the current concerns and future risk for Gupt Rog. The purpose of focusing is to provide support yet challenge the patient's faulty thinking, discrepancies in what patient says and does, or risky behaviours. For example, in Step 2 of NPC, the goal is to help patient to see how beliefs, lifestyle and personal concerns link to Gupt Rog and create continued risk.

Example: "You say that you want to stop going to CSW yet you continue to hang out with your friends who encourage you to go."

In NPC, the purpose of influencing is to help the patient see his problem in a different way (e.g., the real problem is that my sexual relationship with my wife is not satisfactory) and develop strategies for making life changes (e.gog focusing on improving communication with his wife).

\section{Influencing skills}

The purpose of influencing skills is to encourage the patient to change those life factors which contribute to risk. Specific strategies include giving information or advice, providing feedback, giving specific directives (telling the patient what to do), pointing out logical consequences of behaviour, helping patient to see a problem in a different way, or sharing your own experiences. In NPC, the purpose of influencing is to help the patient see his problem in a different way (e.g., the real problem is that my sexual relationship with my wife is not satisfactory) and develop strategies for making life changes (focusing on improving communication with his wife). Thus, effective influencing goes beyond 
advice giving to creating with the patient a new way of thinking about and conducting his life.

Interpretation/reframing refers to presenting a different way to view the problem. It is often used as a way to correct 'faulty thinking' or challenge beliefs that create risk.

Example: "You say you think going to a commercial sex worker when your wife is away is better than masturbation. But going to a commercial sex worker is more risky for contracting STIS/HIV."

Logical consequences refers to pointing out what consequences or risks are likely to follow from certain behaviours.

Example: "If you go drinking and then to video palours with your friends, you are more likely to go to commercial sex workers and engage in risky behaviour." "If you contract an STD, you can also infect your wife."
Self-disclosure involves sharing your own related experience with the patient, as a way of conveying your understanding of the patient's problem or situation. This strategy of course should be used sparingly, as the primary focus should be the patient's life situation.

Feedback involves providing to the patient an honest appraisal of the patient's behaviour or lifestyle.

Example: "You seem to be putting yourself at risk by hanging with your friends who like to go to beer bars and video palours." "I notice that your sense of manliness is very important to you. You have mentioned that several times today."

Information/advice is used primarily to educate about STIs, HIV, risks, and prevention strategies.

Directives refer to recommendations regarding treatment, follow-up and referral; and suggestions for alternatives to current risky behaviours.

\section{Exercise 7}

How do you communicate with patients?

Consider the communication skills described above. Based on your own knowledge and experiences, answer the following questions.

What skills do you typically use in diagnosis and treament of Gupt Rog?

What skills might you use to extend your current approach to include the process of gathering the patient's story, interpreting the patient's story and helping the patient recreate his life story related to Gupt Rog risks? 
Example: "Instead of going to CSW, it would be less risky to masturbate." "My recommendation is that you avoid extramarital sex, but if you choose to do so, then use a condom."

Source: Ivey, A. E., \& Ivey, M. B. (2003). Intentional interviewing and Counselling: Facilitating client development in a multicultural society (5th ed.). Pacific Grove, CA: Brooks/Cole.

Negotiation/co-construction involves a collaborative effort by the provider and patient to generate ideas about how to prevent risky behaviour and how to address factors that create risk, and is central to NPC. Co-construction of health promoting beliefs and behaviours involves the use of all the above mentioned communication strategies so that the patient not only gets information or advice, but also comes to understand the relationship between Gupt Rog and lifestyle, beliefs, marital relationship, etc; understands how changes in his beliefs or behaviour can reduce risk; and makes choice to engage in different thinking and behaviour.

In NPC, the doctor initially focused on gathering the patient's story of Gupt Rog; then interprets the patients life story, and finally helps the patient to 'recreate' his story to include healthy decision making and behaviour. This process is illustrated in the case examples of NPC application.

\section{Record Keeping}

Some form of record keeping or notation can help to guide the assessment process and facilitate identification of factors that need to be addressed through education and Counselling. In the activities associated with NPC, we provide some examples of how to record information through use of graphic profile and case sheets (see Annexure B). The case sheet was used successfully in the RISHTA project as a way for recording information about cases and as permanent record for follow-up with patients. Providers are encouraged to adopt record keeping strategy for treatment and prevention.

\section{The Steps of NPC}

This section includes description of the key components of NPC; questions for eliciting information from patients; key messages related to health promotion and risk reduction; examples of the application of NPC from actual cases of AYUSH providers; and exercises for practicing the application of NPC to different types of cases.

\section{Step I: Assessment}

The Assessment process is depicted in Figure 2. In Step I, you want to collect information about all the factors depicted in the figure in order to do a comprehensive assessment of the patient's life situation and potential sources of risk. In the next step, you identify which are important and warrant attention through education and Counselling. Thus, although you will collect information about all of these factors, your subsequent prevention efforts will only be focused on those that you deem relevant to the patient's Gupt Rog risk. This process permits individualisation of prevention efforts based on the patient's specific needs. Assessment also involves medical aspects of history taking and physical exam, which are described in a later subsection

Figure 2.

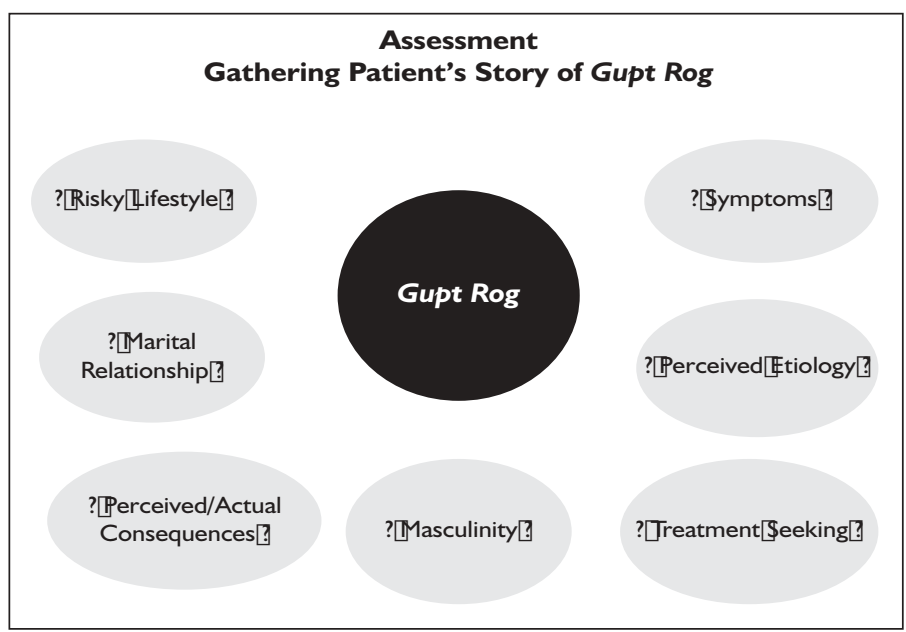




\section{The three steps of NPC in a nut shell are:}

\section{Assesment}

Interpretation

\section{Prevention}

6. What do you think first caused the problem?

TREATMENT SEEKING: What has the patient done to relieve the symptoms before coming to you?

7. Have you talked with anyone else about these symptoms? Friends? Relatives? Other doctors? [inquire about sources of information or referral]

8. What have you done to relieve the symptoms? Have you gone to other doctors? What did the doctor say? What medicines were prescribed? Did that help? [inquire about all attempts, types of doctors seen, their diagnosis and treatment, effect on symptoms]

2. To depict the patient's narrative or story of Gupt Rog and related life factors.

3. To conduct physical exam to assess visible symptoms.

4. To identify need for referral for testing.

\section{Key Questions: Provider's Guide}

Here are examples of questions that the provider can use to elicit information about the factors depicted in Figure 2.

SYMPTOMS: Description of sexual health problem - history and current status of that, kamjori or garmi

I. What brought you to the clinic?

2. Tell me more about the problem(s) you are currently having? [elicit a list of symptoms; question for detailed and comprehensive description of sexual health concerns]

3. How long have you had this problem? [get a full history of the problem]

PERCEIVED ETIOLOGY/CAUSE: Patient's view of what caused the Gupt Rog

4. When did you first notice the [symptoms]?

5. Did something happen around that time that might be related to the symptoms?
9. What other medicines have you taken? How did you get those? Did they help? [inquire about self-treatment, in which patient gets medication from pharmacist, friend, relative without seeing doctor first]

PERCEIVED OR ACTUAL CONSEQUENCES: How have the symptoms affected the patient's life thus far? What are the patient's concerns about potential consequences for him, his health, health of his wife/partner, etc.?

10. How have the symptoms affected your life? [Use the following questions to probe for details.]

a. Are you experiencing physical discomfort/ pain?

b. Are you experienced tension (emotional discomfort such as guilt, shame, fear, anxiety, anger)

c. Does it affect your ability to do your job? How?

d. Has it affected your relationship with your wife (or other sexual partners)? How?

e. How has your wife (or other sexual partners) reacted to the problem? 
f. Has your wife (or other sexual partners) experienced similar symptoms? If so, has she/ he sought treatment?

g. Has it affected your sex life? How?

h. Has it affected your relationship with your friends? Or relatives? How?

LIFESTYLE: Exploring the lifestyle factors that could be contributing to current problem and/or future risk of Gupt Rog, including:

- Use of alcohol or other drugs,

- Exposure to erotic/pornographic media such as blue films,

- Engaging in unprotected sex outside of marriage or primary relationship, for example, with commercial sex worker, beer bar girl, other female partner, male partner [risky sex]

- Associated with peers who encourage or pressure him to engage in the activities listed above

- Occupation requiring long periods of separation from wife (primary partner)

1 I. Do you do any of the following activities alone or with your male friends? Tell me about your recent activities. [probe for patterns of risky behaviour, past and current activities; probe for peer influence - does he engage in these activities with friends/co-workers? Do the friends encourage or pressure him?]

a. Drinking? Using other drugs?

b. Hanging out?

c. Visiting commercial sex workers?

d. Having sex with beer bar girls or other female partners?

e. Watching blue films?

f. Male-to-male sex? g. Sex with eunuchs?

12. What type of work do you do? [probe for periods of separation from wife/primary partner and increased opportunities for risky sex because of work habits, type of job, etc. Is work source of stress that may be impetus for engaging in activities listed in \# | I.]

MASCULINITY: What is the patient's perception of 'real man'? How does he define manliness? To what extent does sexual performance and sexual prowess define manliness?

13. What does it mean to be a 'real man'? [inquire about personal perception or sense of masculinity or 'manliness'; probe for beliefs that might influence sexual risk taking]

MARITAL RELATIONSHIP: Explore the patient's relationship with his wife-sexual and nonsexual aspects_including quality of the relationship, presence and sources of conflict, domestic violence, sexual satisfaction (quality of sexual relationship), frequency of sexual activity, any sexual difficulties, and domestic violence

14. Tell me about your relationship with your wife (primary sex partner).

15. How long have you been married?

16. Does your wife stay in this community with you? If not, how often do you see your wife? How long have you been living apart?

17. Do you and your wife get along well?

18. Do you have disagreements or fights? What do you fight/argue about (children, finance, household responsibilities)? How often do you fight?

19. Do the arguments ever lead to physical fighting/ violence-hitting, kicking, etc.? [probe for frequency, causes such as alcohol abuse, nature of violence] 


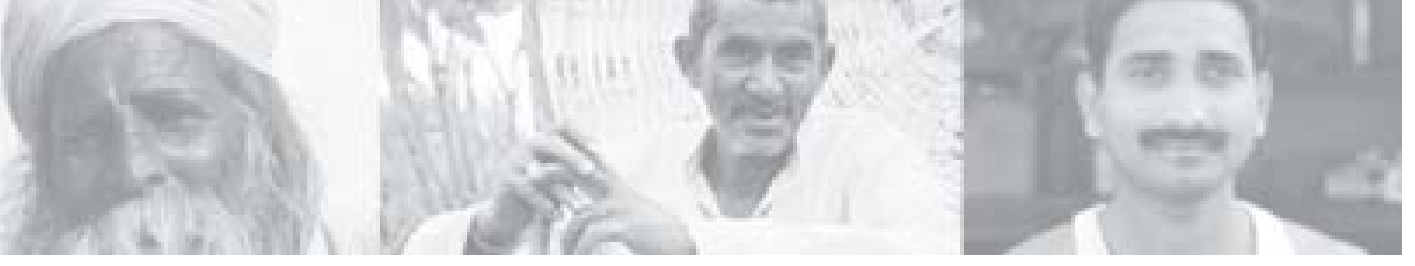

\section{Exercise 8 \\ Patient A comes to your clinic and presents the following problem: \\ I am suffering from burning urination, pain in penis, itching and pimples around genital, pus discharge from those pimples.}

List the main questions you would ask in order to gather information on the following factors:

Symptoms

Perceived etiology

Risky lifestyle

Masculinity

Marital relationships

Treatment seeking

Perceived consequences 


\section{Exercise 9}

Patient B comes to your clinic and presents the following problem:

I don't get proper erection when I want to do sex with my wife. Occasionally I do sex with her, even for that, my wife has to try hard. She has to masturbate me to get the erection. It loses its strength before ejaculation.

List the main questions you would ask in order to gather information on the following factors:

Symptoms

Perceived etiology

Risky lifestyle

Masculinity

Marital relationships

Treatment seeking

Perceived consequences 
20. What do you expect from your wife? What are her responsibilities? What do you think are the responsibilities of the husband? Do you and your wife agree about household and family responsibilities?

21. Are you happy in your marriage? Why or why not?

22. How would you describe your sexual relationship with your wife? [Probe for information about satisfaction, sources of tension or disagreement, factors that interfere with sex such as household structure (no privacy), dissatisfaction in marriage, wife's lack of interest, incompatible interest or sex drive, alcohol abuse, forced sex. Also probe for history of any problems and relationship to current Gupt Rog.]

23. Would you say that you are satisfied with your sex life? Do you have any difficulties or concerns in terms of your sexual performance (interest, satisfaction, erection, ejaculation)? If difficulty or dissatisfaction is indicated, probe for details, history, links to current problem and sexual relationship with wife/sex partner, or lifestyle factors.

These are suggested questions for guiding assessment of the patient. Many times you need only ask the initial question (e.g., Would you say that you are satisfied with your sex life?) and the patient will tell you all you need to know. Other times you will need to use additional question to get elaboration and details. It is important that the provider identify questions that are consistent with his/her style of history taking. The next two exercises provide an opportunity for you to think about the main questions you would use to gather information on the factors depicted in Figure 2.

\section{History taking and examination}

History taking and physical examination are the two important pillars of STI case management. The first important step of the process is to build rapport with the patient, create confidence and ensure that patient is comfortable and sure that whatever he/she communicates will be kept confidential. Do not be judgmental about the patient's behaviour and do not moralise.

\section{What question to ask?}

The questions asked pertain to:

- General details of patients including social history and factors that may increase risk of STIS

- History of presenting illness

- Past medical history

- Detailed sexual history

- Treatment history

General details of patient: Patient's name, age, marital status, occupation, level of education, area and community to which the patient belongs and the actual address, etc. are noted. These details help the provider to form a provisional opinion about the possible risk behaviour of the patient, and build rapport with the patient.

History of presenting illness: The following details are noted by the provider:

- Presenting complaints and their duration (e.g. ulcer, discharge, others)

- If genital ulcer, then note whether one or many, the location, painful or not, recurrent, spontaneous or followed some injury, etc.

- If inguinal bubo, then whether painful and associated with ulcer on genitalia

- If urethral, then whether associated with dysuria and frequency of micturion (passing urine frequently)

- Vaginal discharge, then whether associated with dysuria, frequency of micturition, lower 
abdominal pain, dyspareunia (painful intercourse), dysmenorrhoea (pain during periods), vaginal bleeding, irregular periods, missed or delayed periods, parity (number of pregnancies), use of oral contraceptive, type of discharge (thin, thick, blood stained, foul smelling, amount, stains clothes, etc.)

- Any other symptoms developed recently

- Any treatment taken.

Past medical history: This includes:

- History of STIs suffered in the past with type, dates, treatment, response and report of laboratory test undertaken if any

- Any other illnesses like diabetes, hypertension, etc.

- History of drugs taken/being taken

- History of substance abuse (alcohol, drugs)

- History of any drug allergies.

Sexual history: This includes:

- History of last intercourse - date, with whom, condom used or not

- Previous sexual intercourse - date, with whom, condom used or not

- History of substance abuse

- New partner in the last three months

- Partner details - partner has symptoms or not.

\section{Contraceptive history}

- Whether condom used during intercourse

- Whether patient knows the correct use of condom

- Always used or used sometimes

- Used with whom (wife, other sexual partners).

\section{Examination}

You may wish to carry out a physical examination of the patient, including a genital examination. This process enables the health provider to confirm the symptoms described by the patient and if possible check for signs of STIs.
Standard work precautions should be followed while examining ulcers, bleeding lesions. Wear gloves, fresh for each patient. After use discard used gloves in sodium hypochlorite solution.

Requirements for physical examination: The physical examination is important to make the diagnosis. However, the examination should never be forced, rather the history taking should be conducted in a way which ensures patient's compliance for physical examination. Following points should be taken into consideration to conduct physical examination;

- Provider should maintain confidentiality and privacy

- Should treat patient with respect

- Should behave in a friendly and professional manner

- Should not show embarrassment or shyness while examining

- Should offer female patients to have someone present (friend/relative/female health provider)

- Reluctant patients should be persuaded to undergo the physical examination through communication about advantages in simple language.

\section{Examining a male patient}

Ask the patient to remove his shirt.

- Ask him to sit in a chair, then palpate (feel) the

I. The anterior and posterior triangles of the neck for lymph nodes

2. Submandibular and suboccipital areas for lymph nodes

3. Axillae and epitrochlear regions for lymph nodes.

- Ask the patient to stand-up and lower his pants up to the knee. Patient can be examined standing up or lying down 
- Look for rashes, swelling, and ulcers by inspecting the skin of the face, thighs, abdomen, buttocks, groin and genitals, palm and sole

- Examine the pubic hair for lice

- Palpate the inguinal region in order to detect the presence or absence of lymph nodes and buboes

- Ask the patient to bend forward and spread his buttocks with his hands so that the provider can examine the anus and perineum

- Palpate the scrotum for swelling and tenderness (pain on pressure) of testis, epididymis and spermatic cord

- Examine the penis noting any rashes or sores. Ask the patient to retract the foreskin of penis and inspect the glands, penis, coronal sulcus, frenum and urethral meatus.

In case there is no obvious discharge, the urethra should be gently milked to express any discharge if present.

\section{Examining a female patient}

The health provider should make sure that a female nurse/assistant/patient's relative or friend is present in the room when the examination is being done. The examination as described for males in first six points is the same for females. There are three components of examination specific in females for STIs and type of examination conducted depends on the facilities available.

- External genital examination

- Speculum examination

- Bimanual examination

\section{The external genital examination}

- Ensure privacy

- Ask the woman to pass urine

- Ask her to loosen her clothing, lie on her back, with her heels close to her bottom with knees up. Explain what is going to be done

- Wash hands with soap and clean water

- Wear clean gloves for per-vaginal examination.

- Look at the external genitalia including perineum and anus with the gloved hand.

- Look for lumps, swelling, unusual discharge, sores, tears and scars around genitals and in between the skin folds of vulva.

The patient should be referred to a specialist for speculum and bimanual examination.

\section{Common STI symptoms}

Many patients with STIs complain of symptoms associated with specific syndromes. The chart below

\begin{tabular}{|l|l|l|}
\hline Women & Men & Syndrome \\
\hline $\begin{array}{l}\text { Vaginal discharge which is abnormal in } \\
\text { colour, consistency, odour (smell) and } \\
\text { amount.Itching or irritation of vulva } \\
\text { or vagina }\end{array}$ & Vaginal discharge \\
\hline & $\begin{array}{l}\text { Urethral discharge Painful } \\
\text { urination (dysuria) }\end{array}$ & Urethral discharge \\
\hline Lower abdominal pain & Lenital ulcers, sore or blisters & Genital ulcer \\
\hline Genital ulcers, sore or blisters & $\begin{array}{l}\text { Swelling, lumps or ulcers in } \\
\text { the groin area }\end{array}$ & Inguinal bubo \\
\hline Swelling, lumps or ulcers in the groin area & & \\
\hline
\end{tabular}


links the common symptoms that people complain of with the corresponding STI syndrome as per NACO guidelines.

A syndromic diagnosis is made as given in the chart on the basis of signs, symptoms and physical examination and treatment is given following the flow charts as per NACO guidelines (see Annexure A). A specific etiological diagnosis can also be made in cases where ever the laboratory infrastructure is available/accessible.

\section{Step 2: Interpretation}

The process of interpretation is depicted in Figure 3. Step 2 focuses on analysing the information collected in Step I in order to interpret the patient's life story - that is, to identify which life factors are related to current Gupt Rog or future risk for Gupt Rog. Whereas you collect information on all factors in Step 1, Step 2 is focused on identifying which are important for explaining the problem and conducting education and Counselling in Step 3.

Figure 3

\section{Objectives}

I. To diagnose the Gupt Rog

2. To critically examine how the patient's lifestyle, marital relationship, perceptions of masculinity, and Gupt Rog etiology and consequences influence or maintain sexual risks

3. Provide for the patient a picture of how the patient's lifestyle, marital relationship, perceptions of masculinity, and Gupt Rog etiology and consequences might contribute to risk Gupt Rog

Key questions for the provider: Case interpretation and diagnosis

1. What is your diagnosis/assessment of the Gupt Rog?

2. Which factors are important for understanding and treating this patient's Gupt Rog?

3. Which factors might be contributing to the present Gupt Rog and future sexual risks?

4. How do I explain diagnosis?

5. How do I explain how the factors might be contributing to present Gupt Rog or future sexual risks?

Completing this step requires the doctor to review the information (e.g., from the case sheet) that was collected during Step I, and develop a picture of the Gupt Rog and contributing factors. In the following two exercises, you will be asked to depict the patient's profile (symptoms and contributing factors), using the model presented in Figure 3. 


\section{Example Case History on Patient A for practising Exercise 10}

Through history taking you gain the following information from Patient A (see Exercise 8).

"I am suffering from burning sensation during urination, and pain in penis. I feel severe pain for the last couple of months. I have been afraid to come to you with this problem, so I have waited till now. These days, I am not able to sleep properly or concentrate in my work because of this problem. I am worried about my wife."

"Before marriage, I used to sleep inside the hotel with four other fellow workers and we had sex with each other. I had this problem first time at the age of 19 years. My friends told me to take English medicine and we went to the pharmacy to get it."

"I had sex with a CSW when I was around 20 years. I went along with my friend. I found that interesting and continued to do so further. Even after marriage, I continued going to that lady, but for the last five months I stopped visiting. I like doing sex with sex workers, because they are prepared to do sex in different ways as is shown in blue films, which one can not do with their wives." "Recently I got married (current age is 26). Till I get a child, my wife's desire is more for sex; also she is very passionate. But because of my problem, I can't fulfill her desire,

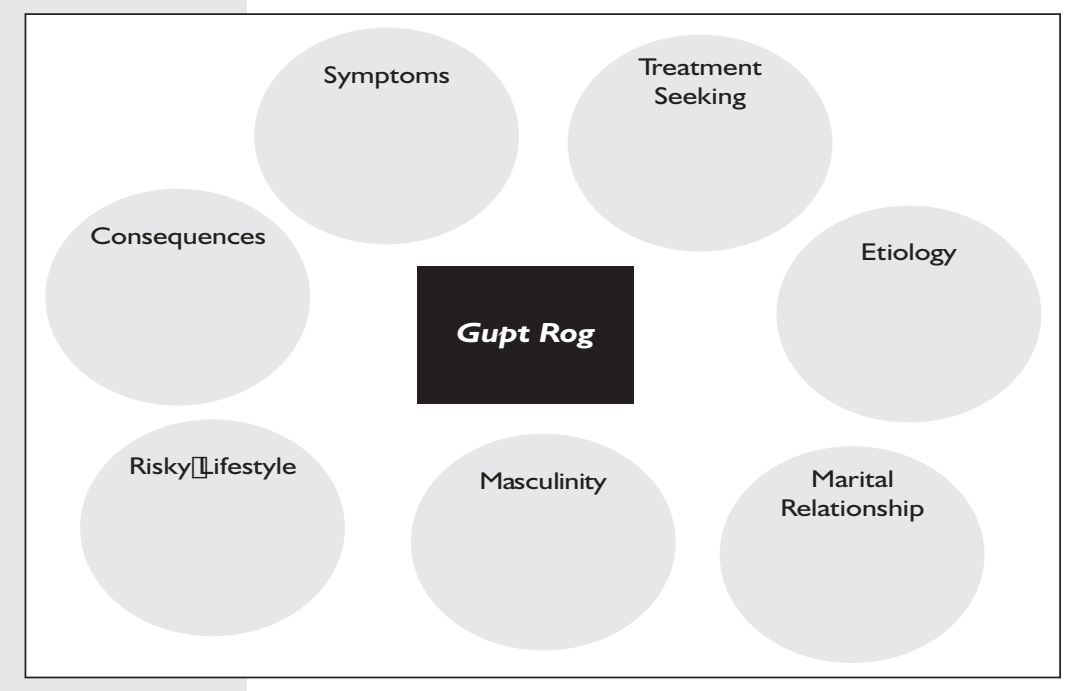

satisfaction, the couple should have a separate room. A real man should be able to do sex for a longer period, at least for 30 minutes."

"I never did any kind of violence with her. But once I drank a bit, so she got upset and did not take food. I also didn't take food. In the morning, she threatened me that she is leaving for her mother's place. I tried to make her understand, then she did not go."

"I do not know if my wife has similar problems. I have not asked her. I was not aware that she could get the symptoms from me."

\section{Exercise 10.}

Depict Patient A's 'profile' using the following graphic. Within each circle, record the respective information about the patient. Then draw lines to link what you consider to be contributing factors to Gupt Rog.

so, she feels unhappy often. Both should be ready to enjoy sex in different acts, like CSWs are ready to do. Also after intercourse, both should get complete satisfaction and feel happy. But, to get complete 
Case Sheet: Patient A

Case No:

Date:

I. Name of the patient:

2. Age: Years:

3. Occupation: Income:

4. Address:

General complaints

\begin{tabular}{|l|l|l|}
\hline S. No. & Complaints & Duration \\
\hline & & \\
\hline & & \\
\hline
\end{tabular}

Past history - Any major illnesses

\section{Personal History}

Marital Status:

Habits:

Residing with Family:

History of exposure:

Condom used:

Sex with spouse after exposure: Yes / No

SHP complaints in spouse

$\square$ None $\quad \square$ Urethral discharge

\section{General / Systemic Examination}

Pulse / minute, $\mathrm{BP}$ mm of Hg, Temp:

Married / Unmarried

Alcohol / Smoking / Gambling / Visiting Video Parlour

Yes / No

Yes / No

Yes / No

CVS / CNS / RS / PA

\section{Complaints on SHPs}

$\square$ Ulcer $\square$ Boil $\square$ Urethral Discharge $\square$ Scrotal swelling $\square$ Warts $\square$ Inguinal Bubo

$\square$ Erectile dysfunction - specify

$\square$ Ejaculatory dysfunction - specify

$\square$ Sexual dissatisfaction - specify

$\square$ Others-specify 


\section{Probable causes of SHPs}

\section{Past history of SHPs}

\section{Genital Examination}

$\square$ Urethral Discharge $\quad \square$ Ulcer $\quad \square$ Boil $\quad \square$ Inguinal Bubo $\square$ Scrotal swelling $\square$ Warts

Site:

Size:

Painful / painless:

If Ulcer

Superficial / Deep:

Bleeds on touch: Yes / No

Margins: Smooth Indurated / Ragged

History of Vesicles: Yes / No

If scrotal swelling: Right / Left

H/o Injury: Yes / No

Tender / Non-tender

Investigations advised

Blood test (TPPA/RPR)

Urine test (Routine)

Yes / No

Date

Results

HSV-II-lgG/lgM

Yes $/$ No

Date

Results

PCR

Yes / No

Date

Results

Yes / No

Date

Results

\section{Provisional diagnosis / Syndromic diagnosis}

\section{Treatment}

\begin{tabular}{|l|l|l|l|l|}
\hline Visit & Date & $\begin{array}{l}\text { Treatment } \\
(\text { Drugs } \times \text { days })\end{array}$ & $\begin{array}{l}\text { a) Advice } \\
\text { b) Health Education } \\
\text { c) Referral }\end{array}$ & $\begin{array}{l}\text { a) Contact Trace }(\mathrm{Y} / \mathrm{N}) \\
\text { b) Rx to contact }(\mathrm{Y} / \mathrm{N})\end{array}$ \\
\hline First & & & & \\
\hline Follow- up & & & & \\
\hline
\end{tabular}

Name and Signature of Health Provider 

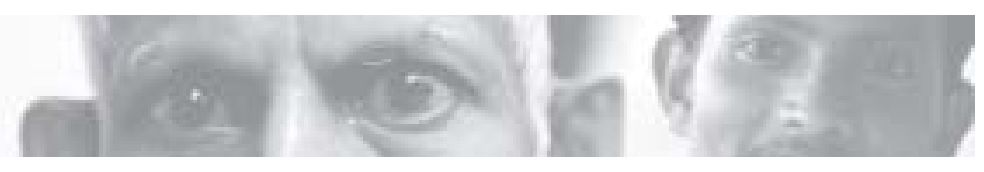

\section{Example Case History on Patient B for Practicing Exercise II}

Through history taking you gain the following information from your patient (this is Patient B from Exercise 9).

"I don't get proper erection when I want to do sex with my wife. Occasionally I do sex with her, even for that, my wife has to try hard. She has to masturbate me to get the erection. It loses its strength before ejaculation."

"My wife is getting angry. My friends have said that, if I take rum, then I can enjoy sex for a longer period. But ifI drink, I don't get erection. Now I am habituated to rum, for which my wife scolds me always."

"I have this problem since beginning of marriage. But I did not get any difficulty in reproduction. After the birth of children, my wife went for sterilisation, and since then she wanted to do more sex. She gets more excitement because there is no fear of pregnancy. But I don't get that excitement due to my problem in erection. I have gone to two other doctors with no satisfaction. They gave me some pills but those did not help."

"I have the problem because I had sex with one of my neighbour's relative when I was very young. In the first experience, I was scared to do sex with her. I did not get propererection. She masturbated me and I goterection, but within few minutes / lost that. Once again, she tried to masturbate me, but I did not like it, so, I told her to do some other time. Later, many times we had sex till I came to Mumbai. I think it is due to my relation with that lady back home. We continued the relation for three to four years, in which the frequency of intercourse was quite more. I think the quantity of semen reduced a lot by this relationship for which I am suffering now. If there is no semen (pani) in the penis, how can I get erection?"

"Now if at all I get excitement, I don't try to take initiative. I am scared for loss of erection and her anger. So, when she takes initiative and arouse me, then only we do sex. When I get erection, and during the intercourse I fondle her breasts and I try to touch other parts of her body."

"My wife also works. She studied up to I Oth standard and earns more than me. For sex I never fought with her rather she gets angry and abuses me. But when I drink more, sometimes I also scold her. I can't beat her, rather she will beat me. Because always she looks upset. When I drink bit more, that time I try to abuse her. But if I try to retaliate her or do something against her wishes, she might beat me."

"I agree with my wife working. I don't get upset about the extra money she earns. But I don't feel like a man if I cannot satisfy her. Man should be able to be ready for sex whenever his wife wants and he should be able to keep her satisfied. Otherwise, she might go outside of marriage for sex."

\section{Exercise II}

Depict Patient B's 'profile' using the following graphic. Within each circle, record the respective information about the patient. Then draw lines to link what you consider to be contributing factors to Gupt Rog.

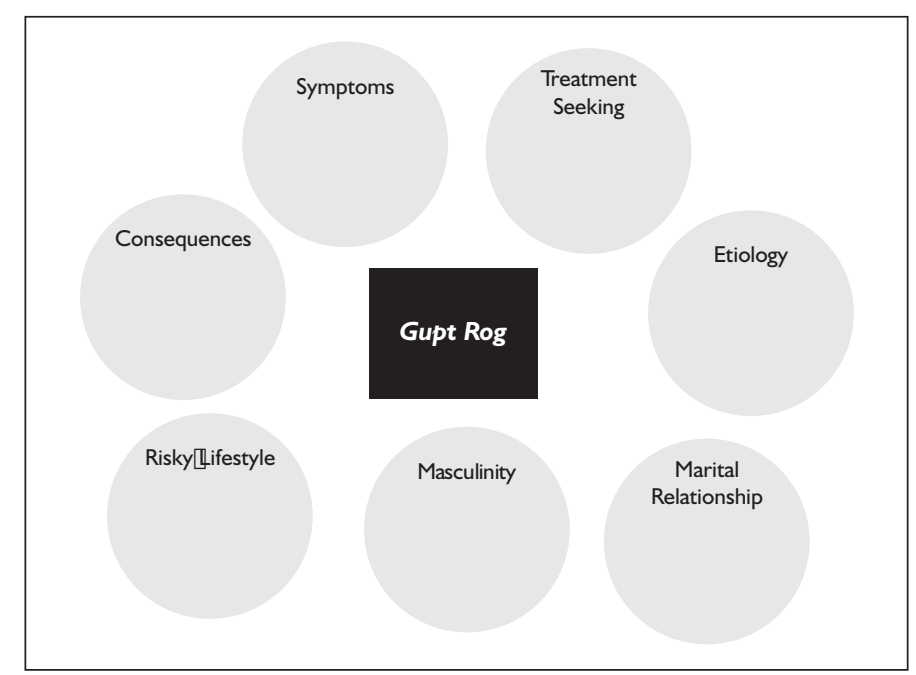


Case Sheet: Patient B

Case No:

Date:

5. Name of the patient:

6. Age:

Years:

7. Occupation:

Income:

8. Address:

General complaints

\begin{tabular}{|l|l|l|}
\hline S. No. & Complaints & Duration \\
\hline & & \\
\hline & & \\
\hline
\end{tabular}

Past History: Any Major IIInesses

\section{Personal History}

Marital Status:

Married / Unmarried

Habits:

Residing with Family:

Alcohol / Smoking / Gambling / Visiting Video Parlour

History of exposure:

Yes / No

Yes / No

Condom used:

Yes / No

Sex with spouse after exposure:

Yes / No

SHP Complaints in spouse

$\square$ None $\quad \square$ Urethral discharge $\quad \square$ Vaginal discharge $\quad \square$ Ulcer / Boil

General / Systemic Examination

Pulse_ _ / minute, BP $\mathrm{mm}$ of $\mathrm{Hg}, \quad$ Temp:

${ }^{\circ}$ F, Lymphadenopathy: Yes / No

CVS / CNS / RS / PA

\section{Complaints on SHPs}

$\square$ Ulcer $\square$ Boil $\square$ Urethral Discharge $\square$ Scrotal swelling $\square$ Warts $\square$ Inguinal Bubo

$\square$ Erectile dysfunction - specify

$\square$ Ejaculatory dysfunction - specify

$\square$ Sexual Dissatisfaction - specify

$\square$ Other - specify 
Probable causes of SHPs

Past History of SHPs -

Genital Examination

$\square$ Urethral Discharge $\quad \square$ Ulcer $\square$ Boil $\quad \square$ Inguinal Bubo $\square$ Scrotal swelling $\square$ Warts

Site:

Size:

Painful / painless:

If Ulcer

Superficial / Deep:

Margins: Smooth Indurated / Ragged

Bleeds on touch: Yes / No

History of Vesicles: Yes / No

If scrotal swelling: Right / Left

History of Injury: Yes / No

Tender / Non-tender

Investigations advised

Blood Test (TPPA/RPR)

Urine test (Routine)

HSV-II-IgG/IgM

PCR

$\begin{array}{lll}\text { Yes / No } & \text { Date } & \text { Results } \\ \text { Yes / No } & \text { Date } & \text { Results } \\ \text { Yes / No } & \text { Date } & \text { Results } \\ \text { Yes / No } & \text { Date } & \text { Results }\end{array}$

Provisional diagnosis / Syndromic diagnosis

\section{Treatment}

\begin{tabular}{|l|l|l|l|l|}
\hline Visit & Date & $\begin{array}{l}\text { Treatment } \\
(\text { Drugs } x \text { days })\end{array}$ & $\begin{array}{l}\text { a) Advice } \\
\text { b) Health Education } \\
\text { c) Referral }\end{array}$ & $\begin{array}{l}\text { a) Contact Trace }(y / n) \\
\text { b) Rx to contact }(y / n)\end{array}$ \\
\hline First & & & & \\
\hline Follow-up & & & & \\
\hline
\end{tabular}

Name and Signature of Health Provider 


\section{Step 3. Prevention}

Step 3 is depicted in Figure 4. This step focuses on helping the patient to create new narrative or life story that supports health promoting and risk reducing beliefs, behaviours, relationships, and experiences. The primary focus is on those life factors that you identified in Step 2.

Step 3 also involves partner notification, referral, STI/HIV Counselling, and providing specific information about STI/HIV prevention strategies, including condom promotion. These aspects are also covered in this section.

\section{Figure 4}

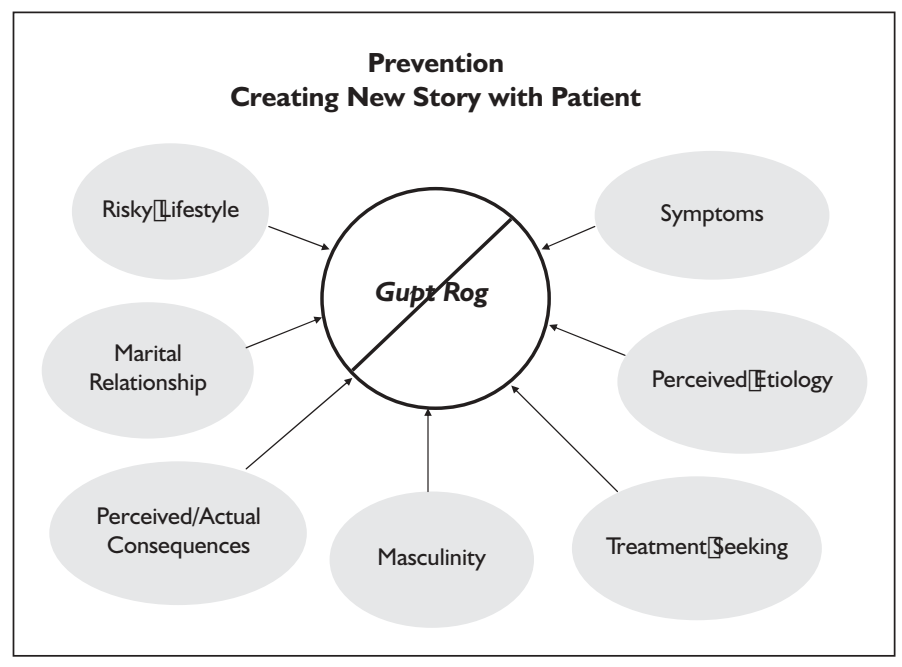

\section{Objectives}

I. To treat current symptoms through syndromic management for STIS

2. To make referrals for testing related to STI symptoms

3. To make referrals for social services related to life factors (e.g., individual Counselling for tension, marital Counselling to address conflict and violence)
4. To discuss partner notification regarding STIs

5. Educate the patient about how life factors can contribute to risk of STI/HIV.

6. Help the patient to see how changes in thinking and behaviour related lifestyle, marital relationship, perceptions of masculinity, treatment seeking, and perceived etiology and consequences can help to alleviate symptoms, prevent future risk, etc.

7. Help the patient to identify ways by which he can reduce sexual risk and promote health by changing his thinking and/or behaviours.

Key questions for the provider: Planning treatment and prevention

I. What links in patient profile (see Figure 4) need to be addressed?

2. What educational and prevention messages do you want to convey? [to enhance patient's knowledge, attitudes, beliefs]

3. What intervention/prevention strategies might be discussed with the patient? [to facilitate behaviour change]

4. What medical [syndromic] treatment would you provide?

5. What are your recommendations for referral and follow-up?

Key considerations for the provider: Delivering treatment and prevention

How would you approach the following in your interaction with patient:

I. Explain the links (patient profile)

2. Convey educational and prevention messages

3. Generate with patient strategies for behaviour change

4. Provide medical [syndromic] treatment

5. Provide recommendations for referral and follow-up 


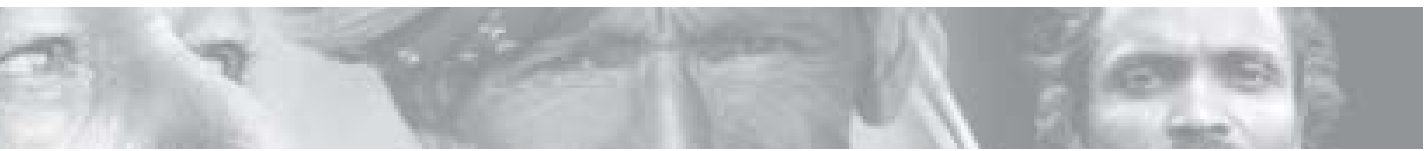

\section{Key messages: In providers' words}

Messages are created to address key life factors in patient profile. The following examples are based on interviews with providers trained in NPC.

\section{- Emotional support for client - reducing tension}

"He reported to suffer from wet-dreams since last two to three weeks; gets weekly average of wet dreams two to three times per week. [His wife is away since last six months, as her mother is ill.] The patient was scared that if he gets more frequent wet-dreams, he will be physically weak. He will not be able to do physical labour. He was concerned about his further deterioration of health... I tried to make him comfortable. I told him, this is natural, this might happen to anybody. He was relaxed to listen to my words. He already experienced this complaint earlier, but was still worried."

"I advised him that whatever is done is done. I told him that the treatment would cure him, not to worry. I also told him that he should not dwell much on what has already happened, instead he should take care that it does not happen in future."

"When I gave him assurance that he will be alright, I observed from his facial expression that he was feeling a bit better."

\section{- Etiology of client's symptoms}

"He was not having any knowledge regarding STIs. I talked to him about STIs and HIV. I showed him flipcharts having pictures of STI symptoms like herpes, condaloma, chancroid. I mentioned about $A B C$ of conduct: $A$ - abstinence, $B$ - be faithful to wife, $C$ - use condom."

"For the patient with erection difficulties (linked to anxiety about pregnancy), I told him not to think about pregnancy, they can very well go for contraception."
- Potential consequences of symptoms and risky behaviours

"I informed him that HIV/Chancroid and other STDS are communicable and he even can transmit these to his wife. He was not much concerned about his health before Counselling, rather after that he started to get scared. He was frightened about transmitting infection to his wife and acquired HIV infection in due course of time. He was also scared to acquiring HIV in future... I told him to relax, told him that whatever has happened is past now but henceforth he needs to avoid risky behaviour."

\section{- Perceptions of masculinity}

"About mardangi, I told him that a person who can satisfy his wife during sex, feed his children and wife, and protect a girl who is in danger, is a real mard, not a person who can produce 10 children or who can satisfy every woman".

The following pertains to masculinity and marital relationship.

"I advised him to try and become a joru ka gulam ('wife slave') for two weeks, and see if there is any change. I asked him to do as his wife would like, such as, he should remove the shoes outside the house, and do some household chores like purchasing vegetables, etc. I asked him to come for follow-up after those two weeks. Convincing him was very difficult, as he had chauvinistic notions. He said, he being the lord of the house, he should remove the shoes anywhere and it is his wife who should carry his shoes for him and keep them in the proper place. But he followed my instructions, and when he came back for followup, he was smiling. He told me that he changed his behaviour, and his wife now prepares tea for him when he comes back from work."

- Marital relationship: communication, quality of relationship, sexual relationship, marital conflict, domestic violence

"I suggested him to be peaceful. Understanding each other is the key to lead a happy life. Both of 
them needed to enjoy life. I suggested him to spend more time with wife and children."

"I gave him a lot of advice regarding his sex life. I told him that everything has an atmosphere. If you hurry up, and want to have instant fun, it will not work for her. If you alone enjoy, and she does not, then it is unfair on her. I told him everything about foreplay. After I explained to him, he has now realised that he is wrong, and that his wife is justified. I think now his behaviour has also changed."

"I advised him not to think about sex and to take wife for outings. Whatever she likes, such as films or going out, I told him to take her there."

"I tried to point out the links to him, saying that he is having a good family life, but staying without family for larger part of a month, is actually disposing him at risk of having sex outside marriage. I asked him to look for another job in Mumbai, so that he would be able to stay together with his wife."

"I suggested him on his sexual relationship. Told him that whenever he comes back home, he should discuss about his daily activities there were not having a very good communication somehow. He should take family out in holidays, other than relative's place; it was necessary for his wife. She should feel comfortable to share her mind."

"He did not have enough rapport with wife. I counselled him on hyper-sexuality, told him that sex should be mutual. He started thinking on my advice. I suggested him to go for sex when she is ready for it. When he followed my suggestion, problems started to get solved."

- Lifestyle factors: alcohol abuse, blue films, peer influence, risky sexual practices

"I told him if at all he needs to go to CSW, he should never go without condom. It will be the best if he could stop it entirely, other alternative way could be masturbation."
"I suggested him whatever he watches in blue films cannot be true in real life, that is abnormal. Gave him examples of heroes and villains in films, where even after attacks made by number of persons heroes can fight out successfully. I asked him whether he thinks that is possible in real life."

"I told him to keep away from bad company as it is the friends who instigate all these troubles."

"As I know that he indulges on Saturday nights, I have asked him to meet me next Saturday night at 9 pm. That is my way of stopping him from going there, because I know that if he goes there, it will be difficult for him to restrain himself. If I directly tell him to avoid the company of friends, he will feel bad, and might never come back to me again."

"I told him alcohol is one of the factors, which leads to high risk behaviour and also poses adverse effect on health."

"I thoroughly explained him the vicious cycle; as he stays alone he goes for alcohol since it's the only source of entertainment for him, but increases sexual urge in him and finally he indulges into such activities. Insisted him to quit alcohol and to stop going to CSWs. If in case it was not possible for him to quit, at least he should use condom consistently."

"I advised him not to go there brothel again. But, if he has to go to these women commercial sex workers], he should use condoms."

"I suggested him not to make (sexual) contact with anyone except wife."

"Advised him to stay faithful to wife; that is the only way to prevent STDs. I provided him condom."

\section{- Partner notification/transmission to partner}

"I suggested him not to make sexual relation with wife since she might get contracted. But he should share his complaints with her; unless it is shared 

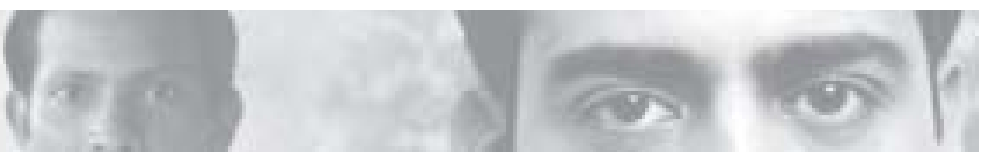

he will continue to suffer alone. However it was not known whether he really had informed his wife. I also told him that if he comes along with his wife it would better for me to understand, but they had never turned up."

"I asked him to enquire about his wife's complaints. It was essential to know whether even she had developed any such symptoms, and suggested that if anything found she should be brought for treatment and Counselling. He should communicate his complaint to his wife and should inform her that he is infected. But he never made a follow up visit with spouse. I guess his wife might not have been infected."

\section{- Referral for testing (e.g., VDRL)}

"I suggested him to take the VDRL test and also the routine urine test. He has not yet come back with the reports. I also thought of suggesting him ELISA test for HIV but I have not told him yet. I am waiting for the other reports. I asked him to take the test anywhere which is convenient to him."

"I advised him on HIV/AIDS and STDs. He was ready for ELISA test after Counselling and then I sent him to local hospital."

\section{Exercise 12}

In Exercise 10, you interpreted Patient A's story. Go back to the picture/profile you created, which shows the life factors and how they are related to Gupt Rog. In Step 3, your goal is to help the patient to identify alternative health promoting and risk reducing thinking and behaviours - to create a story of health, rather than risk.

Which life factors contribute to Gupt Rog risk for this patient?

What educational and prevention messages do you want to convey to this patient? Be sure you address all the relevant life factors.

What prevention strategies might you discuss with the patient? Be sure you address all the relevant life factors. What communication strategies would you use with this patient to: (a) help him understand how his life factors contribute to Gupt Rog risk, and (b) help him generate alternative health promoting and risk reducing behaviours and practices.

Please also complete the case sheet from Exercise 10. 


\section{Exercise 13}

In Exercise II, you interpreted Patient B's story. Go back to the picture/profile you created, which shows the life factors and how they are related to Gupt Rog. In Step 3, your goal is to help the patient to identify alternative health promoting and risk reducing thinking and behaviours - to create a story of health, rather than risk.

Which life factors contribute to Gupt Rog risk for this patient?

What educational and prevention messages do you want to convey to this patient? Be sure you address all the relevant life factors.

What prevention strategies might you discuss with the patient? Be sure you address all the relevant life factors.

What communication strategaies would you use with this patient to: (a) help him understand how his life factors contribute to Gupt Rog risk, and (b) help him generate alternative health promoting and risk reducing behaviours and practices.

Please also complete the case sheet from Exercise II.

For your information, we have provided our own analysis and prevention plan for the presented cases in Annexure D.

\section{HIV/STI Counselling}

Counselling for STIs and HIV/AIDS is important because:

I. These are transferrable diseases. It is only through good, well informed counselling that the disease transmission can be stopped. Behaviour change resulting from counselling can prevent a person acquiring STIS/HIV and transmitting it to others.

2. STIs and HIV usually result from a person's sexual experience. This is a very personal and intimate area of someone's life and the infections can create enormous psychological and social pressures that can delay constructive change, or even worsen the illness. 
3. Infection with HIV is lifelong and, as such, people require ongoing support to help them come to terms with the infection as is affects themselves and / or others.

\section{Prevention of STIs/HIV}

There are three main methods $(A B C)$ of preventing STIs/HIV. These are:

I. Abstinence from sexual intercourse: The safest way to avoid Sexually Transmitted Infections is, of course, to avoid having sex at all. This is not a realistic situation for most people but may be an option for some e.g. unmarried youth, etc.

2. Being Faithful: If couples are free from infections and only have sex with each other, then there is no chance of getting STIs/HIV. Once again, this is an ideal situation but may not be possible for all for various reasons.

3. Condoms: Although we may advise । and 2 , when talking to our patients, we can assess whether these options are feasible for them. If not, condoms form the best, safest method of preventing STIs and HIV.

\section{Condom Promotion}

The condom is a protective medium that is used to prevent direct skin to skin contact during a sexual act. It does not allow the male sperm during ejaculation to enter the female reproductive tract, thereby preventing unwanted pregnancies and Sexually Transmitted Infection and Reproductive Tract Infection (RTI) in women. It therefore acts as a protective cover for the spread of the HIV virus from the seminal fluids.

The use of condom would protect the uninfected from acquiring infection as well as prevent the infection from spreading from an infected person. Hence, it can be termed as a protector or prophylactic preventing STI/RTI, unwanted pregnancies and the spread of HIV. 


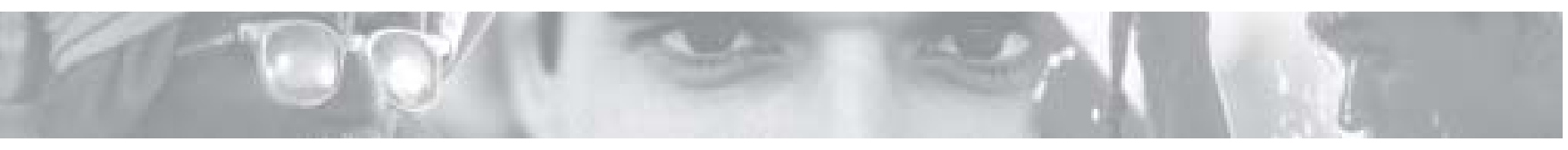

\section{Partner Notification}

When a person is infected with an STI/HIV, by definition, they have caught this from someone else. Unless the person they caught the infection from gets treatment, they will go on infecting others and the infections will not get controlled. Thus it is important to advise that, along with the patient, their partner also receives treatment for the same STIs and goes to see a practitioner. This should include non-regular as well as regular partners. Counselling a couple may also be a good option.

\section{Referral}

If you wish your patient to receive treatment under the National Guidelines or for any other reason, there are numerous resources to which the patient can be referred.
These are:

- Voluntary Testing and Counselling for HIV VCTC centres

- Prevention of Parent to Child to Child Transmission for pregnant women - PPTCT centres at district hospitals

- Anti-retroviral therapy - ART centres in government hospitals

- STI treatment - departments of STIs and Dermatology in any hospital.

- Local NGOs and community care centres may be involved in care and support of PLHAs. Numerous networks of positive people exist that provide support to PLHAs. 


\section{Annexure A}

FLOW-CHARTS ON SYNDROMIC MANAGEMENT OF STIS

\section{URETHRAL DISCHARGE}

Examine male patients complaining of urethral discharge and/or dysuria for evidence of discharge. If no discharge is seen, massage along the ventral aspect of penis towards the meatus, to look for discharge. The common causes of uretheral discharge are $\mathrm{N}$. gonorrohoeae and/or C. trachomatis.

\section{TREATMENT}

Treat far both gonococcal and chlamydial infections.

\section{Recommended regimen}

Azithromyein2Gorallysingledose, under supervison (to treat both gonococcal and chlamydial infections)

Alteruate regimens

\section{Option I}

Cefiiime 400 mg orally, single dose, under supervision (to treat gonococcal infection)

Plus

Doxyeyeline* $100 \mathrm{mg}$ orally, 2 times daily for 7 days (to treat chlamydial infection)

\section{Option 2}

Inj, Ceftriaxone $250 \mathrm{mg} \mathrm{I,M}$. single dose (to treat gonococcal infection)

Plus

Doxyeyeline* 100 mg orally, 2 times daily for 7 days (to treat chlamydial infection)

* In individuals allergic/intolerant to doxyeyeline,

Erythromycin base/stearate $500 \mathrm{mg}$ orally, 4 times daily for 7 days

Treat for Trichomoniasis if discharge persists even after full treatment for gonococcal and chlamydial infections.

\section{SYNDROME I URETHRAL DISCHARGE}
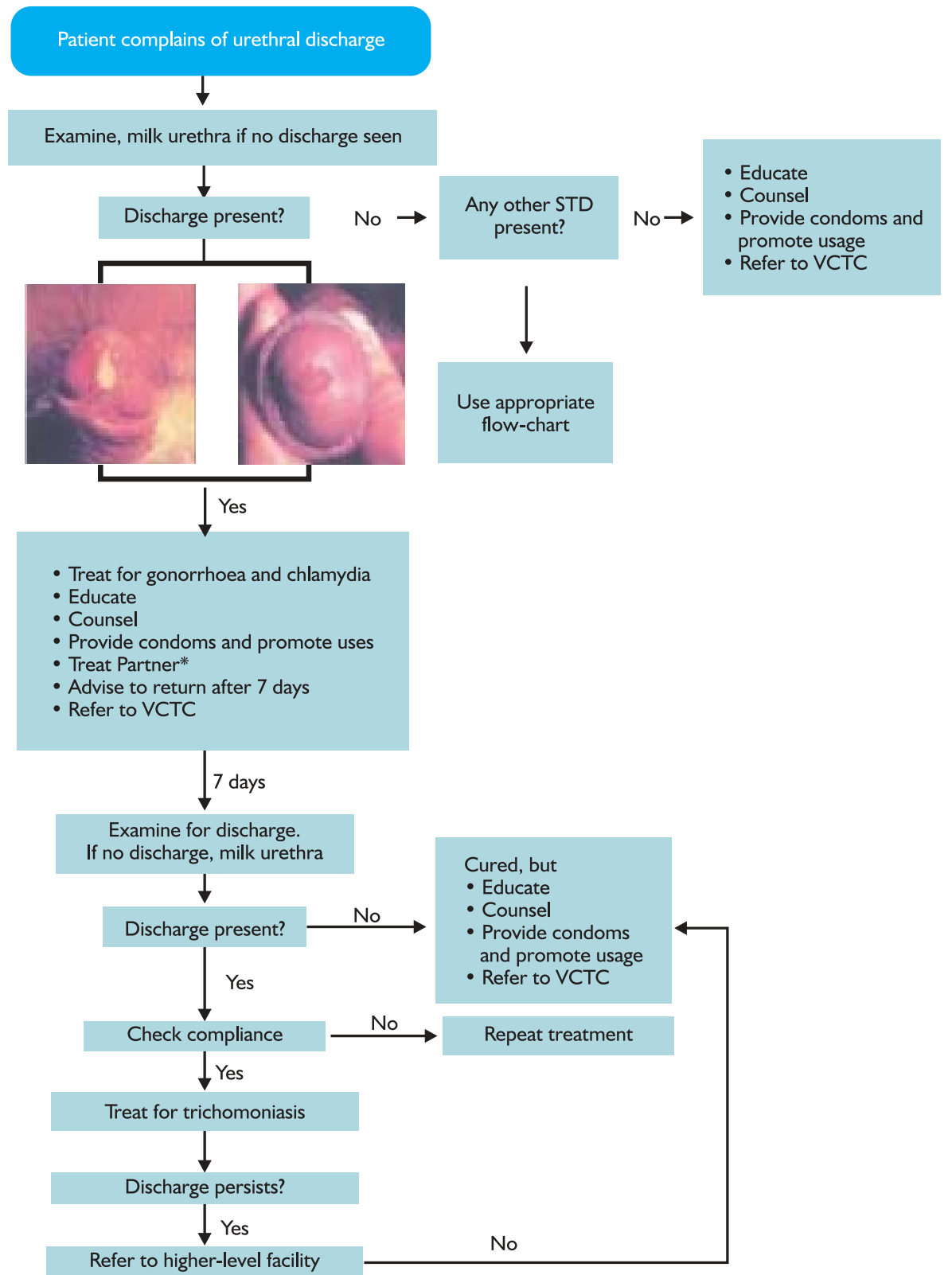

*Treat partner for gonocoocal and chlamydial infections 


\section{GENITAL ULCER}

The most common STls presenting with genital ulcer(s) are syphilis, chancroid and genital herpes. Treat adequately to cover both syphilis and chancroid or genital herpes depending on history and examination.

\section{TREATMENT}

Ask all patients to wash genital area with soap and water.

IF VESICLES ARE SEEN OR / AND HISTORY OF RECURRENCES GIVEN

First episode: Acyclovir 200 mg orally 5 times daily for 7 days

Recurrent episodes: Acyclovir, 400 mg orally, 3 times daily for 5 days

Note: There is no known cure of herpes but the course of the symptoms can be modified byacyclovir.

IFVESICLES ARE NOT SEEN AND NO HISTORY OF RECURRENCES GIVEN

Treat for both syphilis and chancroid. Recommended regimen

Inj. benzathine penicillin, 2.4 million units I.M, in two equally divided doses. Give injection in each buttock, after testing for sensitivity for penicillin (to treat syphilis)

Plus

Azithromycin: G, single dose, orally under supervision (to treat chancroid)

Alternate regimen

\section{Option I}

Inj. beuzathine penicillin, 2.4 million units I.M, in 2 equally divided doses; give one injection in each buttock, after testing for sensitivity for penicillin (to treat syphilis)

Plus

Inj. ceftriaxone, $250 \mathrm{mg}$, single dose I.M (to treat chancroid)

Option 2.

(Do not use in case of pregnant women)

Inj. benzathine penicillin,* 2.4 million units, I.M in 2 equally divided doses. Give, one injection in each buttock, after testing for sensitivity for penicillin (to treat syphilis)

Plus

Ciprofloxacin 500 mg two times a day orally for 3 days (to treat chancroid)

*In individuals allergic/intolerant to penicillin

Doxycycline 100 mg, 2 times daily, for 15 days, but in pregnant women allergic / intolerant to penicillin Erythromycin base/ stearte 500 mg, 4 times daily for I 5 days. Ask these women to bring the new born baby for treatment within 7 days of birth

\section{SYNDROME 2}

GENITAL UKCER

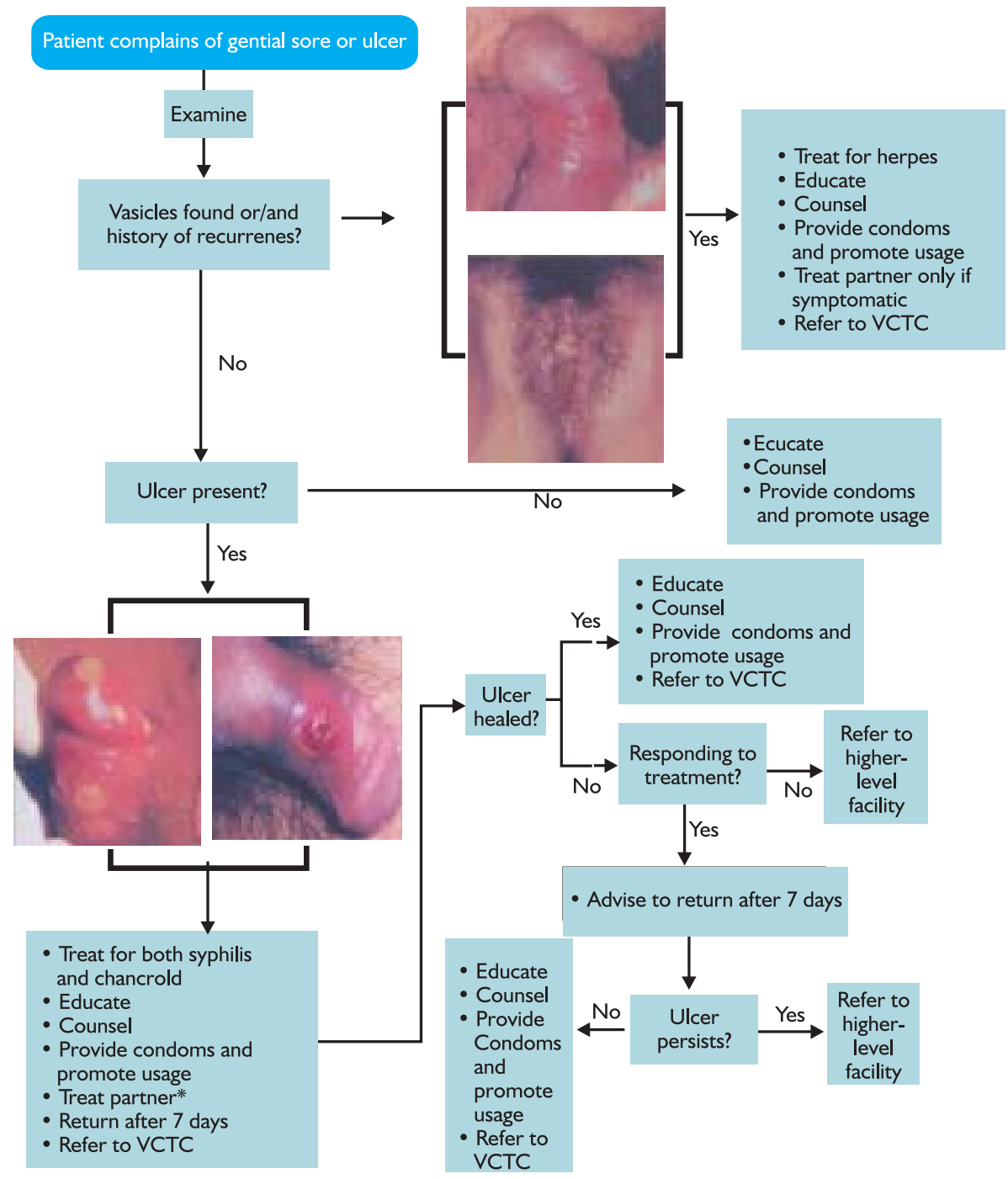

* Treat for syphilis, chancroid and counsel on herpes genitalis. 
VAGINAL DISCHARGE (WITHOUT SPECULUM)

Vaginal discharge is commonly due to vaginitis and/or cervicitis. Cervicitis is caused by $\mathrm{N}$. gonorrhoeae and $\mathrm{O}$. trachomatis while Trichomonas vaginalis, Candida albicans, and bacterial vaginosis cause vaginitis. However, clinical differentiation between the two conditions is difficult. An assessment of the woman's risk status may help in making a diagnosis of cervicitis if risk assessment is negative treat for vaginitis.

Where it is not possible to differentiate and/or the risk assessment is positive, treat patients for both cervicitis and vaginitis.

\section{TREATMENT}

\section{CERVICITIS:}

\section{Recommended regimen}

Azithromycin, 2 G orally, single dose, under supervision (to treat both gonococcal and chlamydial infections).

Alternate regimen

\section{Option I}

Cefixime $400 \mathrm{mg}$, orally, single dose, under supervision (to treat gonococcal infection) Plus

Doxycycline* 100 mg orally, 2 times daily for 7 days (to treat chlamydial infection).

\section{Option 2}

Inj. Ceftriaxone $250 \mathrm{mg}$ I.M, single dose (to treat gonococcal infection)

Plus

Doxyeycline* 100 mg orally, 2 times daily for 7 days (to treat chlamydial infection).

\section{VAGINITIS:}

Recommended regimen

Metronidazole*** 2G orally, single dose, under supervision (to treat trichomoniasis and bacterial vaginosis).

Plus

Fluconazole $150 \mathrm{mg}$ orally, single dose (to treat candidiasis)

Alternate regimen

Metronidazole*** 400 mg orally 2 times a day, for 7 days. (to treat trichomoniasis and bacterial vaginosis.

Plus

Clotrimazole 500 mg vaginal pessary one only (to treat candidiasis)

* In individuals allergic intolerant to doxyeyeline and in all pregnant woman give erythromycin base/stearate, $500 \mathrm{mg}$ orally, 4 times daily, for 7 days instead of doxycycline.

*** Do not give Metronidazole during the first trimester of pregnancy.

\section{SYNDROME 3.1 VAGINAL DISCHARGE (Without Speculum Examination)}

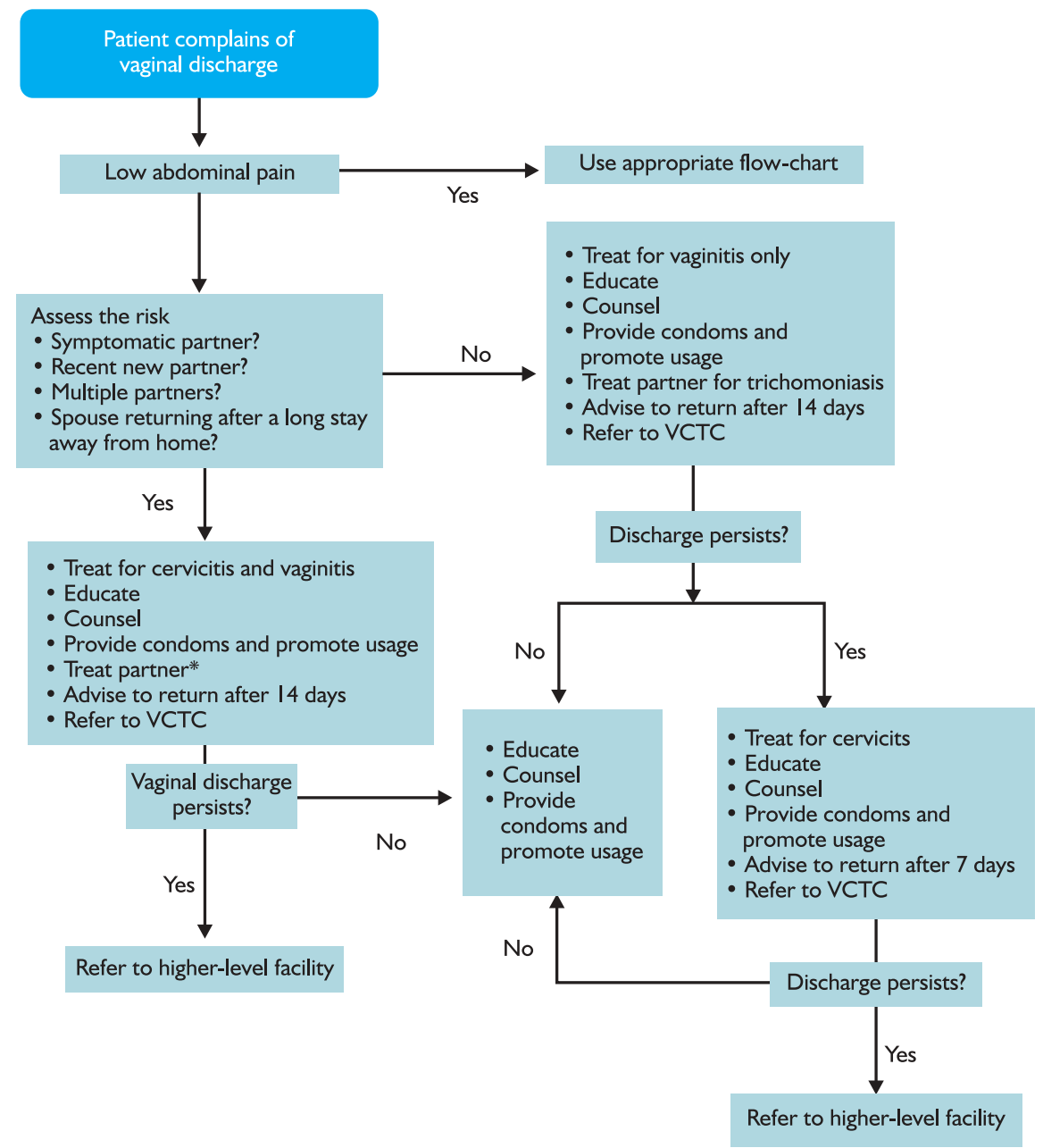

* Vaginitis may or may not be associated with an STD but the treatment of the parter may be helpful Treat parter for gonocoocal, chlamydial and trichomonas infections. 
VAGINAL DISCHARGE (WITH SPECULUM EXAMINATION)

Vaginal discharge is due tot vaginitis and/or cervicitis, Cervicitis is caused by $\mathrm{N}$. gonoryhoeae and C. trachomatis while Trichomonas vaginalis, Canadida albicans, and Bacterial vaginosis cause vaginitis However, clinical differentiation between the two conditions is diffcult. An assessment of the woman's risk status may help in making a diagnosis of cervicitis. If risk assessment is negative treat for vaginitis. Where it is not possible to differentiate and/or the risk assessment is positiye, treat the patients for both cervicitis and vaginitis.

\section{TREATMENT}

\section{CERVICITIS}

Recommended regimen

Azithromyein, 2 G orally, single dose, under supervision (to treat both gonococcal and chlamydial infections).

Alternate regimen

Option I

Cefixime $400 \mathrm{mg}$, orally, single dose, under supervision (to treat gonococcal infection)

Plus

Doxycycline* 100 mg orally, 2 times daily for 7 days (to treat chlamydial infection).

\section{Option 2}

Inj. Ceftriaxone $250 \mathrm{mg}$ I.M, single dose (to treat gonococcal infection)

Doxyeyeline* 100 mg orally, 2 times daily for 7 days (to treat chlamydial infection).

Plus

\section{VAGINITIS:}

Recommended regimen

Metronidazole** 2 G orally, single dose, under supervision (to treat trichomoniasis and bacterial vaginosis).

Plus

Fluconazole $150 \mathrm{mg}$ orally, single dose (to treat candidiasis)

Plus

Clotrimazole pessary, I $00 \mathrm{mg}$ intravaginally, once daily for six days (to treat candidiasis).

\section{Alternate regimen}

Metronidazole** $400 \mathrm{mg}$ orally 2 times a day, for 7 days (to treat trichomoniasis and bacterial vaginosis)

Plus

Clotrimazole pessary, $500 \mathrm{mg}$ intravaginally, once only ( to treat candidiasis).

* In individuals allergic/intolerant ot doxycycline and in all pregnant women, give erythromycin base/ stearate, $500 \mathrm{mg}$ orally, 4 times daily, for 7 days, instead of doxycycline.

*** Do not give Metronidazole during the first trimester of pregnancy.

\section{SYNDROME 3.2 \\ VAGINAL DISCHARGE \\ (With Speculum Examination)}

Patient complains of vaginal discharge

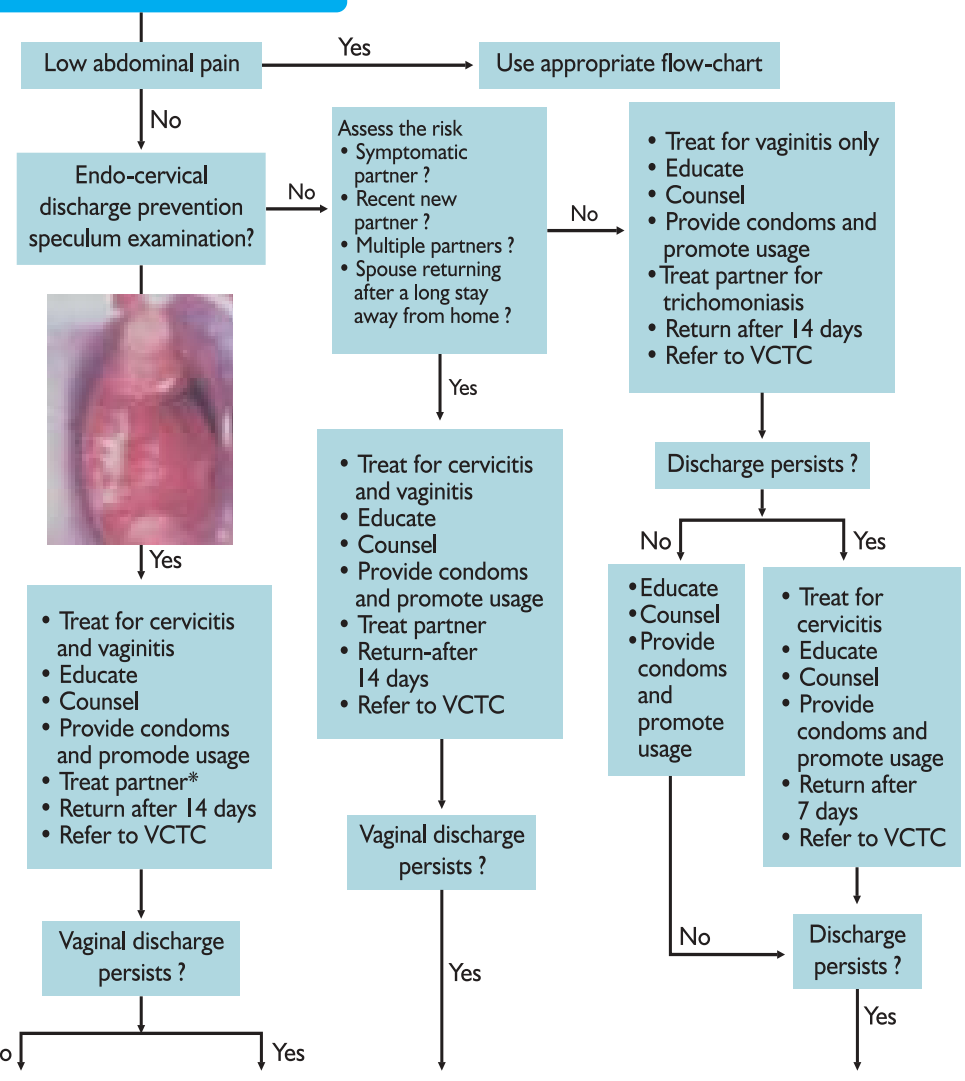

- Educate

Refer to higher-level facility

- Counsel

- Provide condoms and

promote usage

- Refer to VCTC

*Vaginitis mayor may not be associated with an STD but the treatment of the partner may be helpfulTreat partner for gonococcal, chlamydial and trichomonal infections. 


\section{SCROTAL SWELLING}

A serious complicaiont of gonococcal and chlamydial urethritis is epididymo-orchitis. the patient often gives a history of urethral discharge. The scrotum becomes swollen, warm and painful. If quick and effective therapy is not given, distruction and scarring of the testicular tissues may occur, causing sub-fertility. Other causes of sub-fertility are mumps virus infection and filariasis.

\section{TREATMENT}

Treat for both gonococcal and chlamydial infections.

\section{Recommended regimen}

Azithromycin 2G orally, single dose under supervision (to treat both gonococcal and chlamydial infection)

\section{Alternative regimen}

\section{Option I}

Cefixime $400 \mathrm{mg}$ orally, single dose under supervision (to treat gonococcal infection)

Plus

Doxyeycline* $100 \mathrm{mg}$ orally 2 times daily for 14 days (to treat chlamydial infection)

\section{Option 2}

Inj. Ceftriaxone $250 \mathrm{mg}$ I.M, single dose (to treat gonococcal infection)

Plus

Doxycycline* $100 \mathrm{mg}$ orally, 2 times daily, for 14 days (to treat chlamydial infection)

\section{Supportive therapy:}

To reduce pain advise bed rest, serotal elevation with a scrotal support (T-bandage) and analgesies

* In individuals allergic/intolerant to doxycycline, Erythromycin, 500 mg, 4 times daily orally, for 14 days.

\section{SYNDROME 4 SCROTAL SWELLING}

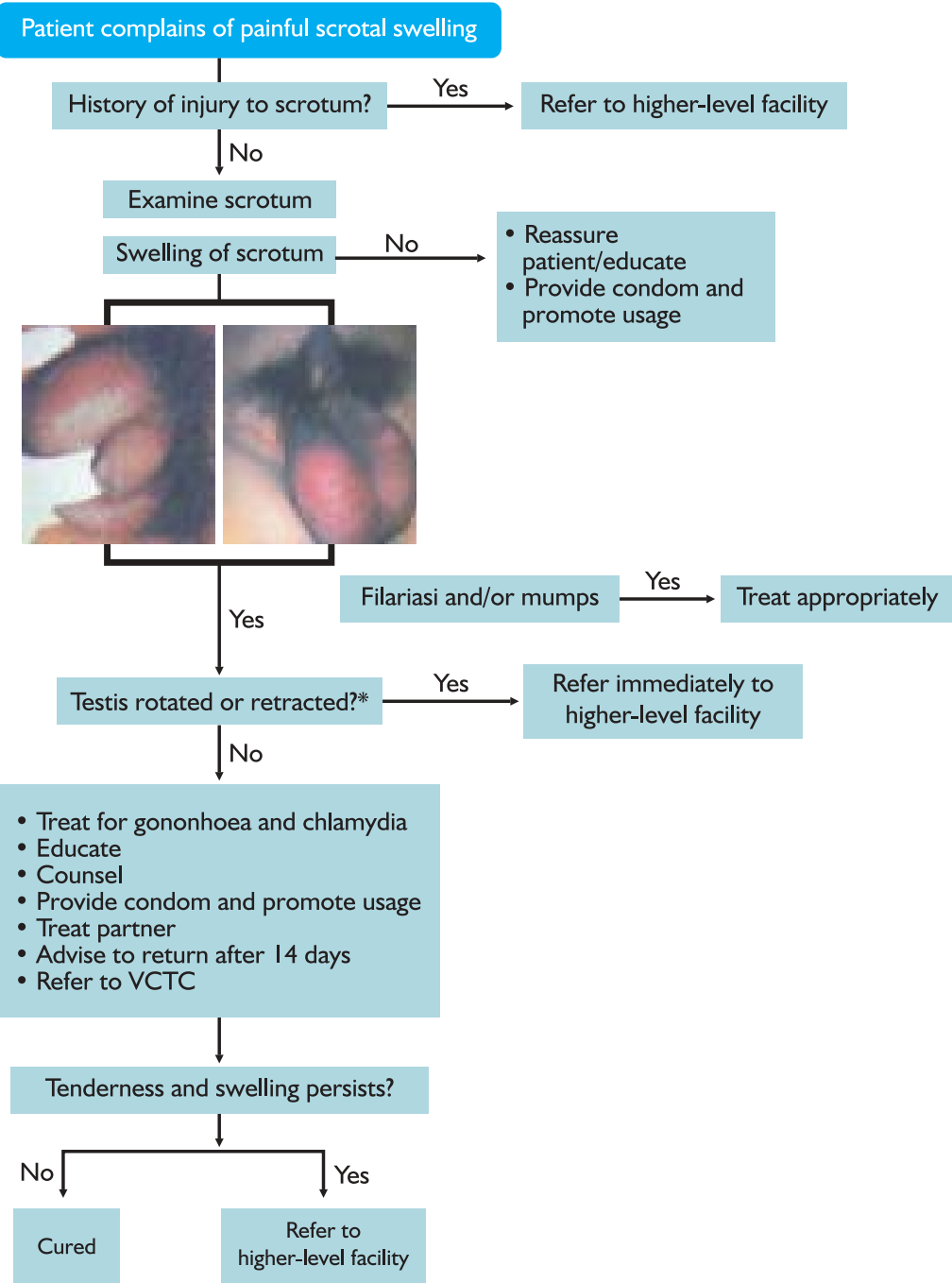

* A rotated testis is usally found in adolescents and young adults. Also, patients with rotated testis usally give a history of previous scrotal pain. 


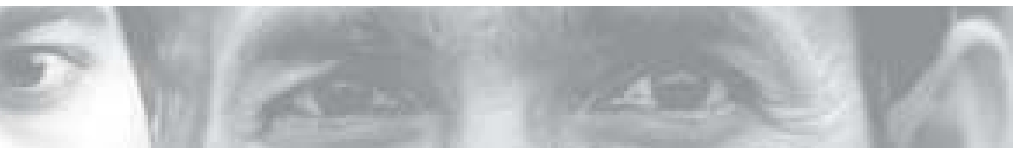

LOWER ABDOMINAL PAIN IN FEMALES

Lower abdominal pain is often the presenting feature of women with pelvie inflammatory diseas (PID). PID is defined as an infection of the female genita tract above the cervix and may include endometritis, salpingitis, tubo-ovarian abscess and peritouitis, PID occurs as a result of ascending infection from the cervix and is caused by N. gonorrhoeae, C. trachomatis and anaerobic bacteria. Occasionally, PID may be caused by Mycaplasma hominis. Infertilty due to tubal occlusion and ectopic pregnancy are serious complications of PID.

\section{TREATMENT}

Treat patient for gonococcal and chlamydial infection as well as for anaerobic bacteria.

Recommended regimen

Azithromycin 2G orally, single dose under supervision (to treat both gonococcal and chlamydial infectious)

Plus

Metronidazole** $400 \mathrm{mg}$ orally, 2 times daily, for 14 days (to treat anaerobic bacteria).

Alternate regimen

Option I

Cefixime $400 \mathrm{mg}$ orally single dose under supervision (to treat gonococcal infection)

Plus

Doxyeyeline* 100 mg orally, 2 times daily, for 14 days (to treat chlamydial infection)

Plus

Metrouidazole** $400 \mathrm{mg}$ orally, 2 times daily, for 14 days (to treat anaerobic bacteria)

\section{Option 2}

Inj. ceftriaxone $250 \mathrm{mg}$ I.M, single dose (to treat gonococcal infection)

Plus

Doxyeycline* 100 mg orally, 2 times daily, for 14 days (to treat chlamydial infections)

Plus

Metronidazole** 400 mg orally, 2 times daily, for 14 days (to treat anaerobic bacteria)

*In individuals allergic/intolerant to doxycycline and in all pregnant/lactaring women use Erythromyein base/stearate, 500 mg orally, 4 times daily, for I4 days instead of doxycycline.

** Generally, Metronidazole is not recommanded during the first trimester of pregnancy. However, it should not be withheld from a highly acute case of PID, which always represents an emergency.

Caution: PID can be a serious condition. Treating doctor must refer the patient to the hospital if she does not respond to treatment within 3 days and even earlier in case there is worsening of her condition.

\section{SYNDROME 5 LOWER ABDOMINAL PAIN IN THE FEMALE}

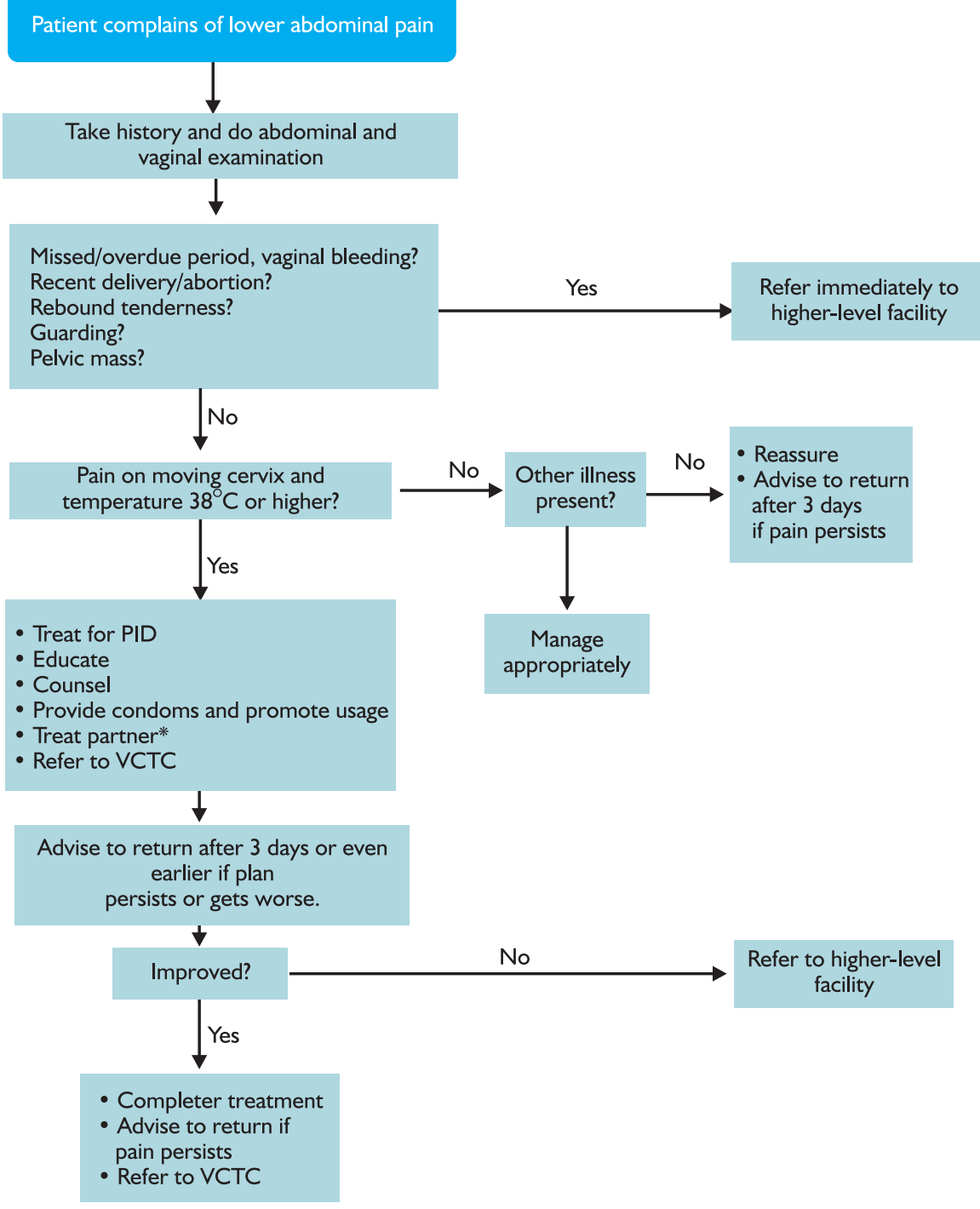




\section{INGUINAL BUBO}

This is a painful swelling of the lymph nodes in the inguinal region. A bubo may occur in chaucroid or lymphogranuloma venereum (LGV). It can also result fromo any kind of acute infection of the skin on the pubic area, genitals, buttocks, anus, things, legs, feet and toes.

\section{TREATMENT}

Recommended regimen

Doxyeycline $100 \mathrm{mg}$ orally, 2 times day, for 2I days.

Alternative regimen

\section{Option I}

Tetracycline $500 \mathrm{mg}$ orally, 4 times a day for 21 days.

\section{Option 2}

(for pregnant and lactating women)

Erythromycin base/stearate $500 \mathrm{mg}$ orally, 4 times a day for 21 days.

If bubo becomes fluctuant, aspurate pus with a wide bore needle and syringe. Make entry into the bubo through adjacent normal healthy skin over a non-dependent area. Never incise and drain.

\section{SYNDROME 6 \\ INGUINAL BUBO}

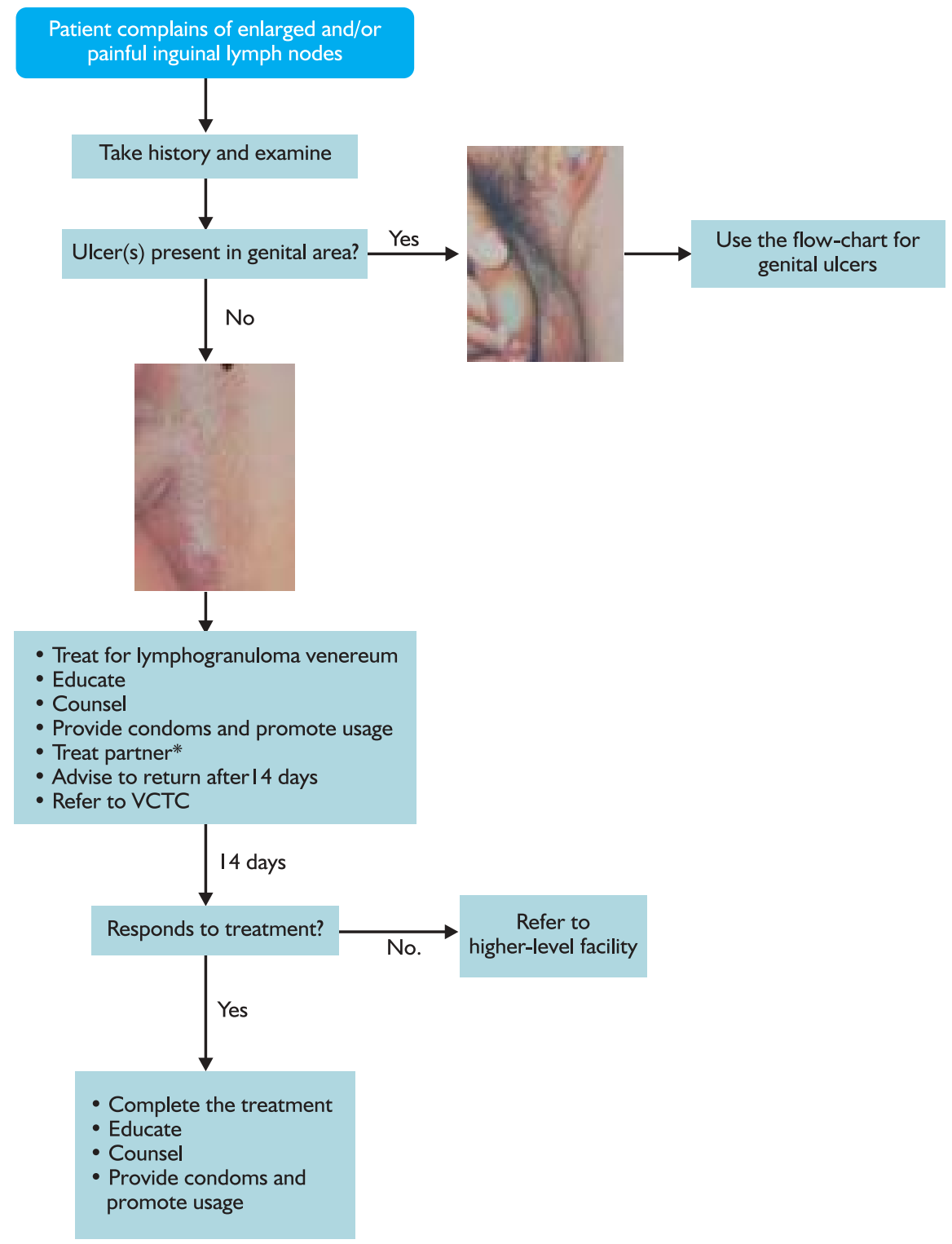

* Treat for LGV and counsel for other STIs 



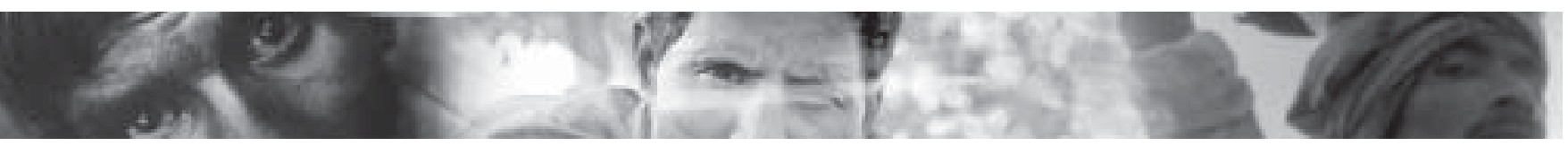

The above mentioned Gupt Rog syndromes were highlighted by RISHTA project conducted in three slums of north-east Mumbai.

While garmi problems were mainly acute sexual health problems, both the that and kamjori syndromes often represented chronic non-contact sexual health concerns, the etiology and diagnosis of which are outside the biomedical or allopathic tradition.

Khalai or Kharai: White vaginal discharge in women, which is the mildest and most common variety, manifested as a thin white discharge with minimal smell and staining of the undercloth. Women believe that it generally occurs due to weakness.

Pandhara pani: White vaginal discharge, which is whitish in colour but more in amount. It too wets the underclothes and the white stain it leaves remains even after washing, leaving the underclothes starched and smelling bad.

Pandhara pani: The white vaginal discharge, which is thin like water (hence is also called dhubani or dhuwani meaning rice water). When underclothes are washed the washed water comes out like rice water. Otherwise it may be thick like curds or sticky white like nasal discharge.

Dhatu or Dhat: It is the white vaginal discharge passed with urine in men. Some say that dhat is also seen in women's urine.
Poo parma or Wasi parma or Dhatu parma: It is a more severe variety of vaginal discharge which is yellowish in colour, smells foul like pus and stains underclothing. Sores present at the vulva region accompanied by burning sensation while urinating are characteristic of this condition.

One of the main causes of these sexual problems is constructed as excess heat in the body, caused by increased sexual desire or sexual excitement. Heat can be transmitted through sexual intercourse, where a woman can acquire it from her husband who has an extra-marital affair or visits the Bhut Khana (ie. the haunted house or the red light area). Similarly, a woman might get excess heat from an extra-marital or a premarital relationship. Thus, the presence of white discharge is associated with more than one sexual relationship, rendering it necessary to maintain social secrecy about such conditions.

Consumption of hot food can also cause or aggravate 'heat' in the body leading to white discharge. Other perceived causes of white discharge consist of witch-craft, ang-rog (bodily predisposition to white discharge), weakness (as both cause and effect of white discharge), contraceptive methods, following birth or abortion, etc.

Women speak about white discharge with great reluctance, because of its perceived link to promiscuity, and this reluctance is carried forward in both the care seeking and treatment seeking behaviour of the women. 


\section{Annexure C}

Case Sheet and Graphic Profile

\section{Case Sheet}

Case No:

Date:

5. Name of the patient:

6. Age: Years:

7. Occupation: Income:

\section{Address:}

General complaints

\begin{tabular}{|l|l|l|}
\hline S. No. & Complaints & Duration \\
\hline & & \\
\hline & & \\
\hline
\end{tabular}

Past history: Any major illnesses

\section{Personal History}

Marital Status:

Habits:

Residing with Family:

History of exposure:

Married / Unmarried

Alcohol / Smoking / Gambling / Visiting Video Parlour

Yes / No

Condom used:

Yes / No

Sex with spouse after exposure:

Yes / No

Yes / No

SHP Complaints in spouse

$\square$ None $\square$ Urethral discharge $\square$ Vaginal discharge $\square$ Ulcer/ Boil

General / Systemic Examination

Pulse_/minute, BP $\mathrm{mm}$ of $\mathrm{Hg}, \quad$ Temp: oF, Lymphadenopathy: Yes / No

CVS / CNS / RS / PA

\section{Complaints on SHPs}

$\square$ Ulcer $\square$ Boil $\quad \square$ Urethral Discharge $\square$ Scrotal swelling $\square$ Warts $\square$ Inguinal Bubo

$\square$ Erectile dysfunction - specify

$\square$ Ejaculatory dysfunction - specify

$\square$ Sexual dissatisfaction - specify

$\square$ Others - specify 
Probable causes of SHPs

Past H/o SHPs -

\section{Genital Examination}

$\square$ Urethral Discharge $\quad \square$ Ulcer $\quad \square$ Boil $\quad \square$ Inguinal Bubo $\quad \square$ Scrotal swelling $\square$ Warts

Site:

Size:

Painful / painless:

If Ulcer

Superficial / Deep:

Margins: Smooth Indurated / Ragged

Bleeds on touch - Yes / No

History of Vesicles - Yes / No

If Scrotal swelling: Right / Left

History of Injury: Yes / No

Tender / Non-tender

\section{Investigations advised}

Blood Test (TPPA/RPR)

Urine test (Routine)

HSV-II-lgG/lgM

PCR

$\begin{array}{lll}\text { Yes / No } & \text { Date } & \text { Results } \\ \text { Yes / No } & \text { Date } & \text { Results } \\ \text { Yes / No } & \text { Date } & \text { Results } \\ \text { Yes / No } & \text { Date } & \text { Results }\end{array}$

Provisional Diagnosis / Syndromic Diagnosis

\section{Treatment}

\begin{tabular}{|l|l|l|l|l|}
\hline Visit & Date & $\begin{array}{l}\text { Treatment } \\
(\text { Drugs } x \text { days })\end{array}$ & $\begin{array}{l}\text { a) Advice } \\
\text { b) Health Education } \\
\text { c) Referral }\end{array}$ & $\begin{array}{l}\text { a) Contact Trace }(y / n) \\
\text { b) Rx to contact }(y / n)\end{array}$ \\
\hline First & & & & \\
\hline Follow- up & & & & \\
\hline
\end{tabular}

Name and Signature of Health Provider 


\section{GRAPHIC PROFILE}

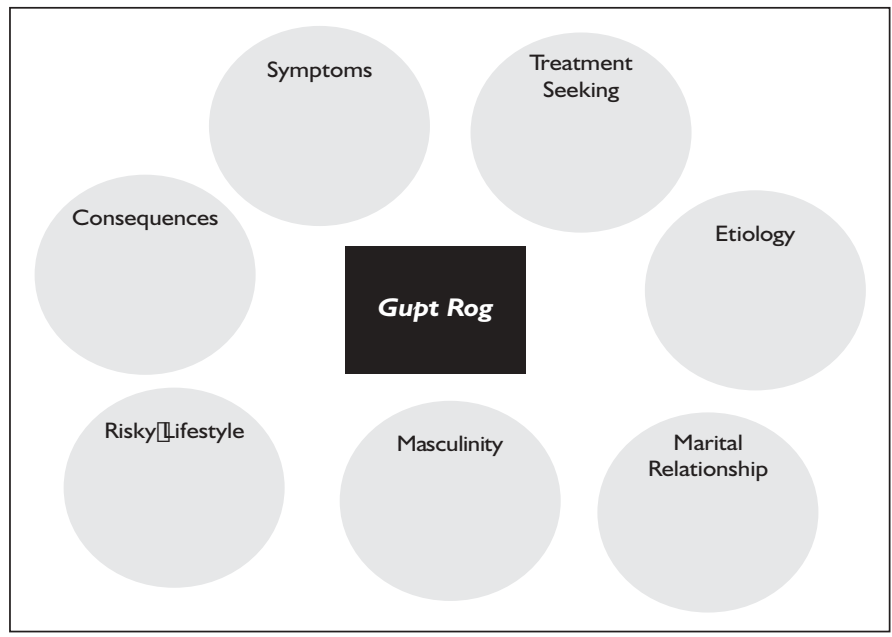

Annexure D

\section{SAMPLE CASE ANALYSIS: Patient A}

Presenting Problem: "I am suffering from burning urination, pain in penis, itching and pimples around genital, pus discharge from those pimples".

Step I: Assessment - through history taking you gain the following information from Patient A:

"I am suffering from burning sensation during urination, and pain in penis. I feel severe pain for the last couple of months. I have been afraid to come to you with this problem, so I have waited till now. These days, I am not able to sleep properly or concentrate in my work because of this problem. I am worried about my wife."

"Before marriage, I used to sleep inside the hotel with four other fellow workers and we had sex with each other. I had this problem first time at the age of 19 years. My friends told me to take English medicine and we went to the pharmacy to get it."

"I had sex with a CSW when I was around 20 years. I went along with my friend. I found that interesting and continued to do so further. Even after marriage, I continued going to that lady, but for the last five months I stopped visiting. I like doing sex with sex workers, because they are prepared to do sex in different ways as is shown in blue films, which one can not do with their wives."

"Recently I got married (current age is 26). Till I get a child, my wife's desire is more for sex; also she is very passionate. But because of my problem, I can't fulfill her desire, so, she feels unhappy often. Both should be ready to enjoy sex in different acts, like CSWs are ready to do. Also after intercourse, both should get complete satisfaction and feel happy. But, to get complete satisfaction, the couple should have a separate room. A real man should be able to do sex for a longer period, at least for 30 minutes."

"I never did any kind of violence with her. But once I drank a bit, so she got upset and did not take food. I also didn't take food. In the morning, she threatened me that she is leaving for her mother's place. I tried to make her understand, then she did not go."

"I do not know if my wife has similar problems. I have not asked her. I was not aware that she could get the symptoms from me."

Step 2. Interpretation. Depict Patient A's 'profile' and complete case sheet, as follows. You identify that all life factors are potentially contributing to Gupt Rog.

Patient Profile

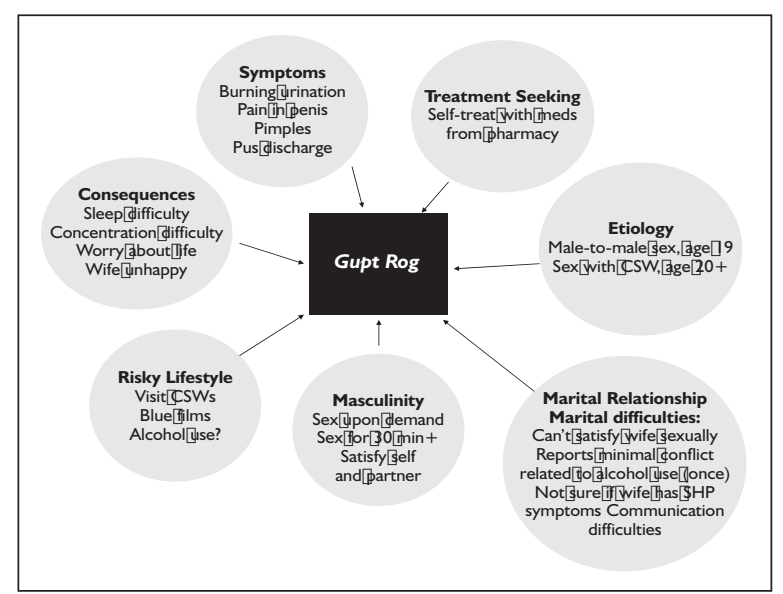


Case Sheet: Patient A

Case No.

Date

13. Name of the patient:

14. Age:

26

Years:

15. Occupation:

Income

16.Address:

General complaints

\begin{tabular}{|l|l|l|}
\hline S. No. & Complaints & Duration \\
\hline 1 & Burning urination & \\
\hline 2 & Pain in penis & \\
\hline 3 & Pimples (penis) & \\
\hline 4 & Pus discharge & \\
\hline
\end{tabular}

[all symptoms present for last couple of months]

\section{Past History - Any Major IIInesses}

Previously exhibited symptoms at age 19 - self-treated with meds from pharmacist

Personal History

Marital Status: Married / Unmarried

Habits - Alcohol / Smoling / Visiting Video Parlour

Residing with Family - Yes / No

History of exposure: Yes/Ato

Condom used: Yes/No-Don't know

Sex with spouse after exposure: Yes/ No

SHP Complaints in spouse - pt did not ask spouse
$X$ None
$\square$ Urethral discharge
$\square$ Vaginal discharge
Ulcer/Boil

\section{General / Systemic Examination}

Pulse / minute,

$\mathrm{BP}$ $\mathrm{mm}$ of $\mathrm{Hg}, \quad$ Temp: $\circ$ F, Lymphadenopathy: Yes / No

CVS / CNS / RS / PA

Complaints on SHPS

$\square$ Ulcer $\quad \square$ Boil $\quad \square$ Urethral Discharge $\quad \square$ Scrotal swelling $\square$ Warts $\square$ Inguinal Bubo

$\square$ Erectile dysfunction - specify

$\square$ Ejaculatory dysfunction - specify

$X$ Sexual dissatisfaction - specify reports difficulty satisfying wife sexually 
X Others - specify

\section{I. burning urination}

2. pain in penis

3. pimples (penis)

4. pus discharge

Probable causes of SHPs

Sex with CSW

\section{Past History of SHPs -}

Yes, same complaint at age 19; self-treat with medicines from pharmacy

\section{Genital Examination}

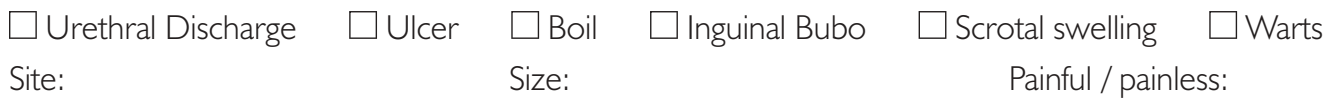

\section{If Ulcer}

Superficial / Deep:

Bleeds on touch: Yes / No

Margins: Smooth Indurated / Ragged

History of Vesicles: Yes / No

If Scrotal swelling: Right / Left

History of Injury: Yes / No Tender / Non-tender

\section{Investigations advised}

Blood test (TPPA/RPR)

Urine test (Routine)

HSV-II-IgG/lgM

PCR

Yes / No

Yes $/ \mathrm{No}$

Yes / No

Yes / No
Date

Date

Date

Date
Results

Results

Results

Results

Provisional Diagnosis: Syndromic Diagnosis

\section{Treatment}

\begin{tabular}{|l|l|l|l|l|}
\hline Visit & Date & $\begin{array}{l}\text { Treatment } \\
\text { (Drugs } x \\
\text { days })\end{array}$ & $\begin{array}{l}\text { a) Advice } \\
\text { b) Health Education } \\
\text { c) Referral }\end{array}$ & $\begin{array}{l}\text { a) Contact Trace }(y / n) \\
\text { b) Rx to contact }(y / n)\end{array}$ \\
\hline First & $\begin{array}{l}\text { Syndromic } \\
\text { treatment }\end{array}$ & $\begin{array}{l}\text { Provide A \& B (see Step 3 that } \\
\text { follows)C: refer for testing for self } \\
\text { and wife }\end{array}$ & $\begin{array}{l}\text { Rec'd follow after testing, individual } \\
\text { and couple's Counselling, partner } \\
\text { notification, for couple }\end{array}$ & \\
\hline
\end{tabular}


Step 3. Prevention

Examination of profile for Patient $A$ indicates that all the life factors are potential contributors to the SHP and thus need attention in Step 3. The recommendations and suggested messages for this patient follow. The doctor will use the full range of counselling strategies suggested in Section III of the manual to facilitate education and support for patient.

\section{Symptoms:}

- Syndromic management, as indicated

- Referral for tests (STIs, and possible HIV) for self and wife

\section{Treatment Seeking - Education about appropriate treatment seeking}

"It is good that you came to see me about this problem, so that we can do proper examination, testing and diagnosis; and I can prescribe the appropriate treatment. Each man's problem can be different and it is best to seek treatment from a provider rather than purchase medication on your own, based on the experiences of your friends. Doing that can result in mistreatment and continuation of the problem."

\section{Consequences - Provide emotional support and Counselling}

"It is good that you have come to me, as this is a treatable problem. It sounds like your concerns (tension) about the symptoms and possible SHP have resulted in difficulty sleeping and concentration and worries about your future, as well as some difficulties in your marriage."

"We will discuss some ways to lessen your worries and help you sleep and concentrate better. Also we will discuss some ways to improve your relationship with your wife."
"The worries are normal reactions to having such symptoms and following my treatment recommendations and avoiding risk of exposure to SHPS in the future are the best ways to combat these worries. However, I can prescribe some medication to help you sleep and concentrate better, and recommend some strategies for reducing your tension (e.g., meditation, relaxation, exercise, talking to friends). Let's discuss how you typically alleviate your tensions and see if we can come up with some helpful strategies for you... Explore strategies used in the past that have worked; encourage use of alternatives such as meditation, relaxation or physical exercise; caution against use of alcohol as way to reduce tension."

\section{Etiology/Risky life style - Education about risks associated with sex with CSW and male-to-male sex $-A B C$}

"Sex with other men or with CSWs creates risk for various STIS and potential HIVIAIDS. It is best that you abstain from sex with partners other than your wife, and avoid situations or friends that put you in contact with these risks. For example, going to blue films with your friends increases the chances that you will then visit CSWs and create expectations for sex with your wife that are not realistic. Come back to this point in discussion of masculinity. As you know alcohol use can also reduce your inhibitions and make it more likely you will engage in risky sex, so it is best to avoid alcohol as a way to relieve your stress. The combination of drinking with your friends, watching blue films together and then visiting CSWs is risky for contracting STIs. If you choose to engage in risky sex, it is most important that you use a condom, provide instruction and condom as warranted. It is best that you focus on improving your relationship with your wife through improved communication and finding ways to increase sexual satisfaction. We will discuss some ways to do that may require follow-up visits." 
Masculinity - Confront the myths about 'real man' by providing information and encouraging more focus on healthy lifestyle and improving relation with wife.

"All men are different when it comes to sex. What you see in blue films is not real. For example, the idea that a man can last for 30 minutes or more is not realistic and creates expectations that most men cannot fulfill. What is most important is that you focus on what satisfies you and your wife sexually, and we will talk about that. This does not mean that you or your wife will always be satisfied. If you or she is tired or worried, that could interfere with your interest, performance or satisfaction. Maintaining good communication with your wife about concerns that you have (about work, family) and about what satisfies both of you sexually can help to increase the satisfaction in your marriage in general and sexually. We will talk about ways to improve your communication and sexual relationship."

\section{Marital relationship - Focus on communication and improving sexual relationship, perhaps recommending couple sessions; recommend partner notification, testing and treatment as needed.}

"I would like you to schedule another session with me where we can talk more about how you and your wife can improve your communication especially about your sexual relationship. Provide some initial suggestions about communication and sex. It might be best if I saw the two of you as a couple. It is also important to make sure your wife is not suffering from SHP, so I suggest you tell her about the problem I have diagnosed and suggest she seek examination and treatment as well. You could bring her to my office (or recommend she go to her doctor)."

\section{SAMPLE CASE ANALYSIS: Patient $B$}

Presenting Problem: "I don't get proper erection when I want to do sex with my wife. Occasionally I do sex with her, even for that, my wife has to try hard. She has to masturbate me to get the erection. It loses its strength before ejaculation."

Step I: Assessment - through history taking you gain the following information from Patient B:

"I don't get proper erection when I want to do sex with my wife. Occasionally I do sex with her, even for that, my wife has to try hard. She has to masturbate me to get the erection. It loses its strength before ejaculation."

"My wife is getting angry. My friends have said that, if I take rum, then I can enjoy sex for a longer period. But if I drink, I don't get erection. Now I am habituated to rum, for which my wife scolds me always. "

"I have this problem since beginning of marriage. But I did not get any difficulty in reproduction. After the birth of children, my wife went for sterilisation, and since then she wanted to do more sex. She gets more excitement because there is no fear of pregnancy. But I don't get that excitement due to my problem in erection. I have gone to two other doctors with no satisfaction. They gave me some pills but those did not help."

"I have the problem because I had sex with one of my neighbour's relative when I was very young. In the first experience, I was scared to do sex with her. I did not get proper erection. She masturbated me and I got erection, but within few minutes I lost that. Once again, she tried to masturbate me, but I did not like it, so, I told her to do some other time. Later, many times we had sex till I came to Mumbai. I think it is due to my relation with that lady back home. We continued the relation for three to four years, in which the frequency of intercourse was quite more. I think the quantity of 


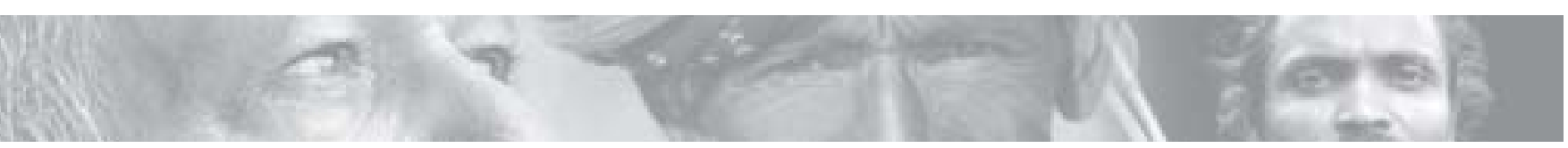

semen reduced a lot by this relationship for which I am suffering now. If there is no semen (pani) in the penis, how can I get erection?"

"Now if at all I get excitement, I don't try to take initiative. I am scared for loss of erection and her anger. So, when she takes initiative and arouse me, then only we do sex. When I get erection, and during the intercourse I fondle her breasts and I try to touch other parts of her body."

"My wife also works. She studied up to I0th standard and earns more than me. For sex I never fought with her rather she gets angry and abuses me. But when I drink more, sometimes I also scold her. I can't beat her, rather she will beat me. Because always she looks upset. When I drink bit more, that time I try to abuse her. But if I try to retaliate her or do something against her wishes, she might beat me."

"I agree with my wife working. I don't get upset about the extra money she earns. But I don't feel like a man if I cannot satisfy her. Man should be able to be ready for sex whenever his wife wants and he should be able to keep her satisfied. Otherwise, she might go outside of marriage for sex."

Step 2. Interpretation. Depict Patient B's 'profile' and complete case sheet, as follows. You identify that all life factors are potentially contributing to Gupt Rog.

Patient Profile

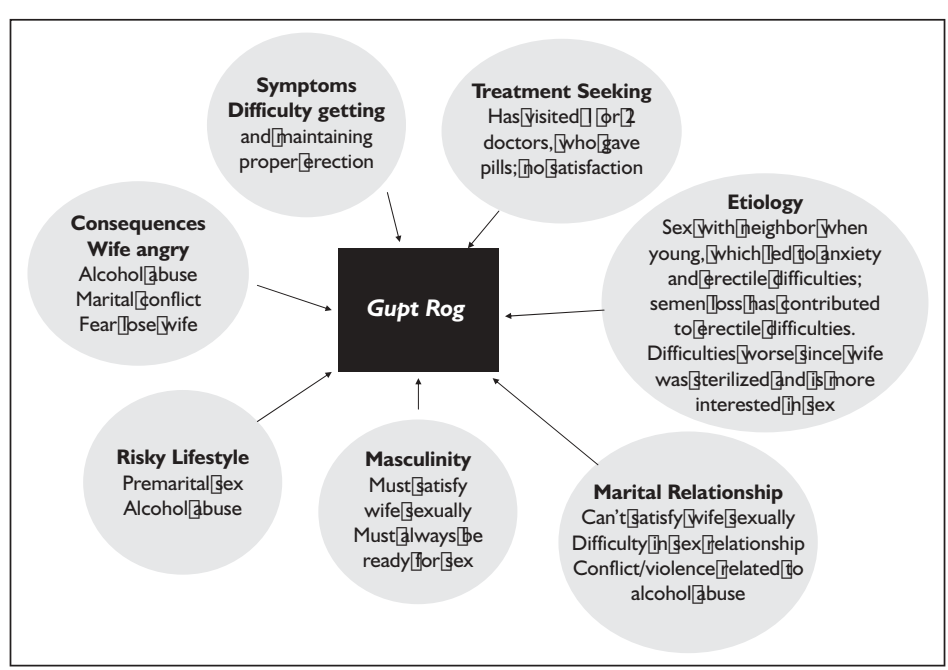




\section{Case Sheet: Patient B}

Case No: Date :

17. Name of the patient:

18. Age: Years:

19. Occupation: Income

20. Address:

General complaints

\begin{tabular}{|l|l|l|}
\hline S. No. & Complaints & Duration \\
\hline & & \\
\hline & & \\
\hline
\end{tabular}

Erectile dysfunction - since youth

Past History - Any major illnesses

n/a

\section{Personal History}

Marital status: $\quad$ Married / Unmarried

Habits - Alcohol /Smoking / Gambling / Visiting Video Parlour

Residing with family - Yes / No

History of exposure: Yes/ No

Condom used: Don't know

Sex with spouse after exposure: Yes/ No

SHP complaints in spouse

$\square$ None $\quad \square$ Urethral discharge $\quad \square$ Vaginal discharge $\quad \square$ Ulcer/ Boil

\section{General / Systemic Examination}

Pulse__minute, BP_ $\quad$ ___

CVS / CNS / RS / PA

\section{Complaints on SHPs}

$\square$ Ulcer $\quad \square$ Boil $\quad \square$ Urethral Discharge $\quad \square$ Scrotal swelling $\quad \square$ Warts o Inguinal Bubo

$X$ Erectile dysfunction - Difficulty getting and maintaining proper erection

$\square$ Ejaculatory dysfunction - specify

$X$ Sexual Dissatisfaction ---related to Erectile Dysfunction

$\square$ Other - specify

\section{Probable causes of SHPs}

Sex at early age $\longrightarrow$ anxiety $\longrightarrow$ ED

Past History of SHPs - 


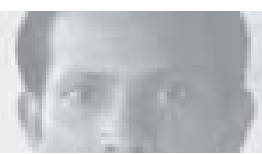

Same problem since youth

Worsened since wife sterilised and more interested in sex

\section{Genital Examination}

$\square$ Urethral Discharge

Site:

\section{If Ulcer}

Superficial / Deep:

Bleeds on touch: Yes / No

If Scrotal swelling: Right / Left

\section{Investigations advised}

Blood Test (TPPA/RPR)

Urine test (Routine)

HSV-II-lgG/lgM

PCR

Provisional Diagnosis

Syndromic Diagnosis
$\square$ Ulcer
$\square$ Boil
$\square$ Inguinal Bubo
$\square$ Scrotal swelling
$\square$ Warts Size:
Painful / painless:

\begin{tabular}{lll}
\multicolumn{3}{c}{$\begin{array}{c}\text { Margins: Smooth Indurated / Ragged } \\
\text { History of Vesicles: Yes / No }\end{array}$} \\
History of Injury: Yes / No & Tender / Non-tender \\
& & \\
Yes / No & Date & Results \\
Yes / No & Date & Results \\
Yes / No & Date & Results \\
Yes / No & Date & Results
\end{tabular}

\section{Treatment}

\begin{tabular}{|l|l|l|l|l|}
\hline Visit & Date & $\begin{array}{l}\text { Treatment } \\
(\text { Drugs } x \text { days })\end{array}$ & $\begin{array}{l}\text { a) Advice } \\
\text { b) Health Education } \\
\text { c) Referral }\end{array}$ & $\begin{array}{l}\text { a) Contact Trace }(y / n) \\
\text { b) Rx to contact }(y / n)\end{array}$ \\
\hline First & $\begin{array}{l}\text { Possibly for ED } \\
\text { and/or anxiety }\end{array}$ & $\begin{array}{l}\text { A \& B [see Step 3]C: referral } \\
\text { possibly for alcohol abuse } \\
\text { treatment }\end{array}$ & $\begin{array}{l}\text { Recommended for } \\
\text { Counselling, monitoring } \\
\text { meds, couples sessions }\end{array}$ & \\
\hline Follow- up & $\begin{array}{l}\text { Possibly for ED } \\
\text { and/or anxiety }\end{array}$ & & & \\
\hline
\end{tabular}

Name and Signature of Health Provider 


\section{Step 3. Prevention}

Examination of profile for Patient B indicates that all the life factors are potential contributors to the SHP and thus need attention in Step 3. The recommendations and suggested messages for this patient follow. The doctor will use the full range of counselling strategies suggested in Section III of the manual to facilitate education and support for patient.

\section{Symptoms}

- Syndromic management, as indicated

- Counselling

- Possible medication for ED and/or related anxiety

\section{Treatment Seeking - Education and assurance about appropriate treatment}

"It is good that you came to see me about this problem, so that we can do proper examination, testing and diagnosis; and I can prescribe the appropriate treatment. It is possible that your problem is best treated through Counselling. Or perhaps a different drug needs to be prescribed. We will explore the options for treating your problem."

\section{Consequences - Provide emotional support and Counselling}

"It is good that you have come to me, as this is a treatable problem. It sounds like the symptoms and your concerns (tension) about the symptoms have led to difficulties in your marriage and concerns about losing your wife. I wonder also if you are drinking to alleviate your tension. As you have learned, drinking does not improve sexual performance but instead interfere with it and make your particular problem worse. In addition, it sounds like drinking is creating additional problems in your marriage."
"We will discuss some ways to address your problems that don't involve alcohol use, discuss ways to better communicate with your wife about your problem, and explore treatment options for alleviating the erection difficulties." Explore current strategies for responding to tension/anxiety and suggest alternatives such as relaxation, exercise, medication, talking to others."

\section{Etiology/Risky lifestyle - Education about potential contributions of early sexual experiences, current marital situation, and alcohol use on erectile difficulties.}

"From what you have told me, it seems that problem started when you were young and had your first sexual experience. The first experience can be create anxiety about performance - that is normal - and anxiety can interfere with getting and maintaining an erection. Unfortunately, that anxiety and the related difficulties have persisted. It also sounds like your wife's increasing interest in sex has heightened expectations for your performance and perhaps increased your anxiety - a vicious cycle gets created, because when you are anxious, it can interfere with erection, and then the erection difficulties make you more anxious. We will talk about ways to alleviate your anxiety and if necessary I can prescribe some medication which may help to break the cycle."

\section{Masculinity - Confront the myths about 'real man' by providing information and encouraging realistic expectations}

"All men are different when it comes to sex. Because we listen to our friends and perhaps get information from magazines or blue films, it is not unusual that men develop unrealistic expectations when it comes to sex. What is most important is that you focus on what satisfies you and your wife sexually, and we will talk about that. This does not mean that you or your wife will always be satisfied, or that you will always have a satisfactory erection. If you or she is tired or worried, 


\section{Initial Training Workshops}

\section{Part I. Introduction and Basics of STIs \& HIV/AIDS}

(4 hours) - Manual Introduction \& Section I.

A. Introduction - Manual Introduction Section

Present purpose of training and role of providers in STI/HIV prevention

B. Basics of STIs and HIV/AIDS (3 hours) - Manual Section I

Present scientific information on STIs and HIV/AIDS, syndromic management of STIs, management of HIV/AIDS, role of AYUSH and allopathic providers in management of STIs and HIV/AIDS, biosafety guidelines

C. Conclusion - Q\&A

Part II. Gupt Rog (4-5 hours) - Manual Section II.

A. Gupt Rog: Epidemiological and psychosocial elements, and management. Content based on findings of RISHTA project and other relevant research (included in Manual Section II)

B. Exercises |-7

Activities are interspersed with content presentation (see Manual Section II). Exercises can be conducted as individual, small group, or large group activities. Schedule 30 minutes for each activity conducted as small group; if all exercises are conducted in small group, schedule this section for 5 hours.

\section{Part III. Narrative Prevention Counselling} (7-8 hours) - Manual Section III
A. Introduction to NPC
B. Applying NPC

I. Counselling and communication skills

2. Step I: Assessment

3. Step 2: Interpretation

4. Step 3: Prevention
C. Exercises 8-13

Activities are interspersed with content presentation and involve the application of NPC to sample cases (see Manual Section III).

Exercises should be conducted as small group, or large group interactive and role play activities. Schedule minimum of 30 minutes for each activity.

D. Conclusion - Q\&A; planning for follow-up training and on-site consultation session.

Individual Consultation (on-site) and Follow-up Training

Throughout the intervention phase, trainers will visit participating practitioners to:

- Review the types of cases that have been handled (e.g., presenting concerns, symptoms, related concerns, case disposition)

- Review the use of intervention strategies

- Discuss client and practitioner acceptance of (i.e., response to) intervention strategies

- Discuss perceived effectiveness of intervention strategies

- Identify intervention difficulties and limitations

- Discuss alternative intervention strategies

- Determine the need for additional training, resources, and support

- Provide additional training or make arrangements for follow-up individual/group training sessions.

Initially, visits may occur on a bi-weekly basis for the first two months, and then will occur monthly as needed. Frequency of visits may vary depending on practitioner need and interest. The visits will serve a dual purpose of providing support and additional training to practitioners and monitoring implementation integrity and acceptability. Follow-up training sessions on monthly or bimonthly basis are recommended, with particular focus on enhancing knowledge of STI syndromic management; and application of NIM in practice (with focus on each stage - assessment, interpretation, prevention). These follow-up sessions should focus on the needs of providers, determined through visits and consultation with individual providers. 


\section{RISHTA Team}

\section{Faculty / Consultants}

Dr. Ravi K. Verma

Dr. Saggurti Niranjan

Dr. T. V. Sekher

Dr. G. Rama Rao

Dr. S. K. Singh

Dr. Hemkothang Lunghdim

Dr. Stephen L. Schensul

Dr. T. K. Roy

Dr. Bonnie K. Nastasi

Dr. Abdelwahed Mekki-Berrada

Dr. Pertti J. Pelto

Dr. Sarah Hawkes

Dr. Joseph Burleson

\section{Support Staff}

Mr. Kamlesh S. Mayekar

Mr. Mandar K. Mainkar

Dr. Sumitra N. Swain

Mr. Rajendra Singh

Dr. Saritha Nair

Dr. Sharad S. Narvekar

Dr. Neena Jadhav

Mr. Alok Kumar
Ms. Deepali Chahande

Mr. Triloki Nath

Mr. Bharat Bhushan Agarwal

Mr. J. I. Pathan

Mr. T. K. Sayed

Ms. Y. Sangeeta

Mr. Rajit Ram Verma

Dr. Radha Y. Aras

Dr. Deepak Kismatrao

Dr. Karun Dev Sharma

Dr. Rahul M. Shimpi

Dr. Amol Bhurkhe

Dr. Ramesh N. Bharmal

Dr. Arun R. Risbud

Dr. S. H. Joshi

Ms. Shubhada Maitra

Mr. Parasnath Verma

Ms. Sunitadevi Mishra

Mr. Pawan V. Palav

Mr. Rajesh D. Kubde

Ms. Padmaja Vempaty

Mr. Rajesh Eknath Bhatkar

Mr. Halloo Yadav

Mr. Surendra Kumar 
Mr. Ravindra Kumar

Mr. Hiraman Janardan Salve

Mr. Dhanraj Jagnnath Khare

Mr. Bansilal Limbajirao Ankulge

Mr. Ranvijay Singh

Mr. Rajesh Kumar Pathak

Mr. Manish Pandurang Bhise

Mr. Faujdar Prajapati

Mr. Kishore P. Telore

Mr. Nagendra Singh

Mr. Rajaram Jaiswal

Mr. Ramjanam Chandel

Mr. Mukesh Ramashankar Pathak

Mr. Omprakash Yadav

Mr. Santosh P. Suryavanshi

Ms. Pravina Kukade

Mr. Dinesh R. More

Mrs. Manisha Desai

Ms. Sushma Anant Baraskar

Mr. Sushil Kumar Shukla

Mr. Mohan Kandekar

Ms. Swatika Rath

Mr. Debabrata Bera

Ms. Varsha D. Karpe

Ms. Papiya Guha
Mr. Lakshimkanth Makaraju

Mr. Shashikant C. Waidande

Ms. Parimala Kandakuru

Ms. Jhimly K. Hazra

Mr. Sudhir Kolambekar

Mr. Premntah Abaram Dalvi

Mr. Kiran Prakash Hire

Mr. Balwant Kirar

Mr. Pradeep Shivram Pawar

Mr. Arif Ibrahim Shaikh

Mr. Mahendra Pratap Singh

Mr. Ranjeet Verma

Mr. Sagar Bhandare

Mr. Apresh Patra

Mr. Ranajit Sengupta

Ms. Anita Bhargava

\section{Implementing Partners:}

- IIPS, Mumbai

- TN Medical College, Mumbai

- CORO for Literacy, Mumbai

- NARI, Pune

- University of Connecticut School of Medicine (USA)

- Institute for Community Research (USA)

- Population Council, New Delhi 


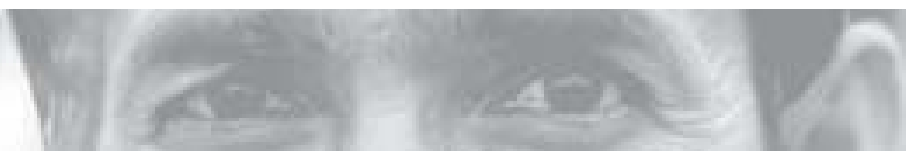

- London School of Hygiene and Tropical Medicine

- GreaterMumbai Municipal Corporation

\section{Funders:}

- National Institute for Mental Health (USA)

- Office of AIDS Research, National Institutes of Health (USA)

- DFID Program for Prevention of Sexually Transmitted Diseases 


\section{(P) Population Council}

\section{Population Council}

142, Golf Links, New Delhi I 10003

Tel: +9| I| 4I7434 I0-I।, Fax: +9| I| 4I7434I2

Website: www.popcouncil.org 